\title{
Drugs for Insomnia beyond Benzodiazepines: Pharmacology, Clinical Applications, and Discovery
}

\author{
Tobias Atkin, Stefano Comai, and Gabriella Gobbi
}

Neurobiological Psychiatry Unit, Department of Psychiatry, McGill University Health Center, McGill University, Montreal, Quebec, Canada (T.A., S.C., G.G.); and Division of Neuroscience, San Raffaele Scientific Institute and Vita-Salute University, Milan, Italy (S.C.)

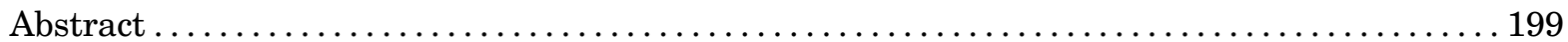

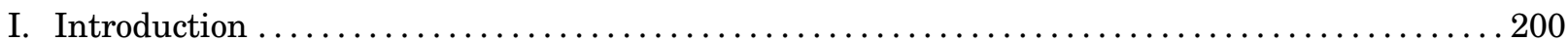

A. Insomnia as a Public Health Burden ...................................... 200

B. Changes in the Nosology of Insomnia in Diagnostic and Statistical Manual of Mental

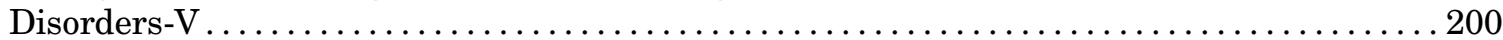

C. Clinical Guidelines for Insomnia Treatment and the Necessity of a Translational

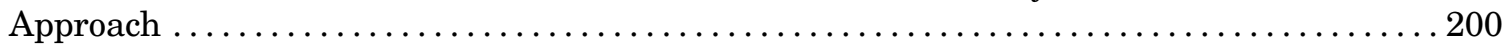

D. The Dark Side of Benzodiazepines and Z-Drugs and the Off-Label Use of Other Drugs _. 201

II. Sleep Architecture ................................................ 201

III. The Receptor-Mediated Mechanism of Action of Hypnotics . . . . . . . . . . . . . . . . . . . . 202

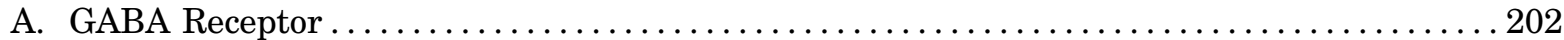

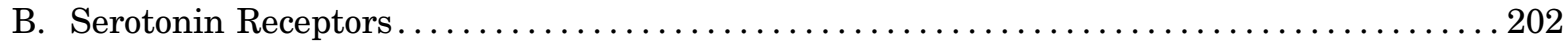

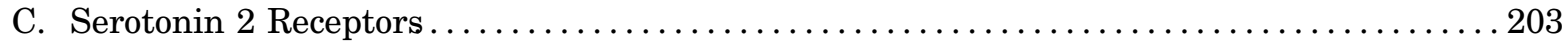

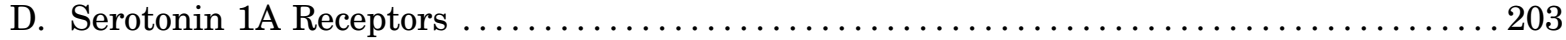

E. Noradrenaline Receptors ............................................. 203

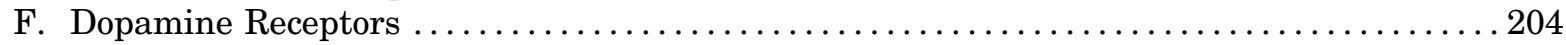

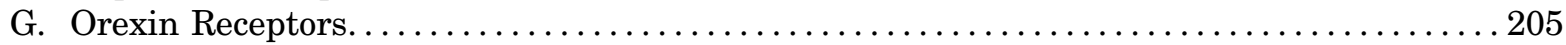

H. Melatonin Receptors ..................................................... 205

I. Histamine Receptors . . . . . . . . . . . . . . . . . . . . . . . . . . . . . . . . . . 206

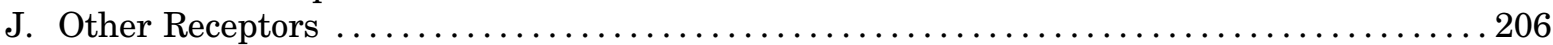

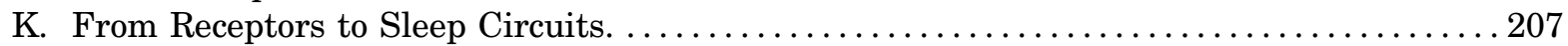

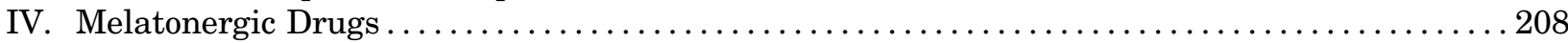

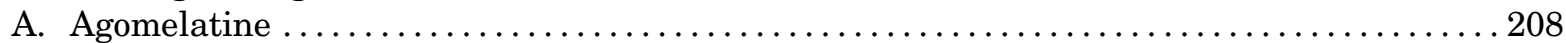

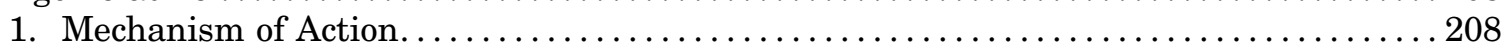

2. Pharmacokinetics............................................. 208

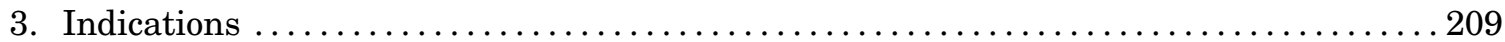

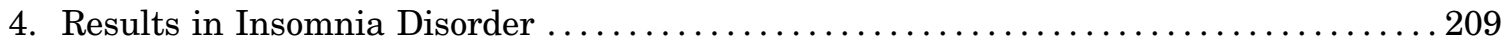

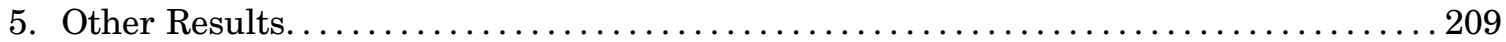

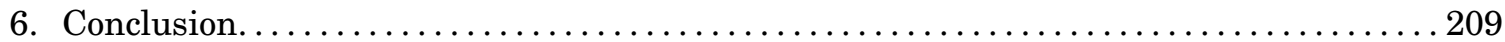

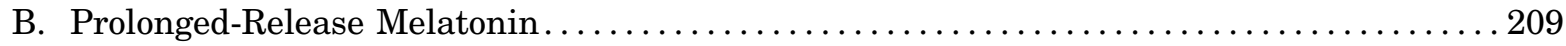

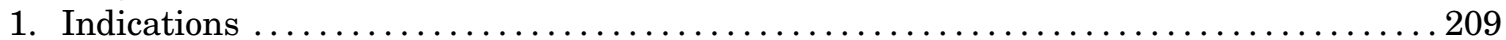

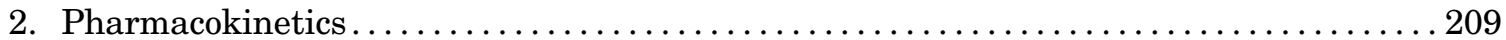

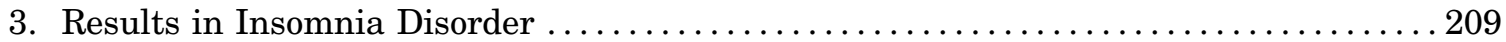

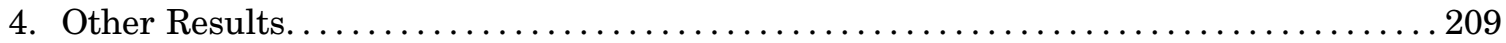

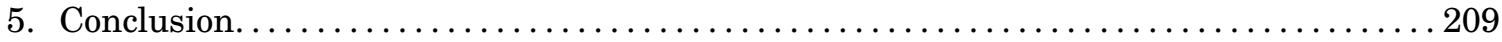

Address correspondence to: Gabriella Gobbi, Neurobiological Psychiatry Unit, Department of Psychiatry, Ludmer Research and Training Building, 1033, Avenue des Pins Ouest, Montreal, Quebec, Canada H3A 1A1. E-mail: gabriella.gobbi@mcgill.ca

This work was supported by the Quebec Network on Suicide, Mood Disorders, and Related Disorders and the Canadian Depression Research and Intervention Network (CDRIN).

G.G. has received grants from the Canadian Institute of Health Research (CIHR), the Canada Foundation for Innovation (CFI), the Fonds de recherche du Québec - Santé (FRQS), and the Quebec Network on Suicide, Mood Disorders and Related Disorders. G.G. is an inventor and assignee in patents regarding the sleep properties of selective melatonin $\mathrm{MT}_{2}$ agonists.

https://doi.org/10.1124/pr.117.014381. 


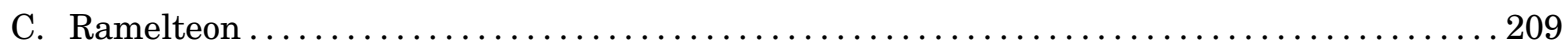

1. Mechanism of Action. . . . . . . . . . . . . . . . . . . . . . . . . . . . . . . . . 209

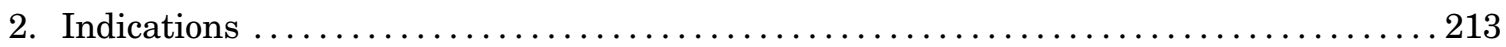

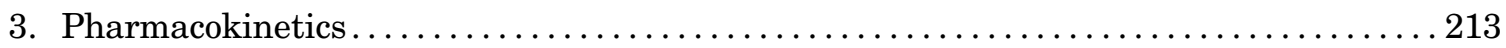

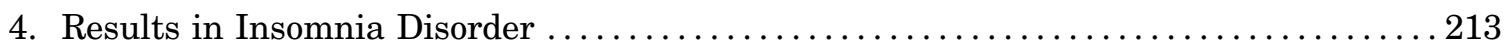

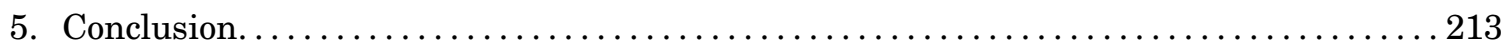

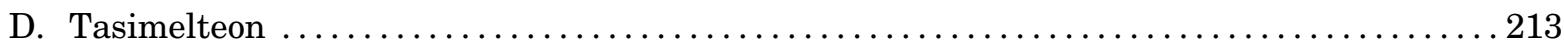

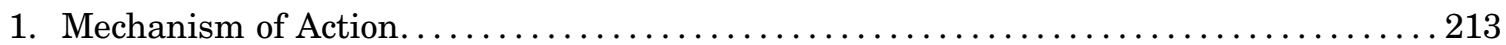

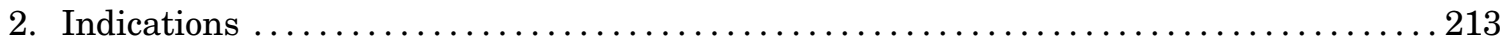

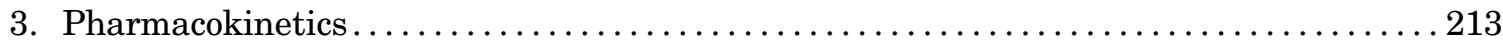

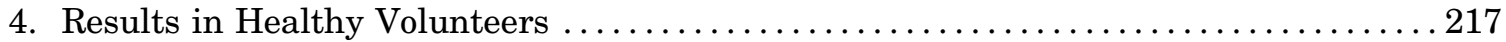

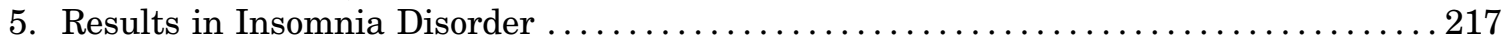

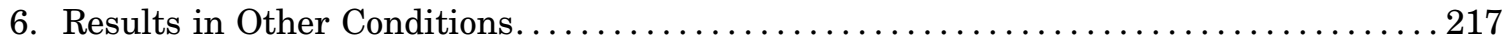

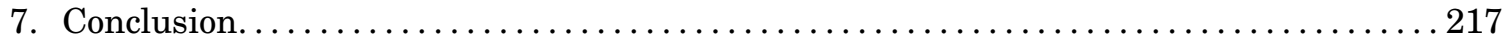

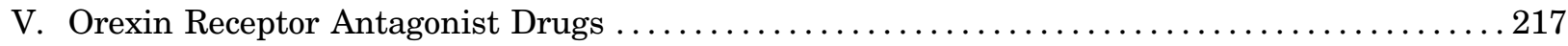

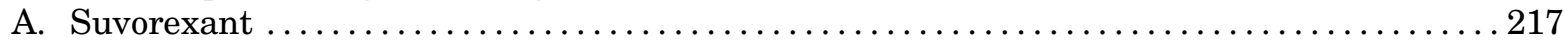

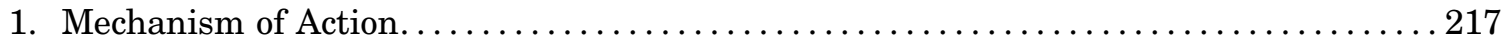

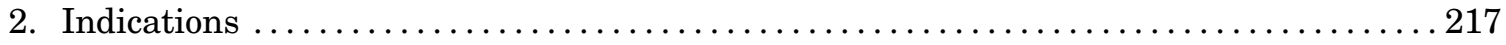

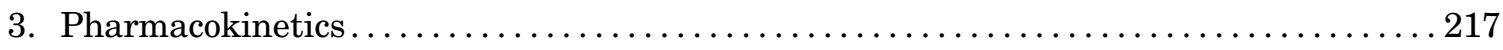

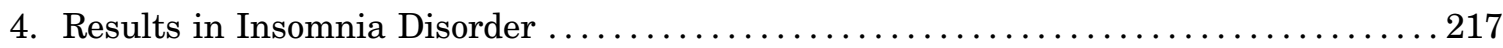

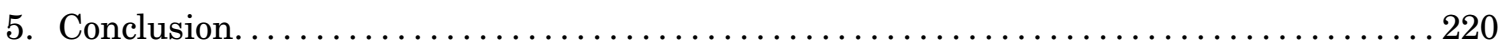

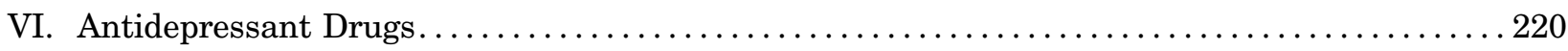

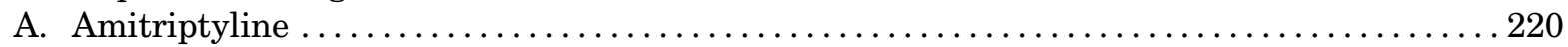

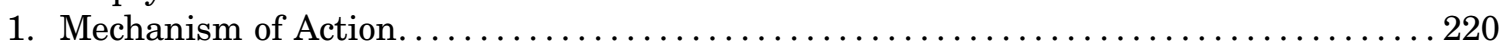

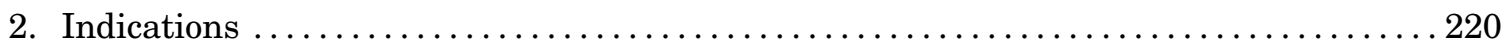

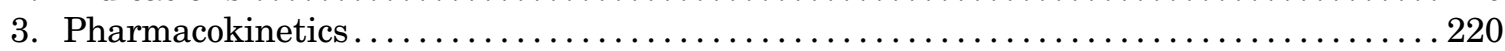

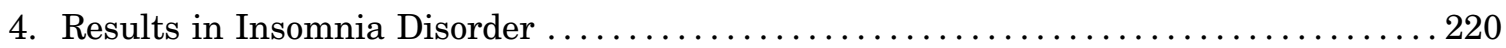

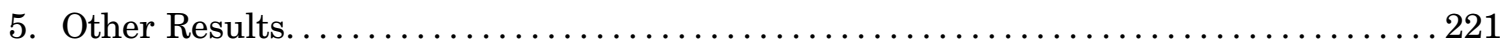

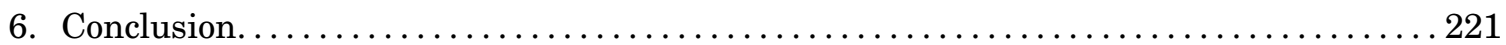

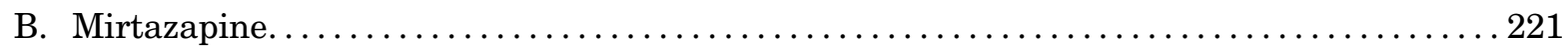

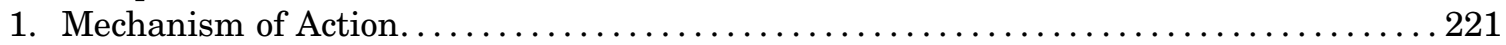

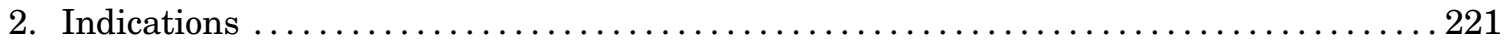

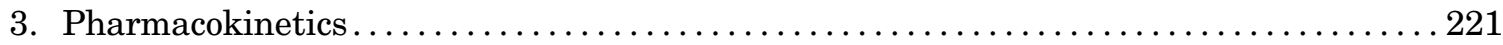

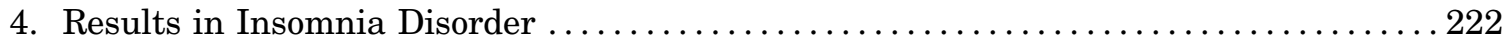

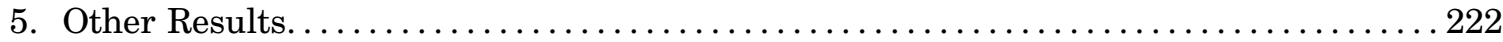

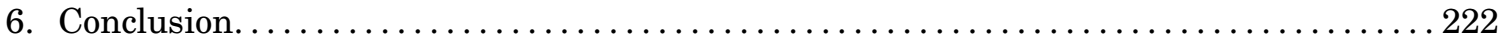

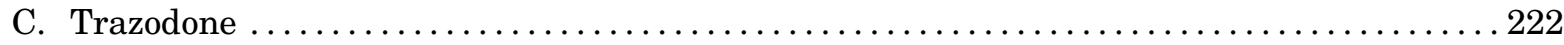

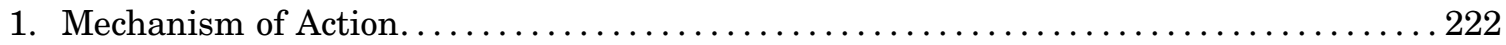

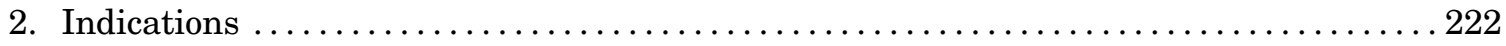

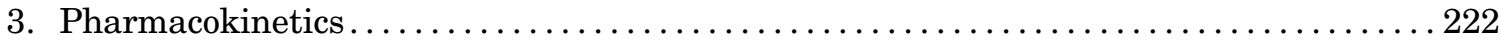

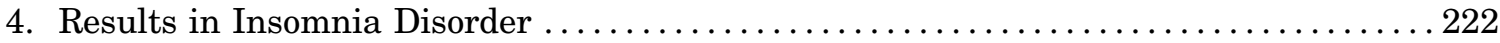

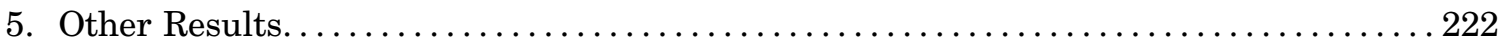

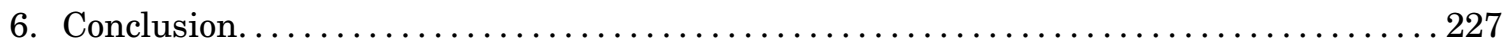

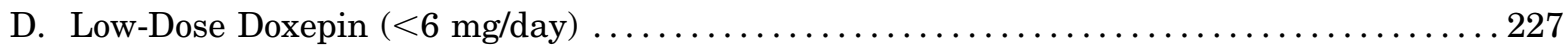

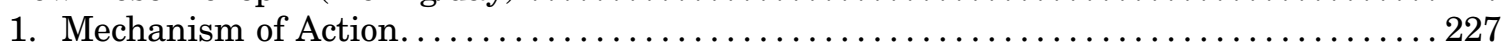

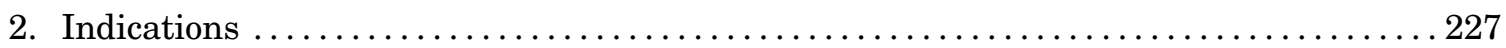

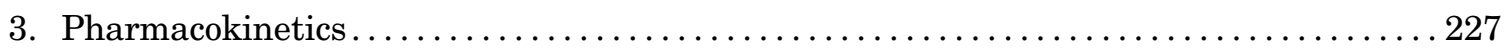

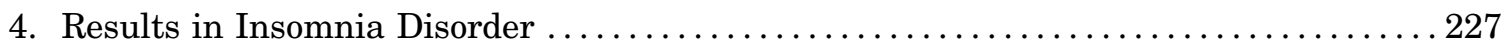

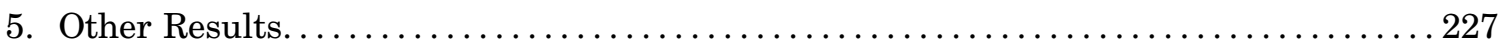

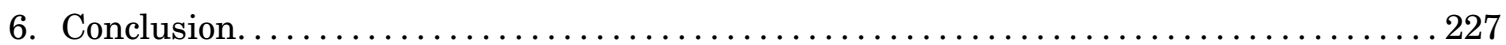

\footnotetext{
ABBREVIATIONS: AUC, area under the curve; BZDs, benzodiazepines; CHMP, Committee for Medicinal Products for Human Use; DSM, Diagnostic and Statistical Manual of Mental Disorders; EEG, electroencephalogram; 5-HT, serotonin; KO, knockout; LC, locus coeruleus; LDT/ PPT, lateralpontine tegmentum/pedunculopontine tegmental nuclei; MDD, major depressive disorder; MNPO, median preoptic nucleus; NREM, non-rapid eye movement sleep; OX, orexin; PRM, prolonged-release melatonin; PSQI, Pittsburgh Sleep Quality Index; PTSD, posttraumatic stress disorder; RCT, randomized-controlled trial; REM, rapid eye movement sleep; RT, reticular thalamus; SCN, suprachiasmatic nuclei; SDL, sublaterodorsal nuclei; SSRI, selective serotonin reuptake inhibitor; SWS, slow-wave sleep; vlPO, ventrolateral preoptic area; WASO, wake after sleep onset; WT, wild type.
} 


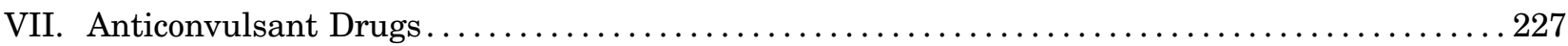

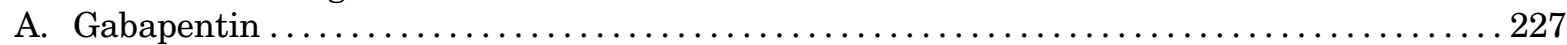

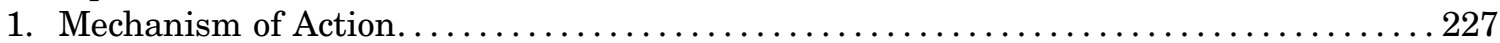

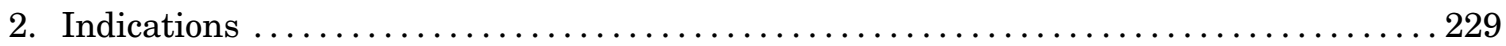

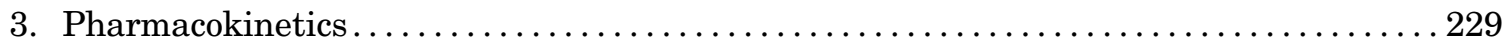

4. Results in Insomnia Disorder ...................................... 229

5. Other Results........................................................ 229

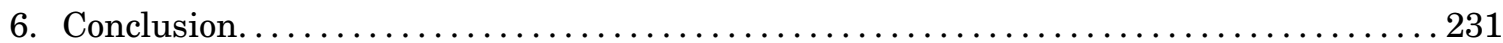

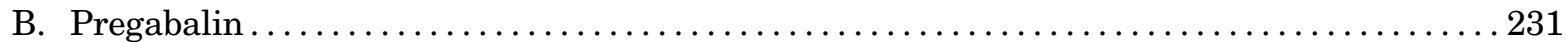

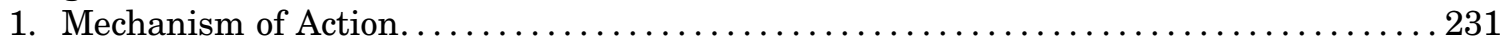

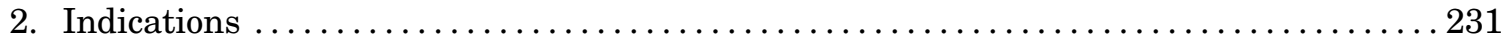

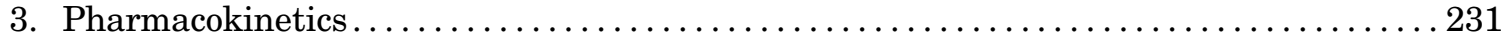

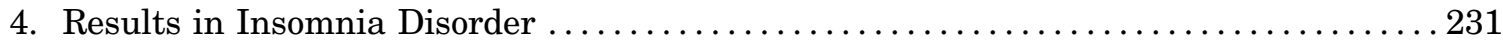

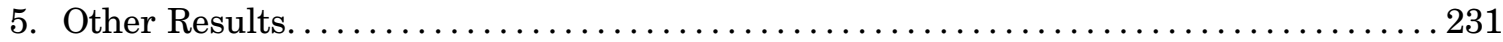

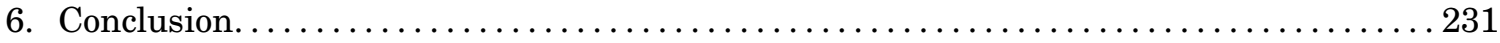

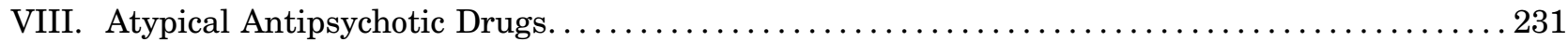

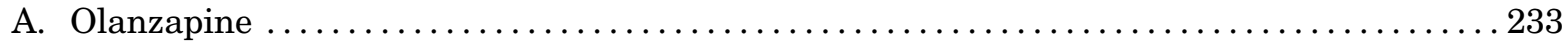

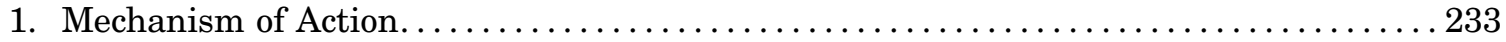

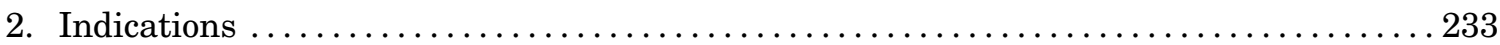

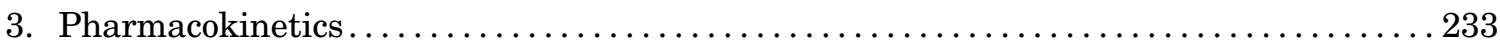

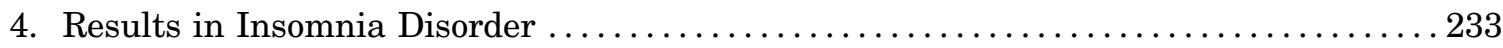

5. Other Results................................................... 233

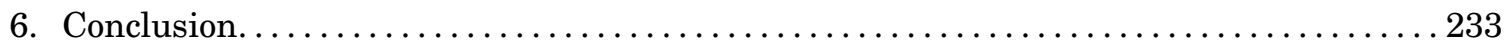

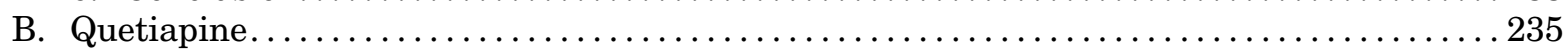

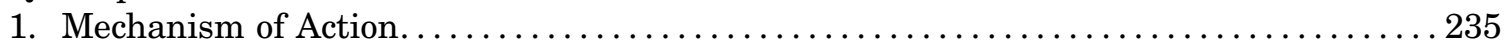

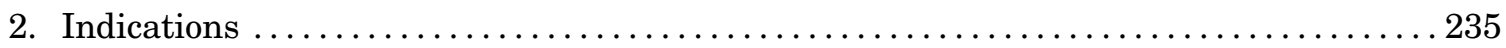

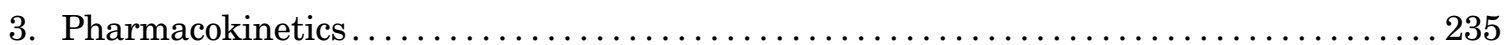

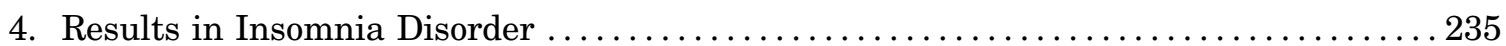

5. Other Results.................................................2235

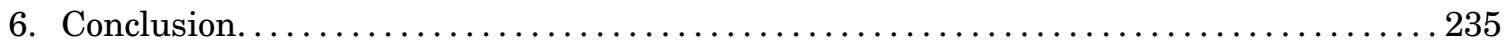

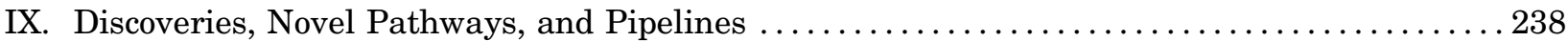

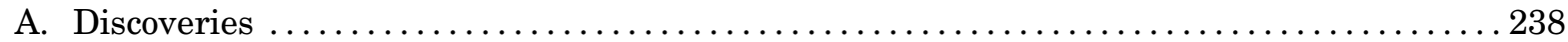

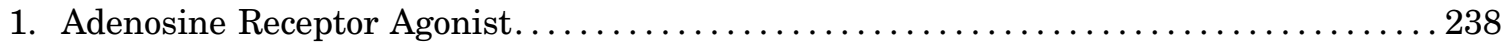

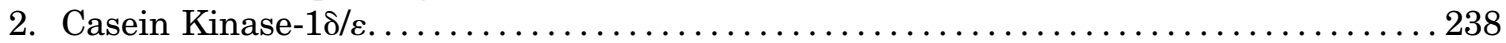

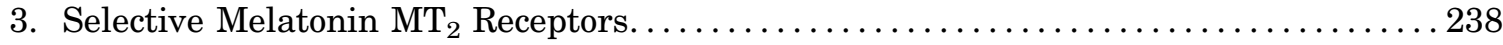

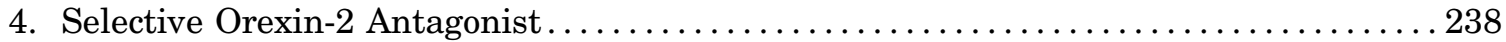

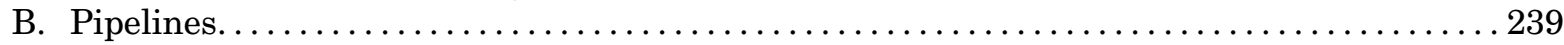

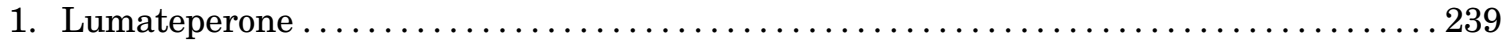

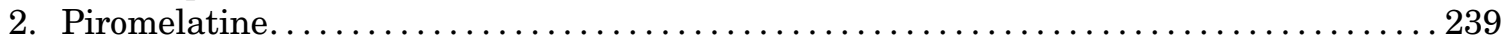

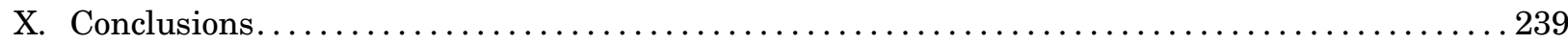

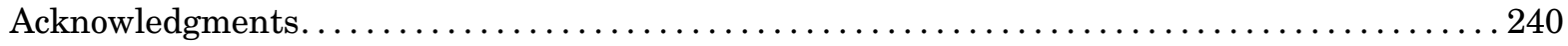

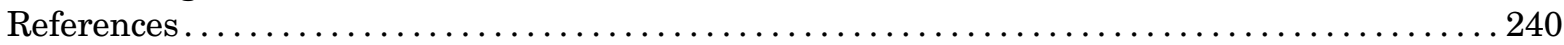

\begin{abstract}
Although the GABAergic benzodiazepines (BZDs) and Z-drugs (zolpidem, zopiclone, and zaleplon) are FDA-approved for insomnia disorders with a strong evidence base, they have many side effects, including cognitive impairment, tolerance, rebound insomnia upon discontinuation, car accidents/falls, abuse, and dependence liability. Consequently, the clinical use of off-label drugs and novel drugs that do not target the GABAergic system is increasing. The purpose of this review is to analyze the neurobiological and clinical evidence of pharmacological treatments of insomnia, excluding the BZDs and Z-drugs. We analyzed the melatonergic agonist drugs, agomelatine, prolongedrelease melatonin, ramelteon, and tasimelteon; the dual orexin receptor antagonist suvorexant; the modulators of
\end{abstract}

the $\alpha_{2} \delta$ subunit of voltage-sensitive calcium channels, gabapentin and pregabalin; the $\mathrm{H}_{1}$ antagonist, low-dose doxepin; and the histamine and serotonin receptor antagonists, amitriptyline, mirtazapine, trazodone, olanzapine, and quetiapine. The pharmacology and mechanism of action of these treatments and the evidence-base for the use of these drugs in clinical practice is outlined along with novel pipelines. There is evidence to recommend suvorexant and low-dose doxepin for sleep maintenance insomnia; there is also sufficient evidence to recommend ramelteon for sleep onset insomnia. Although there is limited evidence for the use of the quetiapine, trazodone, mirtazapine, amitriptyline, pregabalin, gabapentin, agomelatine, and olanzapine as treatments for 
insomnia disorder, these drugs may improve sleep while successfully treating comorbid disorders, with a different side effect profile than the BZDs and
Z-drugs. The unique mechanism of action of each drug allows for a more personalized and targeted medical management of insomnia.

\section{Introduction}

\section{A. Insomnia as a Public Health Burden}

Insomnia is a significant public health burden, increasing work absenteeism and health care costs in a large proportion of the population. It causes altered cognition, emotional disturbances, and reduced quality of life (Zammit et al., 1999; Wickwire et al., 2016). Insomniacs commonly complain of irritability, daytime sleepiness, low energy and motivation, physical discomfort, and impaired cognitive functioning (Buysse et al., 2007; Fortier-Brochu et al., 2012; Morin and Jarrin, 2013), not to mention deficits in working memory, episodic memory, and some aspects of executive functioning (Fortier-Brochu et al., 2012).

The prevalence rate of insomnia in the general population has been estimated as low as $5 \%$ to as high as 50\% (Ohayon, 2002; Morin and Jarrin, 2013). Most epidemiologic studies have found that about one-third of adults $(30 \%-36 \%)$ report at least one symptom of insomnia, like difficulty initiating sleep or maintaining sleep; this rate drops to $10 \%-15 \%$ when daytime consequences, like excessive daytime sleepiness, are added to the definition (Ohayon, 2002; Morin and Jarrin, 2013). From 1999 to 2010, the number of prescriptions for any sleep medication increased by 293\% (Ford et al., 2014). Strong increases in the percentage of office visits resulting in a prescription for second generation benzodiazepines or Z-drugs (zopiclone, zolpidem, or zaleplon) sleep medications $(\sim 350 \%)$, benzodiazepine receptor agonists $(\sim 430 \%)$, and any sleep medication $(\sim 200 \%)$ were noted (Ford et al., 2014).

\section{B. Changes in the Nosology of Insomnia in Diagnostic and Statistical Manual of Mental Disorders-V}

The publication of the fifth edition of the Diagnostic and Statistical Manual of Mental Disorders (DSM-5) (American Psychiatric Association, 2013) fundamentally changed the landscape of sleep medicine and the diagnosis of insomnia. In DSM-IV, primary insomnia was distinguished from insomnia that is secondary to another diagnosis, including major depressive disorder and generalized anxiety disorder. DSM-IV understood secondary insomnia as a symptom of a primary psychiatric disease: the secondary insomnia was expected to normalize with treatment of the primary disorder (American Psychiatric Association, 2013). However, clinical research has established that this "secondary" insomnia is often resistant to treatment of the primary disorder: in the STAR $* \mathrm{D}$ trial, after remission with a course of citalopram therapy, 54.9\% of remitters continued to experience midnocturnal insomnia and $71.7 \%$ continued to experience sleep disturbance in some form (Nierenberg et al., 2010). DSM-5 has eliminated primary insomnia as a diagnosis in favor of insomnia disorder, which may occur alongside other diagnoses like major depressive disorder. This revised definition obliges the clinician to treat insomnia as a comorbidity, rather than a symptom of a primary illness. In this review, we use the term "insomnia disorder," except when a published study explicitly states that it analyzes patients with "primary insomnia."

\section{Clinical Guidelines for Insomnia Treatment and the Necessity of a Translational Approach}

New evidence-based clinical practice guidelines for the treatment of insomnia disorder were recently published in The Journal of Clinical Sleep Medicine (Sateia et al., 2017a), representing the first comprehensive, systematic analysis of single agents for the treatment of insomnia disorder, developed using the GRADE methodology (Grading of Recommendations, Assessment, Development, and Evaluation) (Sateia et al., 2017b). Unfortunately, the level of evidence for all of the authors' recommendations was "weak." This evaluation means that the strength of the evidence in the published data were low. Notably, all of the recommended treatments for sleep onset insomnia besides ramelteon are Z-drugs or BZD hypnotics. For sleep maintenance insomnia, three of five of the treatment options are Z-drugs or BZDs.

The dearth of strong published evidence led us to adopt a translational approach in exploring treatments for insomnia disorder, integrating the neurobiological mechanism of action of each drug gleaned from basic science and integrating it with reported clinical data and current medical practice. This approach is currently the standard in pharmacological research and is a priority for federal and foundational grants. Although clinical research is critical for establishing evidencebased guidelines for treatment, knowledge gleaned from basic research can be helpful for the clinical judgment of the therapeutic efficacy of hypnotics and the treatment of psychiatric comorbidities (Comai et al., 2012a,b).

In this review, we will focus on drugs that are not BZDs or Z-drug, because an extensive literature already exists. Our approach will be translation, offering alternatives to BZDs and Z-drugs. We will also describe novel hypnotic compounds and pharmaceutical pipelines. 


\section{The Dark Side of Benzodiazepines and Z-Drugs and the Off-Label Use of Other Drugs}

Although the market for insomnia medications continues to be dominated by BZDs and Z-drugs, both categories of drug have numerous problematic effects as short-term treatment and, in particular, as long-term therapy. BZDs are associated with hangover effects the next day, cognitive or memory impairment, the rapid development of tolerance, rebound insomnia upon discontinuation, car accidents or falls, and a substantial risk of abuse and dependence (Foy et al., 1995; Hemmelgarn et al., 1997; Soldatos et al., 1999; Ashton, 2005). A large proportion of people prescribed BZD drugs become chronic users. Furthermore, BZDs are a factor in approximately $5 \%-10 \%$ of car accidents, although the rate in individual studies varies from $1 \%$ to $65 \%$ (Thomas, 1998).

Z-drugs also cause cognitive impairments: case control studies find that BZD or Z-drug use approximately doubles the risk of being involved in a motor vehicle accident (Thomas, 1998; Gunja, 2013b). They can produce dependence (Lugoboni et al., 2014) as well as next-day cognitive, memory, psychomotor and balance impairments (Mets et al., 2011).

The problems with BZDs have led clinicians to prescribe other medications that are perceived to be less harmful or to be less liable to addiction. As an example, in the United States in 2002, the antidepressant medication trazodone was the most commonly prescribed medication for insomnia, with 34\% more prescriptions than the most commonly prescribed FDA-approved treatment (Walsh, 2004). The Prescriber National Summary Report, Calendar Year 2014 pools data from all the Medicare recipients in the United States. In one cross-sectional study of American adults, $3 \%$ of 32,328 people used a "prescription medication commonly used for insomnia" in the previous month: $38 \%$ of those who received a hypnotic medication received Z-drugs, $31 \%$ trazodone, $17 \%$ BZDs, $11 \%$ quetiapine, and only $5 \%$ received doxepin (Bertisch et al., 2014). This study confirms that drugs prescribed offlabel are very common in the treatment of insomnia, despite the low number of randomized, controlled trials (RCTs).

\section{Sleep Architecture}

In mammals, physiological sleep is divided into two strikingly distinct states known as non-rapid eye movement (NREM) and rapid eye movement (REM) sleep. Historically, NREM sleep was subdivided into four stages (stages 1, 2, 3, 4) defined according to different electroencephalogram (EEG) patterns (Rechtschaffen and Kales, 1968). According to the manual of the American Academy of Sleep Medicine published in 2007 (Iber et al., 2007), NREM sleep is now divided into three progressively deeper stages of sleep named stage N1, stage N2, and stage N3 (formerly stages 3 and 4). REM sleep is now officially referred to as stage R. The EEG pattern in NREM sleep is synchronous and presents characteristic waveforms: sleep spindles, K-complexes, and high-voltage slow waves. Stage N1 accounts for $2 \%-5 \%$ of total sleep time and is the phase of transition between the awake state and sleep. Stage N2 accounts for $45 \%-55 \%$ of total sleep time and occurs throughout the entire sleep period. The descent from stage N1 to stage N2 is characterized by a decrease in the frequency of the EEG trace paralleled by an increase in its amplitude. The EEG hallmark of N2 are theta waves. N2 is also characterized by the occasional occurrence of a series of high-frequency waves $(8-14 \mathrm{~Hz})$ known as sleep spindles, generated by interactions between thalamic and cortical neurons (De Gennaro and Ferrara, 2003), and fast and high-amplitude wave forms known as K-complexes also occur (Amzica and Steriade, 2002). According to Rechtschaffen and Kales' (1968) criteria, a $\mathrm{K}$-complex is defined as a negative slow wave immediately followed by a positive wave exceeding 0.5 seconds in duration.

As stage N2 sleep progresses, high-voltage, slowwave activity appears as the subject enters stage N3. Stage N3, which corresponds to deep or delta-wave sleep and reflects slow-wave sleep (SWS), occurs mostly in the first third of the night and accounts for 5\%-15\% of total sleep time. During this sleep stage, there is a further fall in blood pressure, a slowing of breathing, and a reduction in body temperature, with reduced muscle activity, although muscles maintain their tonus and thus some movements can be observed.

Stage R or REM sleep is defined by low-amplitude desynchronized theta EEG activity and represents $20 \%-25 \%$ of total sleep time. It occurs in four to five episodes throughout the night and is characterized by complete disappearance of muscle tone paradoxically associated with a cortical but also hippocampal activation and rapid eye movements. Since REM sleep EEG activity closely or paradoxically resembled the EEG of alert-waking subjects, this sleep stage has been also referred as paradoxical sleep, particularly in studies conducted in animals.

In physiological conditions, the activity of the brain over the course of the night proceeds from waking through the three stages of NREM sleep and then REM sleep. NREM sleep and REM sleep continue to alternate through the night in a cyclical fashion, usually with a total of four to five sleep cycles throughout the night. Importantly, as sleep progresses, the time spent in stage N3 becomes shorter, whereas the time spent in REM gets longer. The average length of the first NREMREM sleep cycle is between 70 and 100 minutes and that of the second and later cycles is about 90120 minutes. Sleep architecture, including the duration of the different stages as well as the duration of a NREM-REM cycle, is strongly dependent on the 
subject's age. With aging, humans tend to experience an increase in the latency to fall asleep, more fragmented sleep, and less time spent in SWS, particularly in the early cycles of sleep. One of the parameters providing information concerning sleep fragmentation is the "sleep efficiency index" that is a measure of the percentage of total time in bed actually spent sleeping and is calculated by the sum of the time spent in sleep stage N1, N2, N3, and REM, divided by the total time spent in bed. Specific details on the changes in the sleep structure occurring during aging are outside the scope of this paper but are analyzed in a comprehensive recent review written by Mander et al. (2017). Restorative sleep is not only dependent on an adequate duration of sleep; the physiological architecture of sleep must be conserved. Under certain conditions and with certain pharmacological treatments, the total duration of sleep may remain unchanged or increased, but deviations from normal sleep architecture generate increased sleep fragmentation. Disturbances in subjects' sleep architecture results in a sense of having had nonrestorative sleep and is associated with next-day impairments in conducting daily activities. Unfortunately, most of the drugs currently used as hypnotics-in particular benzodiazepines, but also Z-compounds to a lesser extent-disturb sleep architecture (Bastien et al., 2003; Gunja, 2013a).

\section{The Receptor-Mediated Mechanism of Action of Hypnotics}

Drugs currently used to treat insomnia mainly act on specific ionotropic or G-protein-coupled receptors located in specific brain areas. Each receptor modulates different characteristics of sleep. It is thus important for the clinician to understand the mechanism of action of each hypnotic to target better its effect in individual patients. This translational approach helps to build a more personalized medicine, targeted to the patient, that overcomes the limitations of overarching clinical guidelines. While guidelines tend to homogenize the patient population, a translational approach based on the mechanism of action of each drug may help to target the individual patient and his or her particular comorbidities.

\section{A. GABA Receptor}

The most studied receptors in the treatment of insomnia are the $\mathrm{GABA}_{\mathrm{A}}$ receptors, GABA being the chief inhibitory neurotransmitter in the mammalian nervous system, where BZDs and Z-drugs act. BZDs and Z-drugs act as positive allosteric modulators at the $\mathrm{GABA}_{\mathrm{A}}$ binding site, potentiating GABA's inhibitory effect (Stahl, 2008). The combination of GABA at the receptor's agonist site and benzodiazepine-receptor agonists at the allosteric site increases the frequency of the chloride channel opening to an extent that does not occur with GABA alone (Stahl, 2008). The result is neuronal inhibition. Similar to other ligand-gated ion channels, the $\mathrm{GABA}_{\mathrm{A}}$ receptor is composed of five subunits belonging to different subunit classes $(\alpha 1-6$, $\beta 1-3, \gamma 1-3, \delta, \varepsilon, \theta, \pi)$ that are distributed throughout the brain differentially; there is also some interindividual variability in their localization. For a detailed review on this topic, please see Olsen and Sieghart (2009). In this way, BZDs and Z-drugs exert their effects as sedatives, anxiolytics, anticonvulsants, muscle relaxants, and hypnotics. The main difference between BZDs and Z-drugs is in their receptorial affinities toward the different $\mathrm{GABA}_{\mathrm{A}}$ subunits. BDZs show similar affinity to the $\alpha 1, \alpha 2, \alpha 3$, and $\alpha 5$ receptor subtypes. In contrast, most of the Z-drugs show higher affinity for a subset of the alpha subunits, mainly the $\alpha 1$ receptor subtype, that seems to be specifically implicated in sleep but not in anxiety. Zaleplon, zopiclone, and zolpidem have high affinity and potency for the $\alpha 1$ subunit and low affinity and potency at $\alpha_{2}$ and $\alpha_{3}$ subunits; eszopiclone - the $(S)$-enantiomer of zopiclone - has high affinity and potency for the $\alpha 2$ and $\alpha 3$ subunits (Nutt and Stahl, 2010). Due to their selective agonism, Z-drugs mainly produce sedative and hypnotic properties and likely display improved tolerability over the BZDs (Wilson and Nutt, 2007).

This review will focus on alternate mechanisms of action that are not directly mediated through GABA receptors, with the exception of the gabapentinoids (pregabalin and gabapentin). Although pregabalin and gabapentin are analogs of GABA, they do not bind directly to $\mathrm{GABA}_{\mathrm{A}}$ or benzodiazepine receptors. Instead, they inhibit the $\alpha_{2} \delta$-1 subunit voltage-dependent calcium channels. They have been found to increase SWS sleep in patients diagnosed with epilepsy and insomnia (Bazil et al., 2012) and healthy adults (FoldvarySchaefer et al., 2002; Hindmarch et al., 2005). Further development of novel $\alpha_{2} \delta$ calcium channels like atagabalin (PD 200390) was pursued for the treatment of insomnia but then discontinued following unsatisfactory trial results (Springer Adis Insight, 2017).

\section{B. Serotonin Receptors}

The 5-HT-containing neurons of the dorsal raphe nuclei discharge maximally during waking and decrease their firing during SWS; they cease firing during REM sleep, similar to the norepinephrine-containing neurons of the locus coeruleus (Jones, 2005). The $5-\mathrm{HT}_{1 \mathrm{~A}}$ agonist $\mathrm{OH}-\mathrm{DPAT}$, which decreases 5 -HT firing activity by activating its autoreceptors (Gobbi et al., 2001) increases REM sleep (Portas et al., 1996). Although $5-\mathrm{HT}_{1 \mathrm{~A}}$ receptors are autoreceptors located at the somatodendritic level, $5-\mathrm{HT}_{1 \mathrm{~B}}$ receptors are autoreceptors localized at postsynaptic sites. 5 - $\mathrm{HT}_{1 \mathrm{~B}}$ receptors are also used as heteroceptors in many cells throughout the brain to inhibit the release of neurotransmitters other than serotonin (Marek, 2010). Furthermore, 
serotonergic neurons attenuate cortical activation through inhibitory influences on other neurons of the activating systems, including acetylcholine-containing neurons (Jones, 2005).

\section{Serotonin 2 Receptors}

The $5-\mathrm{HT}_{2}$ receptor is located in the prefrontal and orbitofrontal cortex, the (subgenual) anterior cingulate cortex, the occipital, and parietal cortex (van Dyck et al., 2000; Adams et al., 2004; Hinz et al., 2007); in the nucleus accumbens, olfactory tubercule, and the hippocampus (Pompeiano et al., 1994; Barnes and Sharp, 1999; López-Giménez et al., 2001); and in the locus coeruleus, areas that are important for both sleep modulation and mood regulation (Szabo and Blier, 2001).

At the cellular level, $5-\mathrm{HT}_{2 \mathrm{~A}}$ receptors are located on apical dendrites on pyramidal cells and, particularly in subcortical regions, on local (GABAergic) interneurons (Jakab and Goldman-Rakic, 1998; Barnes and Sharp, 1999; Aghajanian and Sanders-Bush, 2002). Although the mechanism of action of $5-\mathrm{HT}_{2 \mathrm{~A} / 2 \mathrm{C}}$ receptor antagonists has yet to be fully elucidated, it is likely that they promote SWS via a reduction of inhibitory input to the cells of the ventrolateral preoptic nucleus that fire during sleep. Through postsynaptic $5-\mathrm{HT}_{2 \mathrm{~A}}$ receptors on GABAergic cells of the reticular thalamus, serotonergic fibers from the dorsal raphe and supralemniscal nucleus (B9) modulate the reticular thalamus that in turn regulates sleep and wakefulness (Rodrìguez et al., 2011).

Recent studies with more subtype-selective $5-\mathrm{HT}_{2 \mathrm{~A}}$ and $5-\mathrm{HT}_{2 \mathrm{C}}$ receptor ligands (antagonists and inverse agonists), as well as experiments in knockout (KO) mice, support a role for $5-\mathrm{HT}_{2 \mathrm{~A}}$ receptor subtypes in promoting SWS and the $5-\mathrm{HT}_{2 \mathrm{C}}$ receptor in promoting REM (Popa et al., 2005).

Ritanserin, a potent antagonist of the serotonin receptors $5-\mathrm{HT}_{2 \mathrm{~A}}$ and $5-\mathrm{HT}_{2 \mathrm{C}}$, has been found to increase SWS in healthy volunteers to a greater degree than ketanserin (a drug with less potent effects as an antagonist of the 5- $\mathrm{HT}_{2 \mathrm{C}}$ receptor, used clinically as an antihypertensive) (Sharpley et al., 1994). Ritanserin was never commercialized for safety problems, although it did show efficacy at increasing SWS and delta activity in young male poor sleepers (Viola et al., 2002), underlining the importance of these receptors in the regulation of SWS.

Interestingly, many hypnotic drugs prescribed offlabel (trazodone, mirtazapine, olanzapine, quetiapine) act through $5-\mathrm{HT}_{2 \mathrm{~A}}$ and $5-\mathrm{HT}_{2 \mathrm{C}}$ receptors to enhance sleep (Landolt and Wehrle, 2009). Trazodone, the first $5-\mathrm{HT}_{2 \mathrm{~A}}$ antagonist, was initially developed as an antidepressant, but is currently one of the most common hypnotics prescribed in the clinic (Bertisch et al., 2014). Similarly, the 5- and 10-mg doses of olanzapine compared with placebo, significantly increased SWS, sleep continuity measures, and subjective sleep quality (Sharpley et al., 2000). See Tables 1 and 2 for the receptorial affinities of each drug and for their effects on sleep architecture, respectively.

\section{Serotonin $1 A$ Receptors}

The $5-\mathrm{HT}_{1 \mathrm{~A}}$ receptor is the main 5 -HT autoreceptor, located at the somatodendritic level of the 5-HT neurons of the dorsal raphe as well as at synaptic terminals in the hippocampus and prefrontal cortex. $5-\mathrm{HT}_{1}$ knockout (KO) mice have increased 5-HT firing activity (Richer et al., 2002) and decreased REM sleep, but not SWS (Boutrel et al., 2002); the 5-HT $1 \mathrm{~A}$ agonist $\mathrm{OH}-\mathrm{DPAT}$ induces a decrease in REM sleep in the first 2 hours after injection followed by an increase in REM after 6-8 hours (Boutrel et al., 2002). 8-OH-DPAT (1.0-4.0 $\mu \mathrm{g}$ ) injected into the dorsal raphe nucleus increased slowwave sleep and decreased wakefulness, although its administration of subcutaneously induced biphasic effects such that low doses decreased wakefulness and increased slow-wave sleep while higher doses induced opposite effects, perhaps due to the opposing effects of the $5-\mathrm{HT}_{1 \mathrm{~A}}$ autoreceptors and heteroreceptors (Monti and Jantos, 1992). Given these opposing and complex effects, employing $5-\mathrm{HT}_{1 \mathrm{~A}}$ partial agonists is a rational approach to insomnia, given their capacity to act as agonists when the levels of endogenous agonist are low and as antagonists when the levels of endogenous agonist are high.

5 -HT $\mathrm{HB}_{1 \mathrm{~B}}$ knockout mice have increased REM sleep and lower SWS during the light phase and lack REM sleep rebound after deprivation, suggesting that the blockage of $5-\mathrm{HT}_{1 \mathrm{~B}}$ receptors increases $\mathrm{REM}$ and decreases NREM sleep (Boutrel et al., 1999). In agreement with this finding, in wild-type (WT) mice, the $5-\mathrm{HT}_{1 \mathrm{~B}}$ agonists CP 94253 and RU 24969 induced a dose-dependent reduction of paradoxical sleep during the 2-6 hours after injection, whereas the $5-\mathrm{HT}_{1 \mathrm{~B} / 1 \mathrm{D}}$ antagonist GR 127935 enhanced paradoxical sleep (Boutrel et al., 1999).

Quetiapine and trazodone both act on $5-\mathrm{HT}_{1 \mathrm{~A}}$ receptors as partial agonists (Richelson and Souder, 2000; Odagaki et al., 2005).

\section{E. Noradrenaline Receptors}

Similarly to 5-HT neurons, the norepinephrinecontaining neurons of the locus coeruleus (LC) nuclei discharge maximally during waking and decrease their firing during SWS; they are nearly silent during paradoxical or REM sleep (Jones, 2005).

The most important adrenergic receptors implicated in sleep are $\alpha_{1}$ and $\alpha_{2}$ receptors. $\alpha_{2}$ Receptors are located at presynaptic terminals, acting as the main norepinephrine neuron autoreceptors, although they are also present at the postsynaptic terminal. The activation of the $\alpha_{2}$ autoreceptor decreases LC activity, while, in contrast, $\alpha_{2}$ receptor blockade using $\alpha_{2}$ antagonists increases the 


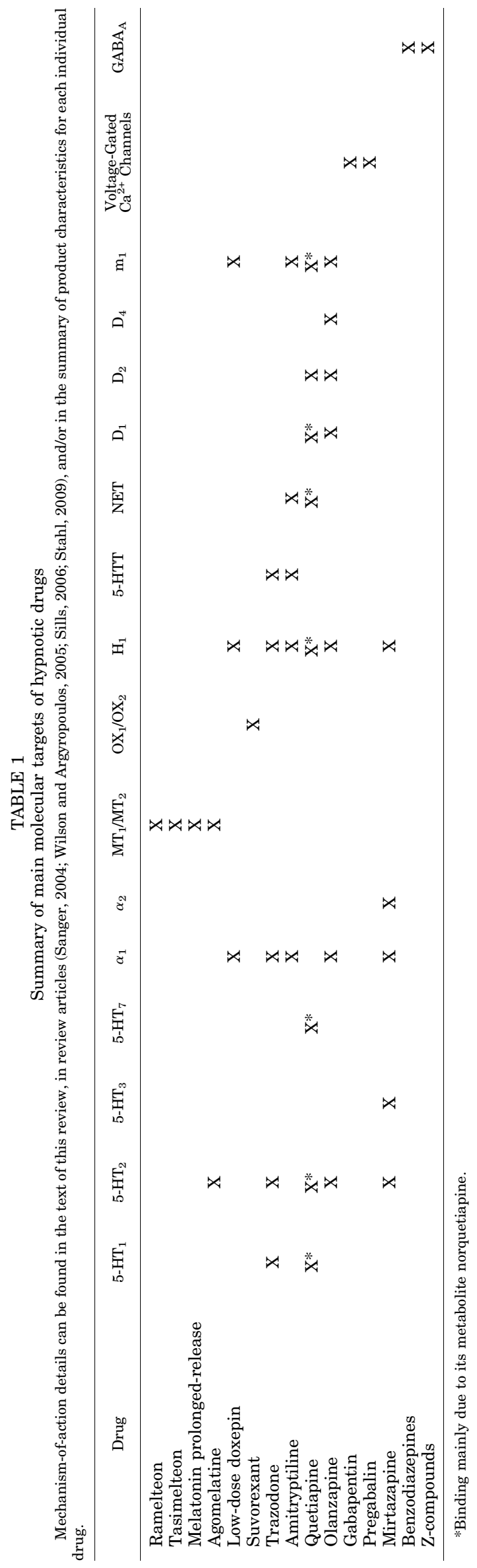

firing activity of LC neurons (Gobbi and Blier, 2005). In fact, although the $\alpha_{2}$ agonist clonidine decreases LC activity and thus promotes sleep (particularly SWS) while inhibiting REM (De Sarro et al., 1987; Berridge et al., 2012), there is evidence that the selective $\alpha_{2}$ antagonist yohimbine increases wakefulness, at least in rats (Mäkelä and Hilakivi, 1986).

However, selective knockdown of $\alpha 2 \mathrm{~A}$-adrenergic receptors in the LC abolished $\alpha_{2}$ agonist dexmedetomidineinduced loss-of-righting-reflex, but not sedation (Zhang et al., 2015). These findings implicate other structures besides the $\mathrm{LC}$ in $\alpha_{2}$ receptorial regulation of arousal: these structures include the preoptic area, in which $\alpha_{2}$ receptors are situated on GABAergic interneurons, which influence sleep through reciprocal inhibitory projections to the $\mathrm{W}$ systems; or the prefrontal cortex, where $\alpha_{2}$ receptors are likewise situated on GABAergic neurons (Manns et al., 2003; Luppi et al., 2017).

Indeed, when GABAergic neurons ("OFF neurons") containing $\alpha_{2}$ receptors located in the prefrontal cortex are stimulated during SWS, their firing activity ceases, which likely produces paradoxical or REM sleep (Manns et al., 2003). This complex $\alpha_{2}$ receptor-mediated mechanism may account for the manner in which the $\alpha_{2}$ antagonist mirtazapine promotes sleep, although it increases LC firing (Gobbi and Blier, 2005).

The $\alpha_{1}$ and beta adrenergic receptors are also involved in the regulation of arousal. While individual administration of the $\alpha_{1}$ blocker prazosin produces decreased behavioral arousal and individual administration of the beta noradrenergic antagonist timolol has no effect, coadministration of prazosin and timolol produces a substantial, synergistic increase in slowwave firing activity with a corresponding strong sedative effect behaviorally (Berridge and Espana, 2000).

\section{F. Dopamine Receptors}

Dopamine neurons are also active during wakefulness and decrease during REM sleep and SWS (Monti and Monti, 2007). In particular, the dopamine $\mathrm{D}_{2}$ receptor is one of the main receptors involved in sleep regulation. $\mathrm{D}_{2} \mathrm{KO}$ mice exhibit a significant decrease in wakefulness, with a concomitant increase in NREM and REM sleep and a drastic decrease in low-frequency electroencephalogram delta power $(0.75-2 \mathrm{~Hz})$ of NREM sleep, especially during the first 4 hours following lights off. In agreement with these findings, the $\mathrm{D}_{2}$ antagonist raclopride mimicked these effects in WT mice ( $\mathrm{Qu}$ et al., 2010). Similarly, the dopamine $\mathrm{D}_{2}$ receptor antagonists haloperidol and chlorpromazine have the tendency to induce sleepiness in human subjects, while blockers of the dopamine transporter like amphetamine and modafinil increase wakefulness by increasing extracellular levels of dopamine in the synapse (Schmitt and Reith, 2010). In contrast, paradoxically, the antiparkinsonian $\mathrm{D}_{2}$ agonist ropinirole 
TABLE 2

Summary of the effects of the different hypnotic drugs on the sleep architecture and their potential to induce dependence liability

\begin{tabular}{|c|c|c|c|c|c|c|c|}
\hline \multirow{2}{*}{ Drug } & \multirow{2}{*}{$\begin{array}{l}\text { Latency to } \\
\text { Sleep Onset }\end{array}$} & \multicolumn{3}{|c|}{ Effect on NREM Sleep } & \multirow{2}{*}{$\begin{array}{c}\text { Effect on } \\
\text { REM Sleep }\end{array}$} & \multirow{2}{*}{$\begin{array}{c}\text { Sleep } \\
\text { Efficiency }\end{array}$} & \multirow{2}{*}{$\begin{array}{c}\text { Dependence } \\
\text { Liability }\end{array}$} \\
\hline & & Stage N1 & Stage N2 & Stage N3 also referred as SWS & & & \\
\hline Benzodiazepines & $\downarrow$ & $\downarrow$ & $\uparrow$ & $\downarrow$ & $\downarrow$ & $\uparrow$ & High \\
\hline Z-drugs & $\downarrow$ & $\leftrightarrow$ & $\uparrow$ & $\leftrightarrow$ & $\leftrightarrow$ & $\uparrow$ & Moderate \\
\hline Ramelteon & $\downarrow$ & $\leftrightarrow$ & $\uparrow$ & $\downarrow$ & $\leftrightarrow$ & $\uparrow$ & Low \\
\hline Tasimelteon & $\downarrow$ & n.a. & n.a. & n.a. & $\uparrow$ & $\uparrow$ & Low \\
\hline Melatonin prolonged-release & $\downarrow$ & $\leftrightarrow$ & $\leftrightarrow$ & $\leftrightarrow$ & $\leftrightarrow$ & $\uparrow$ & Low \\
\hline Agomelatine & $\downarrow$ & $\leftrightarrow$ & $\leftrightarrow$ & $\uparrow$ & $\leftrightarrow$ & $\uparrow$ & Low \\
\hline Low-dose doxepin & $\downarrow$ & $\leftrightarrow$ & $\uparrow$ & $\leftrightarrow$ & $\leftrightarrow$ & $\uparrow$ & Low \\
\hline Suvorexant & $\downarrow$ & $\leftrightarrow$ & $\uparrow$ & $\leftrightarrow$ & $\uparrow$ & $\uparrow$ & Low \\
\hline Trazodone & $\leftrightarrow$ & $\leftrightarrow / \downarrow$ & $\leftrightarrow / \downarrow$ & $\leftrightarrow / \uparrow$ & $\leftrightarrow / \downarrow$ & $\leftrightarrow$ & Low \\
\hline Amitryptiline & $\downarrow$ & n.a. & n.a & $\uparrow$ & $\downarrow$ & $\uparrow$ & Low \\
\hline Quetiapine & $\downarrow$ & $\leftrightarrow$ & $\uparrow$ & $\leftrightarrow \downarrow$ & $\downarrow$ & $\uparrow$ & Low \\
\hline Olanzapine & $\downarrow$ & $\leftrightarrow$ & $\leftrightarrow / \uparrow$ & $\uparrow$ & $\downarrow / \leftrightarrow / \uparrow$ & $\uparrow$ & Low \\
\hline Gabapentin & $\leftrightarrow$ & $\leftrightarrow$ & $\leftrightarrow$ & $\uparrow$ & $\leftrightarrow$ & $\uparrow / \leftrightarrow$ & Moderate \\
\hline Pregabalin & $\downarrow$ & $\leftrightarrow$ & $\leftrightarrow$ & $\uparrow$ & $\downarrow$ & $\uparrow$ & Moderate \\
\hline Mirtazapine & $\leftrightarrow$ & $\downarrow$ & $\leftrightarrow$ & $\uparrow$ & $\leftrightarrow$ & $\uparrow$ & Low \\
\hline
\end{tabular}

$\uparrow$ : Increase; $\downarrow$ : decrease; ↔: no change. n.a.: not assessed.

also induces sleepiness, but mostly daytime sleepiness and sleep attacks during the day (Paus et al., 2003), likely through activation of $\mathrm{D}_{2}$ autoreceptors that decrease DA firing activity during the daytime.

\section{G. Orexin Receptors}

The orexins (OXs), also known as the hypocretins, are a pair of excitatory neuropeptide hormones with approximately $50 \%$ sequence homology: orexin-A and orexin-B (hypocretin-1 and -2). They are produced exclusively by a population of neurons in the lateral hypothalamic area (de Lecea et al., 1998; Sakurai et al., 1998). Physiological effects of the OXs in the brain result from the activation of two G-protein-coupled receptors, named orexin $1\left(\mathrm{OX}_{1}\right)$ and orexin $2\left(\mathrm{OX}_{2}\right)$ receptors (Sakurai et al., 1998). $\mathrm{OX}_{1}$ has one-order higher affinity for OX-A than for OX-B, whereas $\mathrm{OX}_{2}$ binds OX-A and OX-B with similar affinities.

The orexinergic system is known to promote behavioral arousal, increase food intake and locomotor activity (Sakurai et al., 1998; Nakamura et al., 2000), and induce wakefulness (Hagan et al., 1999). In addition, the OXs appear to regulate the stress response by increasing the activity of the hypothalamic-pituitary axis (Al-Barazanji et al., 2001). Furthermore, they are implicated in the pathophysiology and treatment of depressive-like behavior (Nollet et al., 2011).

$\mathrm{KO}$ animals that lack the prepro-orexin gene, $\mathrm{OX}_{2}$ gene, or orexin neurons have narcolepsy-like behavior, including fragmentation of sleep/wakefulness, direct transitions from wake to REM sleep, and sudden loss of muscle tone while still awake (cataplexy) (Chemelli et al., 1999; Lin et al., 1999; Hara et al., 2001; Willie et al., 2003). However, $\mathrm{OX}_{1} \mathrm{KO}$ mice have mild or almost no abnormality in the regulation of sleep and wakefulness, suggesting that the orexin signal through $\mathrm{OX}_{2}$ has a more critical role in the regulation of sleep and wakefulness, especially in the maintenance of arousal.
The expression pattern of orexin receptors matches the afferent projections of orexin neurons throughout the brain. The few studies using selective antagonists of the $\mathrm{OX}_{1}$ and $\mathrm{OX}_{2}$ receptors have demonstrated that selective blockade of $\mathrm{OX}_{2}$, but not $\mathrm{OX}_{1}$, increases REM and NREM. However, coadministration of the selective $\mathrm{OX}_{1}$ antagonist and the selective $\mathrm{OX}_{2}$ antagonist intensified the effect of $\mathrm{OX}_{2}$ blockade on REM and NREM (Dugovic et al., 2009). Other studies have agreed that $\mathrm{OX}_{1}$ may play a role in the regulation of sleep and arousal (Mieda et al., 2011).

A novel orexin antagonist (suvorexant) was recently put on the market and other selective orexin antagonists are under development (Winrow and Renger, 2014).

\section{H. Melatonin Receptors}

The neurohormone melatonin activates two G-proteincoupled receptors, $\mathrm{MT}_{1}$ and $\mathrm{MT}_{2}$. Melatonin is implicated in circadian rhythms and sleep regulation, but the differential role of its individual receptors remains undefined.

Melatonin receptors have a specific localization that implicates them in physiological functions related to sleep (Lacoste et al., 2015). $\mathrm{MT}_{2}$ receptors are located in the reticular thalamus, an area involved in modulating SWS (Steriade et al., 1993), as well as the substantia nigra (pars reticulata), supraoptic nucleus, red nucleus, and the $\mathrm{CA}_{2}, \mathrm{CA}_{3}, \mathrm{CA}_{4}$ areas of the hippocampus and SCN (Ekmekcioglu, 2006; Ochoa-Sanchez et al., 2011), while $\mathrm{MT}_{1}$ is located in the locus coeruleus, the dorsal raphe, and areas CA2 and CA3 of the hippocampus and SCN (Lacoste et al., 2015).

Recently our group has better characterized the differential role of each receptor in sleep function using $\mathrm{MT}_{1} \mathrm{KO}, \mathrm{MT}_{2} \mathrm{KO}$, and double $\mathrm{MT}_{1}-\mathrm{MT}_{2} \mathrm{KO}$ as well as selective $\mathrm{MT}_{2}$ ligands (Comai et al., 2013). $\mathrm{MT}_{2} \mathrm{KO}$ mice have a selective disruption of SWS during the inactive 
phase and increased wakefulness, whereas $\mathrm{MT}_{1} \mathrm{KO}$ mice have a selective disruption of REM during the inactive phase and an increase of NREM. These results elucidate the opposing and differential effects of the two receptors in the neurobiology of sleep.

Dual $\mathrm{MT}_{1}-\mathrm{MT}_{2} \mathrm{KO}$ mice only show a small increase in wakefulness, without a difference in total sleep compared with their WT counterparts (Comai et al., 2013), establishing that the $\mathrm{MT}_{1}$ and $\mathrm{MT}_{2}$ receptors may have opposing roles. This interpretation fits with the fact that melatonin and drugs that bind both $\mathrm{MT}_{1}$ and $\mathrm{MT}_{2}$ only modify the time to induction of sleep, without a global effect on total sleep time or sleep architecture (Comai et al., 2015). Thus, the absolute benefit of melatonin compared with placebo is smaller than other pharmacological treatments for insomnia (FerracioliOda et al., 2013). Similarly, ramelteon, a dual agonist of both $\mathrm{MT}_{1}$ and $\mathrm{MT}_{2}$, has only been approved by the FDA for the treatment of insomnia characterized by difficulty with sleep onset; it does not affect total sleep duration or increase SWS.

\section{Histamine Receptors}

The sole source of brain histamine is neurons localized in the hypothalamic tuberomammillary nuclei (Haas and Panula, 2003). These neurons project axons to the whole brain, although functionally distinct histaminergic neural circuits differentially influence individual brain regions. Four histamine receptors have been identified: $\mathrm{H}_{1}, \mathrm{H}_{2}, \mathrm{H}_{3}$, and $\mathrm{H}_{4}$ (Takahashi et al., 2002). In general, histamine modulates inflammatory responses through peripheral $\mathrm{H}_{1}$ receptors and modulates gastric acid secretion through peripheral $\mathrm{H}_{2}$ receptors. This led to the discovery and therapeutic use of potent selective $\mathrm{H}_{1}$ and $\mathrm{H}_{2}$ receptor antagonists. In contrast to the $\mathrm{H}_{1}, \mathrm{H}_{2}$, and $\mathrm{H}_{4}$ receptors, the $\mathrm{H}_{3}$ receptor is predominantly expressed in the CNS (Lovenberg et al., 1999; Oda et al., 2000), acting as an autoreceptor on presynaptic neurons and controlling histamine turnover. $\mathrm{H}_{3}$ receptors have also been shown to act as heteroreceptors in dopamine-, serotonin-, noradrenaline-, GABA-, and acetylcholine-containing neurons (Schlicker et al., 1994).

The $\mathrm{H}_{1}$ receptor is probably the most important physiological histamine target in the maintenance of waking. In animal studies, $\mathrm{H}_{1}$ receptor agonists increase wake duration (Passani and Blandina, 2011). $\mathrm{H}_{1}$ receptor KO mice show fewer incidents of brief awakening $(<16$ second periods), prolonged durations of NREM sleep episodes, a decreased number of state transitions between NREM sleep and wakefulness, and a shorter latency for initiating NREM sleep. When the $\mathrm{H}_{3}$ receptor antagonist ciproxifan was administered intraperitoneally to WT mice, wakefulness increased in the mice in a dosedependent manner but did not increase at all in $\mathrm{H}_{1} \mathrm{KO}$ mice, highlighting the interdependent functional relationship between $\mathrm{H}_{1}$ and $\mathrm{H}_{3}$ receptors (Huang et al., 2006).
$\mathrm{H}_{3} \mathrm{KO}$ mice show clear signs of enhanced histaminergic neurotransmission and vigilance, with higher EEG $\theta$ power during spontaneous wakefulness and during behavioral tasks. During the dark period, they display deficient wakefulness and signs of sleep deterioration, such as pronounced sleep fragmentation and reduced cortical slow activity during SWS, which occurs due to a desensitization of postsynaptic histaminergic receptors as a result of constant histamine release (Gondard et al., 2013).

Prescription drugs like mirtazapine, quetiapine, and hydroxyzine-not to mention nonprescription sleep aids like diphenhydramine - act on histaminergic neurons.

\section{J. Other Receptors}

Other receptors involved in sleep, but which remain to be pharmacologically exploited, include the adenosine $A_{1}$ and $A_{2}$ receptors (Jacobson and Gao, 2006). Interestingly, the arousal effect of the adenosine antagonist caffeine is mediated through the adenosine $\mathrm{A}_{2 \mathrm{~A}}$ receptor, but not the $A_{1}$ receptor (Huang et al., 2005).

Adenosine mediates the somnogenic effects of prior wakefulness and likewise plays an important role in the regulation of the duration and depth of sleep after wakefulness (reviewed by Greene et al. (2017). Pharmacological data suggest that $\mathrm{A}_{1 \mathrm{~A}}$ receptors are involved in the regulation of sleep, although a lack of $\mathrm{A}_{1 \mathrm{~A}}$ receptors is not sufficient to prevent homeostatic regulation of sleep (Stenberg et al., 2003). It is conceivable that although the $\mathrm{A}_{1 \mathrm{~A}}$ receptor is an important factor for sleep regulation in normal animals, other factors, such as the $A_{2 A}$ receptor, may compensate for the absence of the $A_{1 A}$ receptor when it is deleted in knockout models. Indeed, it has been shown that the $\mathrm{A}_{2 \mathrm{~A}}$ receptor has a key role in adenosine-mediated sleep-promoting effects (Urade et al., 2003).

Melanin-concentrating hormone $(\mathrm{MCH})$ neurons are known to be active during REM sleep and the stimulation of these neurons promotes REM sleep; indeed, electrophysiological recordings of $\mathrm{MCH}$ neurons across the natural sleep-wake demonstrates that they do not fire during waking, fire occasionally during NREM sleep, and fire maximally during REM sleep (Hassani et al., 2009). Importantly, they are colocalized with orexin neurons in the lateral hypothalamic area and adjacent zona incerta but as unique cell populations spatially intermingled with each other (reviewed by Yamashita and Yamanaka (2017).

Importantly, when $\mathrm{MCH}$ neurons are active, they inhibit orexin neurons, and knockout of $\mathrm{MCH}$ peptide and the MCHR1 receptor in mice produces less REM and NREM sleep. Optogenetic studies have confirmed the role of MCH neurons in inducing REM sleep: optogenetic activation of these cells during NREM sleep produces REM, but activation during wakefulness produces no effect. MCH neurons also play a role in NREM sleep, because temporally controlled ablation of 
these cells increases wakefulness and decreases NREM sleep duration without affecting REM sleep (Tsunematsu et al., 2014).

\section{K. From Receptors to Sleep Circuits.}

The manner in which unique neurotransmitters and individual brain areas reciprocally interact is still not understood in its entirety. The neural circuits that generate arousal and sleep (both NREM and REM) remain to be completely elucidated.

Humans are diurnal mammals, with a circadian clock that promotes wakefulness during the day, even as homeostatic sleep drive builds up. Importantly, sleep timing is phase-linked to intrinsic circadian rhythmcontrolled temperature rhythms as well as extrinsic light and dark signaling (Scammell et al., 2017).

In mammals, the circadian rhythm is organized by the suprachiasmatic nuclei (SCN). The retinohypothalamic tract, which contains the intrinsically photosensitive retinal ganglion cells and the photopigment melanopsin, projects directly and monosynaptically to the SCN via the optic nerve and the optic chiasm. The $\mathrm{SCN}$, which is rich in $\mathrm{MT}_{1}$ and $\mathrm{MT}_{2}$ receptors (Lacoste et al., 2015), projects to the paraventricular nucleus, and the "darkness" signal is eventually relayed to sympathetic fibers that innervate the pineal gland, which produces melatonin in response to darkness. Melatonin then stimulates the brain's $\mathrm{MT}_{2}$ receptors in the NREM sleep activating regions of the brain: the reticular thalamus and the preoptic areas, including both the ventrolateral preoptic area (vlPO) and the median preoptic nucleus (MNPO) (Ochoa-Sanchez et al., 2011; Lacoste et al., 2015). Specifically, the MNPO appears to regulate the firing activity of the vlPO (Chou et al., 2002). It has been shown that during the transition from wakefulness to sleep, the MNPOwhich specifically contains neurons that fire during slow-wave and paradoxical sleep, with slow discharging activity $<5 \mathrm{~Hz}$-begin to fire not before, but after, sleep onset, with a gradual increase in discharge rate (Sakai, 2011). During NREM sleep, the vlPO sends inputs that act to reduce the activity of the orexinergic arousal system and the monoamine nuclei (including the ventral tegmental area containing DA neurons, the dorsal raphe containing 5 -HT neurons, and the LC containing NE neurons) by releasing the inhibitory neurotransmitters GABA and galanin. As a feedback mechanism, vlPO neurons receive reciprocal inputs from the arousal nuclei, including the ventral tegmental area, dorsal raphe, and LC; the vlPO also receives input from the histaminergic tuberomammillary nucleus (Adamantidis et al., 2010).

The reticular thalamus (RT) is another area essential for NREM sleep: people suffering from fatal familial insomnia show thalamic disruption that inactivates their ability to sleep, which is paralleled by a dysfunction in melatonin production (Portaluppi et al., 1994).
RT neurons discharge in burst activity exclusively during NREM, and thalamocortical pathways project this synchronous burst activity, intermingled with periods of silence, onto the cortex. This rhythmic firing activity generates the synchronized EEG pattern typical of SWS, which produces disconnection between the cortex and the outside world (Steriade and Timofeev, 2003). The $R T$ is also rich in melatonin $\mathrm{MT}_{2}$ receptors, which are likely activated at the beginning of sleep (Ochoa-Sanchez et al., 2011). Disconnection between the prefrontal cortex and sensory input is greatest during Stage 4 of NREM sleep, when the frequency of the EEG trace is the lowest and its amplitude is the highest. Conversely, during wakefulness, the RT and thalamocortical neurons are depolarized by inputs from the reticular activating system of the brain stem and discharge instead with a tonic activity (adapted from Steriade et al., 1993; Purves et al., 2004).

REM sleep, in contrast, is regulated by other brain areas. Many researchers have hypothesized that REM sleep is mediated mostly through cholinergic neurons located in the lateralpontine tegmentum/peduncolopontine tegmental nuclei (LDT/PPT). These neurons are active during REM sleep and generate the cortical activation and atonia typical of this sleep stage and are inactive during NREM sleep. Indeed, LDT/PPT neurons send inputs to the ventromedial medulla, which inhibits motor neurons by releasing GABA and glycine into the spinal and brain stem motor neurons, producing atonia. LDT/PPT neurons are also the main source of acetylcholine to the thalamus: activation of this acetylcholine pathway depolarizes thalamic neurons, generating the cortical activation associated with REM sleep and dreaming. Other nuclei important for REM sleep regulation are 1) the sublaterodorsal nucleus (SDL), which produces GABA and glutamate and projects to the glycinergic/GABAergic premotor neurons in the ventromedial medulla and ventral horn of the spinal cord, and through these circuits likely inhibits motor neurons during REM sleep, and 2) the MCH-containing neurons that fire during REM sleep and decrease their activity during NREM sleep and wakefulness. The "REM-off versus REM-on" theory of REM sleep hypothesizes that during the REM-on period, LDT/PPT, SDL, and MCH neurons are active and inhibit monoamine neurons as well as motor neurons, while during the REM-off period, the vlPAG/LPT is inhibited by MCH neurons and other neurotransmitters (Saper et al., 2001; reviewed in España and Scammell, 2011).

Other cholinergic nuclei that are active during REM sleep and wakefulness include the basal forebrain and the lateral hypothalamus; these same nuclei are inhibited during NREM sleep.

The manner in which the brain alternates cycles of NREM and REM remains unknown, although some researchers have proposed the existence of a mutually inhibitory circuit between vlPAG/LPT and the SDL. 
Figure 1 is a schematic representation of nuclei important during sleep, illustrating the circuits that modulate the sleep/wake cycle and their respective receptors.

\section{Melatonergic Drugs}

\section{A. Agomelatine}

1. Mechanism of Action. Similar to melatonin, agomelatine inhibits firing activity in the SCN, likely through its full agonist activity at $\mathrm{MT}_{1}$; it is also an agonist at the $\mathrm{MT}_{2}$ receptor (McAllister-Williams et al., 2010). Agomelatine has low affinity for the $5-\mathrm{HT}_{1 \mathrm{~A}}$ and $5-\mathrm{HT}_{2 \mathrm{~B}}$ receptors, and its effects are thought to be mediated by its antagonism of the $5-\mathrm{HT}_{2 \mathrm{C}}$ receptor, with a $\mathrm{p} K_{\mathrm{i}}$ of 6.2 at human receptors (Millan et al., 2003). In animals, chronic administration of agomelatine produces a dose-dependent increase in dopamine and norepinephrine levels in the frontal cortex, without an effect on serotonin (European Medicines Agency, 2008a); like many other antidepressants, agomelatine administration is associated with increased expression of brain-derived neurotrophic factor mRNA and enhanced neurogenesis in the hippocampus (Banasr et al., 2006). In one study, agomelatine given at the onset of the late phase induced no changes in rat polygraphic recordings. However, when it was administered shortly before dark phase, agomelatine (10 and $40 \mathrm{mg} / \mathrm{kg}$ ) enhanced the duration of REM and SWS sleep and decreased the duration of the wake state for 3 hours (Descamps et al., 2009). A summary of the pharmacological targets of agomelatine is reported in Table 1.

2. Pharmacokinetics. Agomelatine is rapidly and well-absorbed following oral administration (>80\%) (European Medicines Agency, 2016). However, absolute bioavailability is low and variation between individuals is substantial, with increased bioavailability in women compared with men. Elderly people likewise experience greater exposure to the drug, with AUC and $C_{\max } 4$ - and

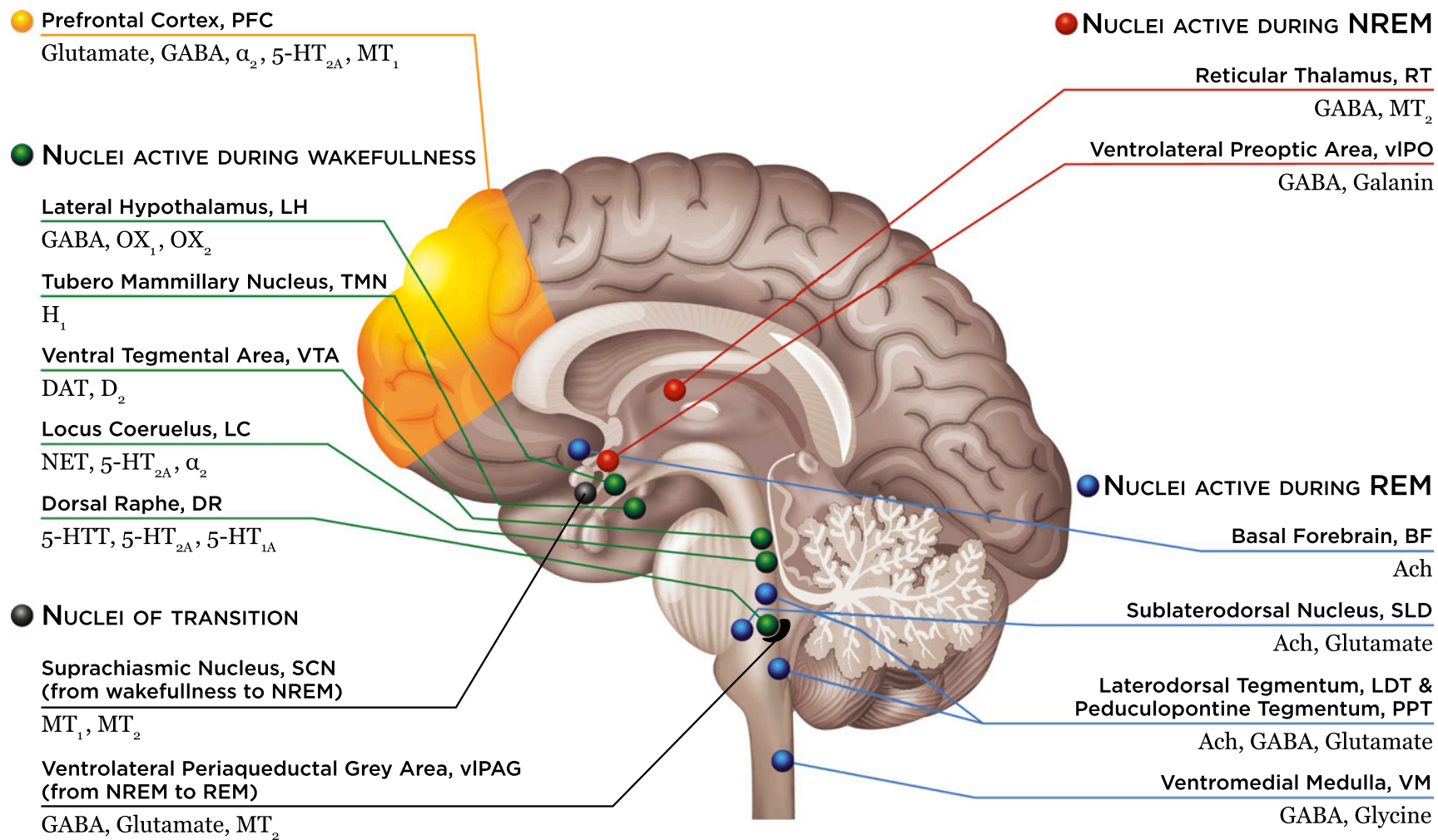

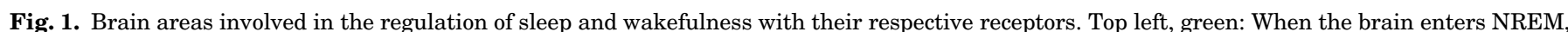

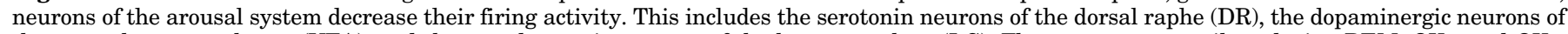

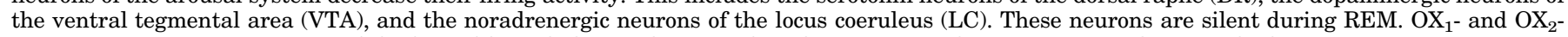

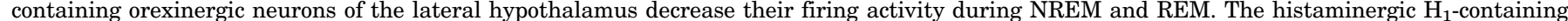

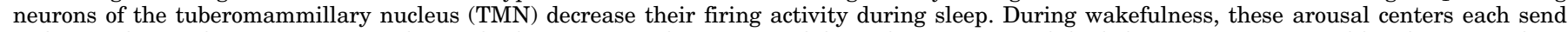

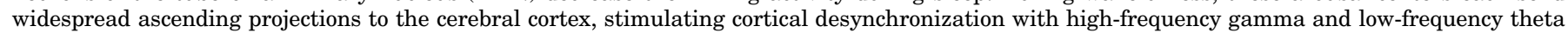

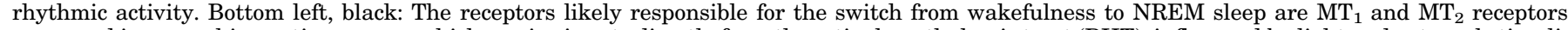

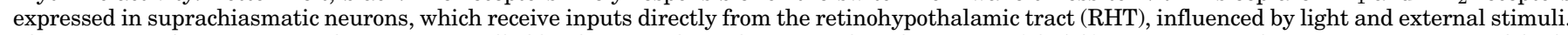

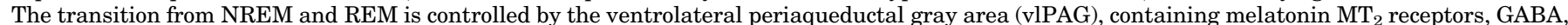

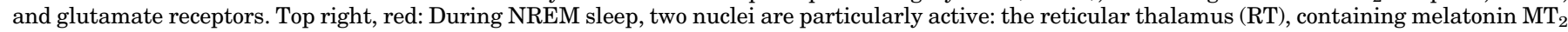

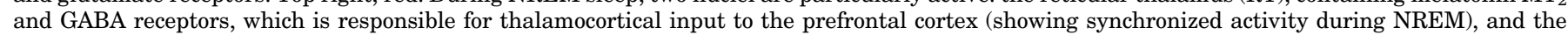

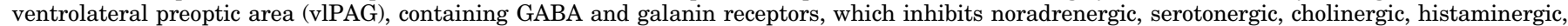

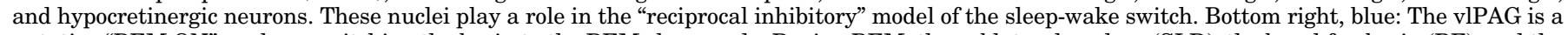

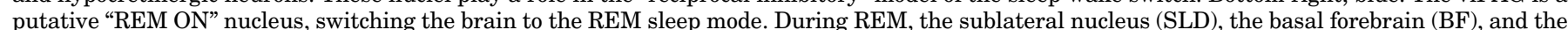

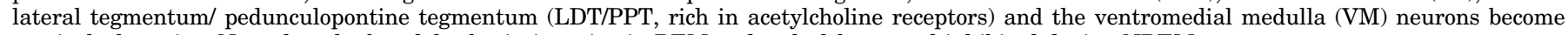
particularly active. Note that the basal forebrain is active in REM and wakefulness and inhibited during NREM. 
13-fold higher for patients $\geq 75$ years old compared with patients $<75$ years old (European Medicines Agency, 2016). Smoking, oral contraceptive pills, and the presence of hepatic impairment likewise significantly affect agomelatine's pharmacokinetics. The metabolism of agomelatine occurs mainly via hepatic CYP1A2, and CYP1A2 polymorphisms have been shown to significantly affect the pharmacokinetics the drug (Song et al., 2014).

3. Indications. Agomelatine is approved for use in the European Union and Canada for the treatment of major depressive disorder (MDD) but not approved in the United States (Sansone and Sansone, 2011). Clinical studies examining the hypnotic effects of agomelatine are detailed in Table 3.

4. Results in Insomnia Disorder. No studies of agomelatine as a treatment of insomnia disorder were found.

5. Other Results. The studies of agomelatine were conducted in people diagnosed with major depressive disorder. In a 6-week randomized, double-blinded comparison study $(N=332)$ in people diagnosed with major depressive disorder (Kasper et al., 2010), agomelatine was significantly superior to sertraline at improving sleep latency $(P<0.001)$ and sleep efficiency $(P<$ $0.001)$; furthermore, symptoms of depression $(P<0.05)$ and anxiety $(P<0.05)$ improved significantly more with agomelatine than with sertraline. Another randomized, double-blinded study comparing agomelatine and escitalopram $(N=138)$ found that agomelatine resulted in a greater reduction in sleep latency than escitalopram from week 2 onward (Quera-Salva et al., 2011). Moreover, although escitalopram reduced the number of sleep cycles relative to baseline, agomelatine preserved the number of sleep cycles. Finally, a review that pooled the results from three randomized studies $(N=721)$ comparing agomelatine to SSRIs or venlafaxine (Quera-Salva et al., 2010) established that agomelatine increases SWS, improves sleep efficiency, and resynchronizes SWS to the first sleep cycle of the night in patients with major depressive disorder while not changing the amount or latency of REM sleep.

6. Conclusion. A summary of the effects of agomelatine on sleep architecture is presented in Table 2. There is good evidence that agomelatine is superior to other antidepressants at reducing sleep latency in patients with major depressive disorder based on one review and two randomized, double-blind comparison studies (Kasper et al., 2010; Quera-Salva et al., 2010, 2011). Based on these same studies, the evidence is weak for the use of agomelatine in insomnia.

\section{B. Prolonged-Release Melatonin}

1. Indications. Melatonin is FDA-approved as a dietary supplement with no dosage restriction. In Europe, prolonged-release melatonin $2 \mathrm{mg} /$ day is approved for the treatment of insomnia in elderly patients.

PRM is a new option in the treatment arsenal for insomnia. It is targeted specifically toward older adults, potentially because endogenous melatonin production declines with age and PRM mimics the pharmacokinetics of endogenous melatonin (Lemoine and Zisapel, 2012). However, a 3-week RCT found that the effects of PRM in patients with low endogenous melatonin among all ages did not differ from placebo (Wade et al., 2010); in contrast, PRM significantly reduced sleep latency compared with the placebo in elderly patients irrespective of melatonin levels ( -19.1 vs. -1.7 minutes). This finding supports the idea that PRM has targeted efficacy specifically among the elderly, the same group of patients for whom benzodiazepine treatment is discouraged due to the increased risk of falls, accidents, and cognitive impairment ("What's Wrong," 2004). Clinical studies examining the hypnotic effects of PRM are detailed in Table 4.

2. Pharmacokinetics. Absorption of orally ingested melatonin is complete in healthy adults, although it may be decreased by up to $50 \%$ in the elderly (European Medicines Agency, 2017). Melatonin has linear pharmacokinetics over the dosage range of $2-8 \mathrm{mg}$, although bioavailability is only about $15 \%$, and the rate of prolonged-release melatonin absorption is affected by food: the presence of food delayed the absorption of prolonged-release melatonin, resulting in a later and lower peak plasma concentration in the fed state. The metabolism of melatonin is mainly mediated by CYP1A enzymes, although exogenous administration of melatonin does not induce these enzymes, even at supratherapeutic dosages (European Medicines Agency, 2017).

3. Results in Insomnia Disorder. Four RCTs and one open-label trial found PRM effective in the treatment of primary insomnia in the elderly. Only one RCT, the largest one $(N=791)$, included patients below 55 years of age; this study demonstrated that PRM was only effective in the subgroup of patients over 55 years old, validating its specific efficacy among the elderly but not other groups (Wade et al., 2010). Among the elderly in this study, PRM reduced subjective sleep latency compared with baseline by -19.1 versus 1.7 minutes for placebo.

4. Other Results. One RCT $(N=80)$ in patients with mild to moderate Alzheimer's disease with and without insomnia comorbidity found that patients treated with PRM had significantly superior cognitive performance during the trial; in contrast, PSQI scores did not significantly change in the study, although sleep efficiency was found significantly to improve in patients with and without comorbid insomnia (Wade et al., 2014).

5. Conclusion. A summary of the effects of PRM on sleep architecture is presented in Table 2. There is good evidence that PRM is effective in the treatment of insomnia disorder in adults over 55 years of age, based on four RCTs. There is also evidence that PRM is not effective in the treatment of primary insomnia in younger adults, based on one RCT (Wade et al., 2010).

\section{Ramelteon}

1. Mechanism of Action. Ramelteon is a potent and highly selective agonist at the $\mathrm{MT}_{1}$ and $\mathrm{MT}_{2}$ receptors 


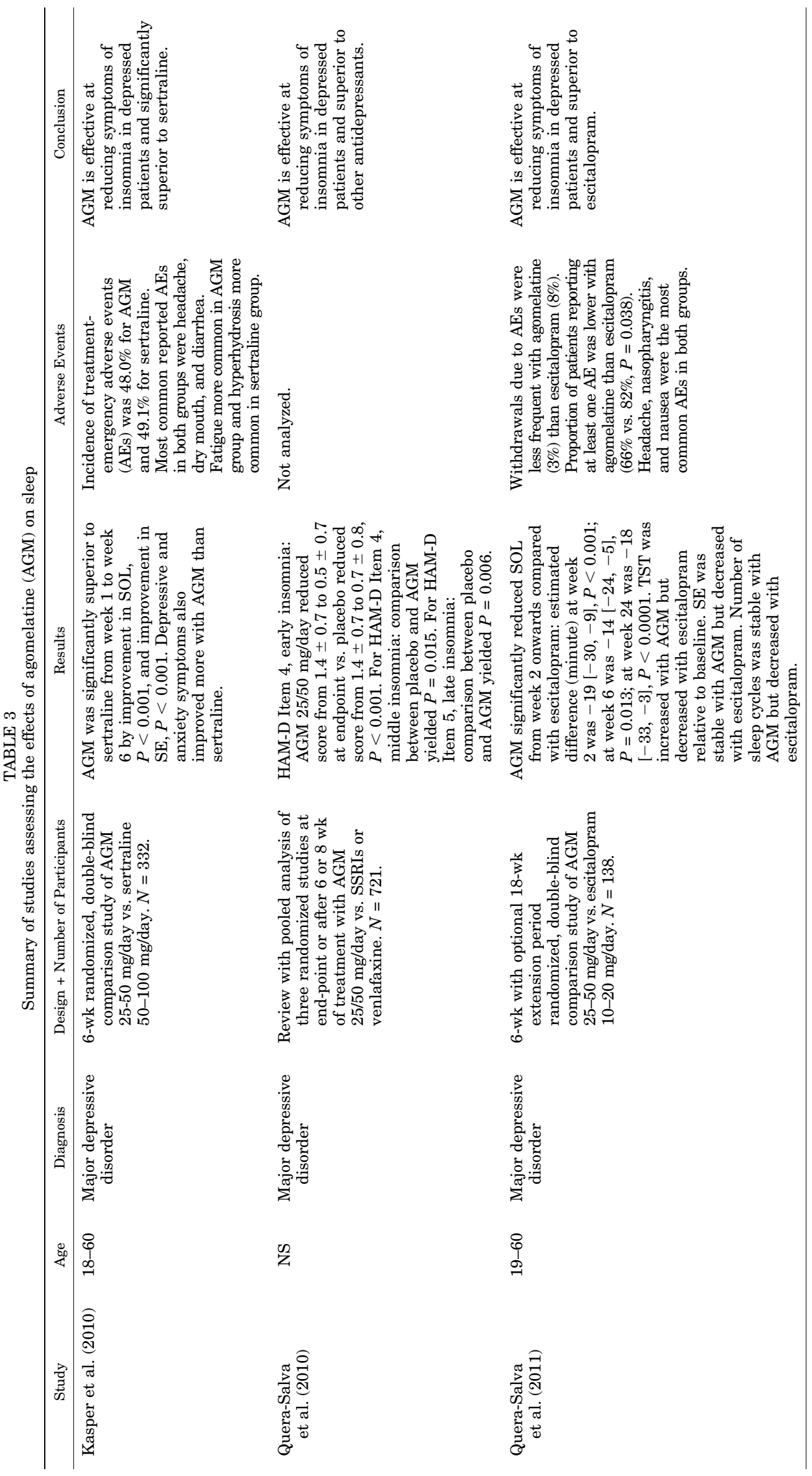




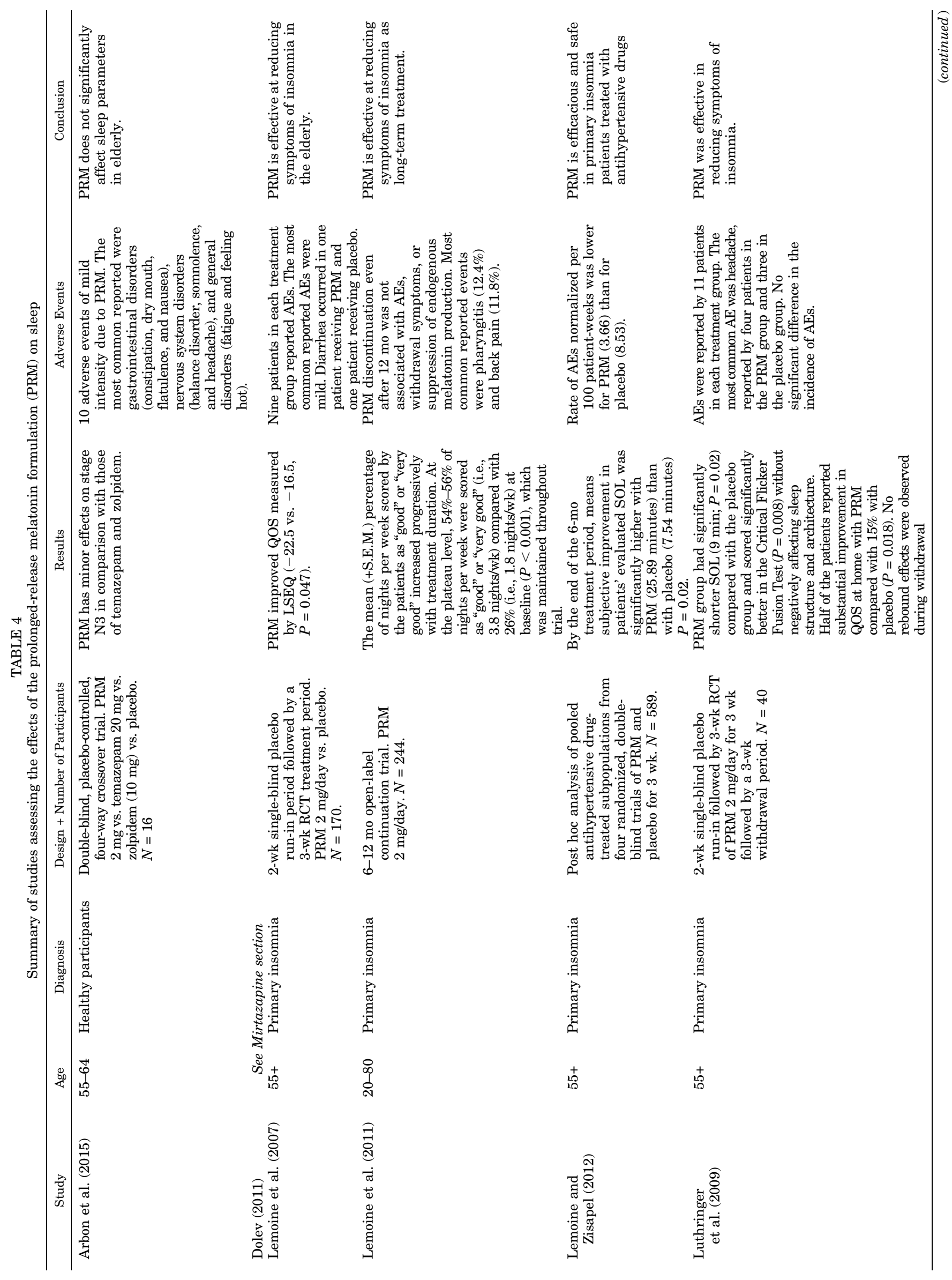




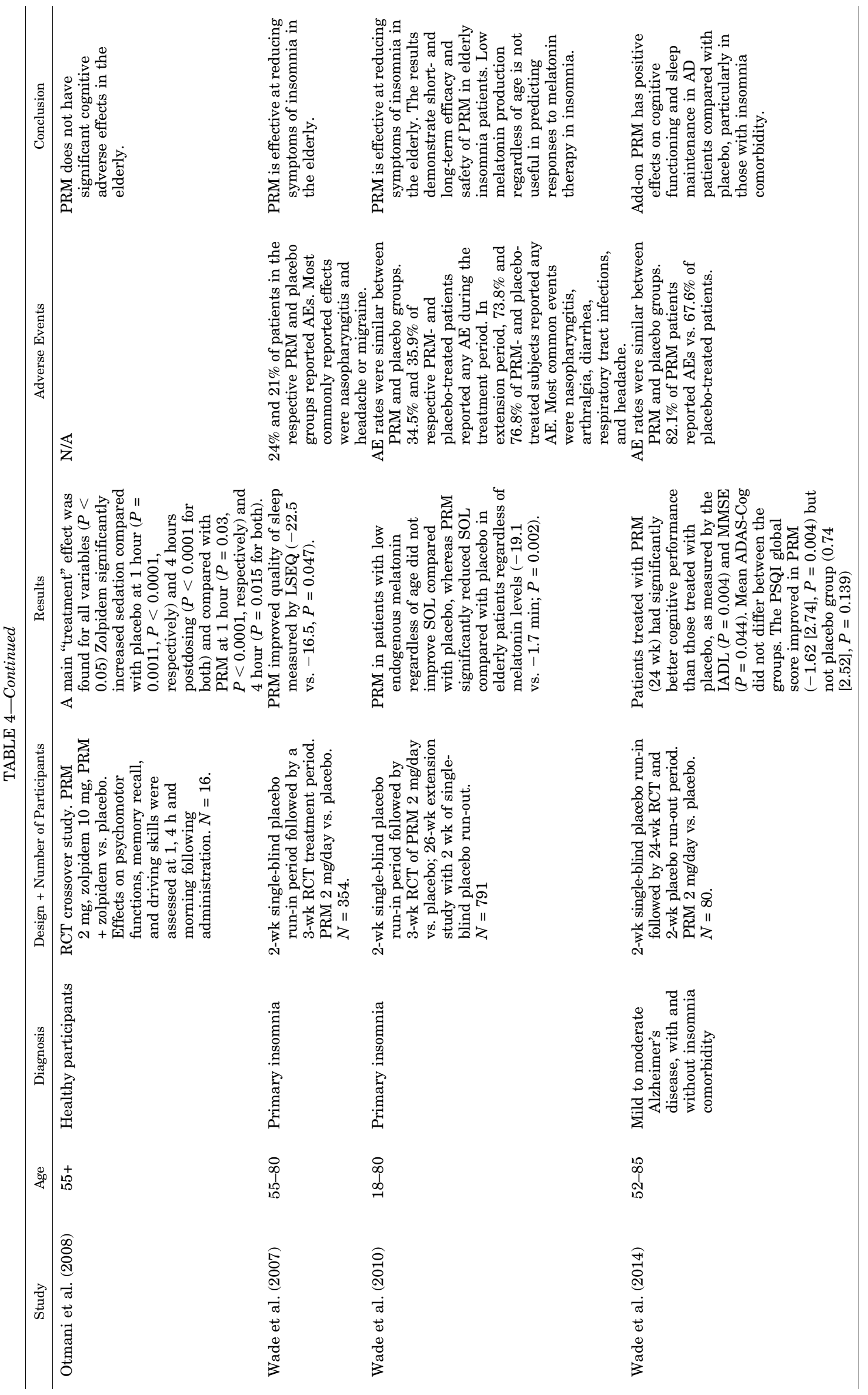


with an affinity 3-16 times higher than that of melatonin (Kato et al., 2005). Its affinity for $\mathrm{MT}_{2}$ is eight times lower than its affinity for $\mathrm{MT}_{1}$. This binding profile distinguishes ramelteon from melatonin and tasimelteon, which both display more affinity for the $\mathrm{MT}_{1}$ receptor than the $\mathrm{MT}_{2}$ receptor (Lavedan et al., 2015). The hypnotic effect of ramelteon is mediated by its potent, long-lasting agonism of the melatonin receptors, because it does not exhibit affinity for benzodiazepine receptors, dopamine receptors, opiate receptors, ion channels, and does not affect the activity of various enzymes (Kato et al., 2005) (Table 1). While studies in rats and monkeys confirm that ramelteon reduces time to sleep onset without affecting total sleep time (Yukuhiro et al., 2004; Fisher et al., 2008), ramelteon increases total sleep time in cats (Miyamoto et al., 2004).

2. Indications. Ramelteon is FDA-approved for the treatment of insomnia characterized by difficulty with sleep onset (US FDA, 2010a). Notably, the European Medicines Agency initially rejected Takeda Pharmaceutical Company's application (filed in March 2007) for lack of efficacy. Later, in September 2008, the company withdrew their Marketing Authorization Application to the Committee for Medicinal Products for Human Use (CHMP). The CHMP was concerned that the company had not demonstrated the effectiveness of ramelteon, because only one aspect of insomnia, the time to fall asleep, had been assessed in the trials (European Medicines Agency, 2008b). Furthermore, only one of the three studies that had been carried out in the natural setting found a significant difference in the time taken to fall asleep between patients taking ramelteon and those taking placebo, and this difference was considered too small to be clinically relevant. When other aspects of sleep were considered, ramelteon did not have any effect (Kuriyama et al., 2014). The CHMP was also concerned that Takeda had not demonstrated the long-term effectiveness of ramelteon (European Medicines Agency, 2008b). Clinical studies examining the hypnotic effects of ramelteon are detailed in Table 5.

3. Pharmacokinetics. At a dose range of 4-64 mg, ramelteon undergoes rapid, high first-pass metabolism and exhibits linear pharmacokinetics (US FDA, 2010a). However, the drug shows substantial intersubject variability in maximal serum concentration and area under the concentration curve. Median peak concentration occurs at about 0.75 hours after fasted oral administration. Although total absorption is at least $84 \%$, absolute bioavailability is only $1.8 \%$ because of extensive firstpass metabolism (US FDA, 2010a). It has a half-life of about 1-2.6 hours. CYP1A2 is the major liver enzyme involved in the hepatic metabolism of ramelteon, although CYP2C and CYP3A4 are also involved to a lesser degree: the drug is extensively transformed to its hydroxylated M-II metabolite, with serum AUC values that average approximately 30 times those of the parent drug (Greenblatt et al., 2007). It has been argued that
M-II, with its longer half-life and greater systemic exposure, may contribute significantly to the hypnotic effect of ramelteon: M-II has been shown to bind to human $\mathrm{MT}_{1}$ and $\mathrm{MT}_{2}$ receptors, although with lower affinity $\left(K_{\mathrm{i}}: 114\right.$ and $566 \mathrm{pmol} / \mathrm{l}$ for $\mathrm{MT}_{1}$ and $\mathrm{MT}_{2}$, respectively) (Nishiyama et al., 2014). Taking ramelteon with a high-fat meal changes its pharmacokinetics; the area under the concentration curve for a single $16 \mathrm{mg}$ dose is $31 \%$ higher, whereas maximal concentration is $22 \%$ lower than when administered in a fasted state (US FDA, 2010b). For this reason, the US FDA does not recommend taking ramelteon after a high-fat meal. Moreover, clearance is significantly reduced in the elderly,

4. Results in Insomnia Disorder. Two metaanalyses found ramelteon effective at reducing subjective sleep latency time in primary insomnia (Liu and Wang, 2012; Kuriyama et al., 2014). The first study analyzed 4055 patients (Liu and Wang, 2012) and the second analyzed 5812 patients (Kuriyama et al., 2014). One, a pooled analysis of four trials comparing ramelteon to placebo, found that active treatment reduced subjective sleep latency by -4.22 minutes, $95 \%$ confidence interval -5.66 to -2.77 minutes $(P<0.00001)$ (Liu and Wang, 2012). The other had similar results for subjective sleep latency reduction, although it pooled results from 12 studies: -4.30 minutes, $95 \%$ confidence interval -7.01 to -1.58 minutes $(Q=23.64 ; \mathrm{df}=11)$ (Kuriyama et al., 2014). However, it did not find that ramelteon increased total sleep time significantly more than placebo (Kuriyama et al., 2014).

5. Conclusion. A summary of the effects of ramelteon on sleep architecture is presented in Table 2 . There is strong evidence that ramelteon is effective in the treatment of insomnia disorder characterized by difficulty with sleep onset, based on two meta-analyses (Liu and Wang, 2012; Kuriyama et al., 2014).

\section{Tasimelteon}

1. Mechanism of Action. Tasimelteon displays comparable potency to melatonin at the $\mathrm{MT}_{1}$ receptor, whereas its affinity for $\mathrm{MT}_{2}$ is 2.1-4.4 times greater than its affinity for $\mathrm{MT}_{1}$ (Lavedan et al., 2015). Its agonism at these receptors is selective, as it lacks any other significant interactions with receptors or enzymes (Table 1).

2. Indications. Tasimelteon is the first FDAapproved treatment of non-24-hour sleep-wake disorder (non-24), for which it was granted orphan drug status. Initially, Vanda Pharmaceuticals evaluated the efficacy of tasimelteon in the treatment of insomnia in phase II and phase III studies (Vanda Pharmaceuticals Inc., 2008; Feeney et al., 2009), but the compound has only received regulatory approval for the treatment of non24. Clinical studies examining the hypnotic effects of ramelteon are detailed in Table 6.

3. Pharmacokinetics. The pharmacokinetics of tasimelteon is linear over dose ranges from 3 to $300 \mathrm{mg}$, with an absolute oral bioavailability of $38.3 \%$ and a mean half-life of 


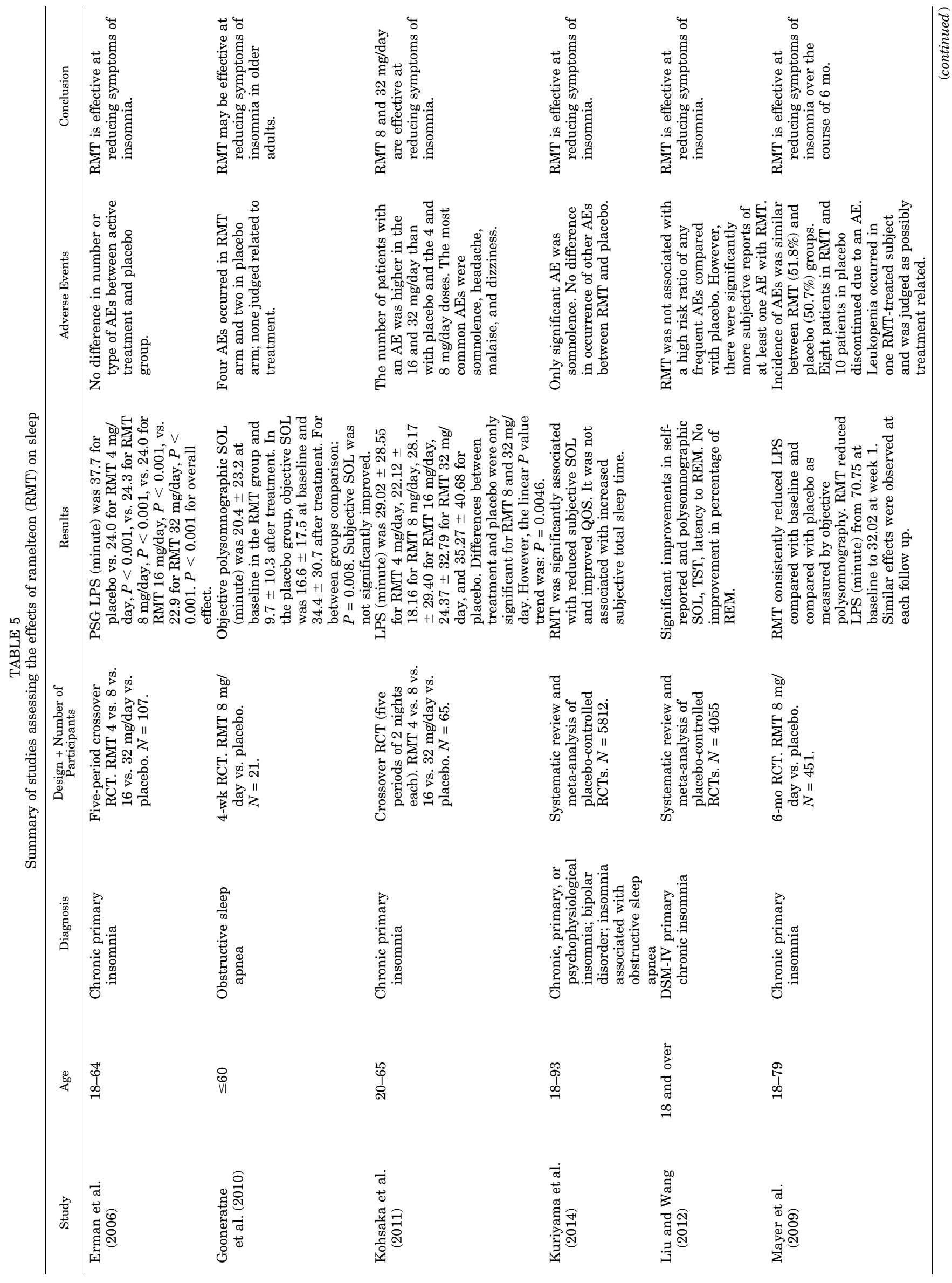




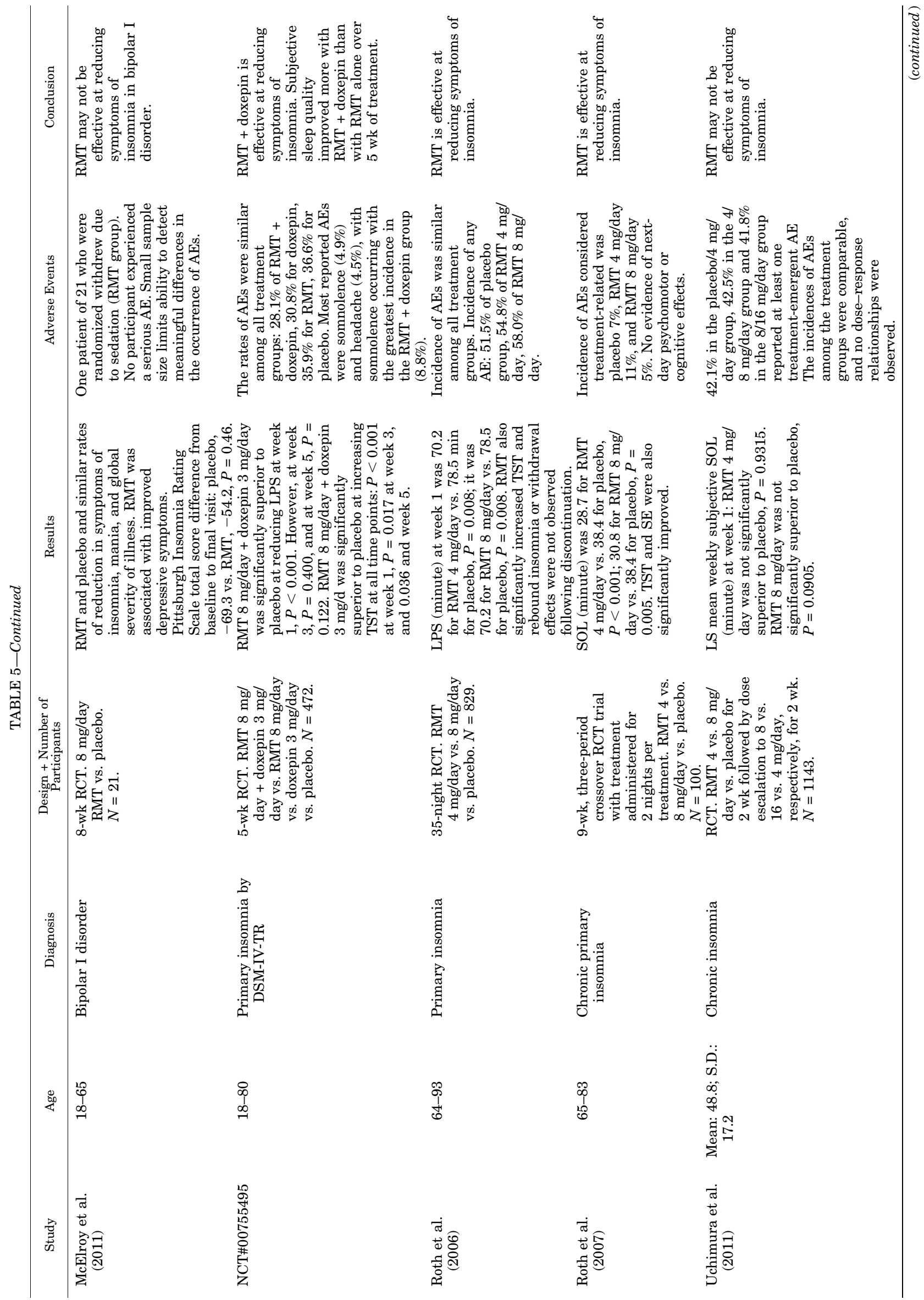


Atkin et al.

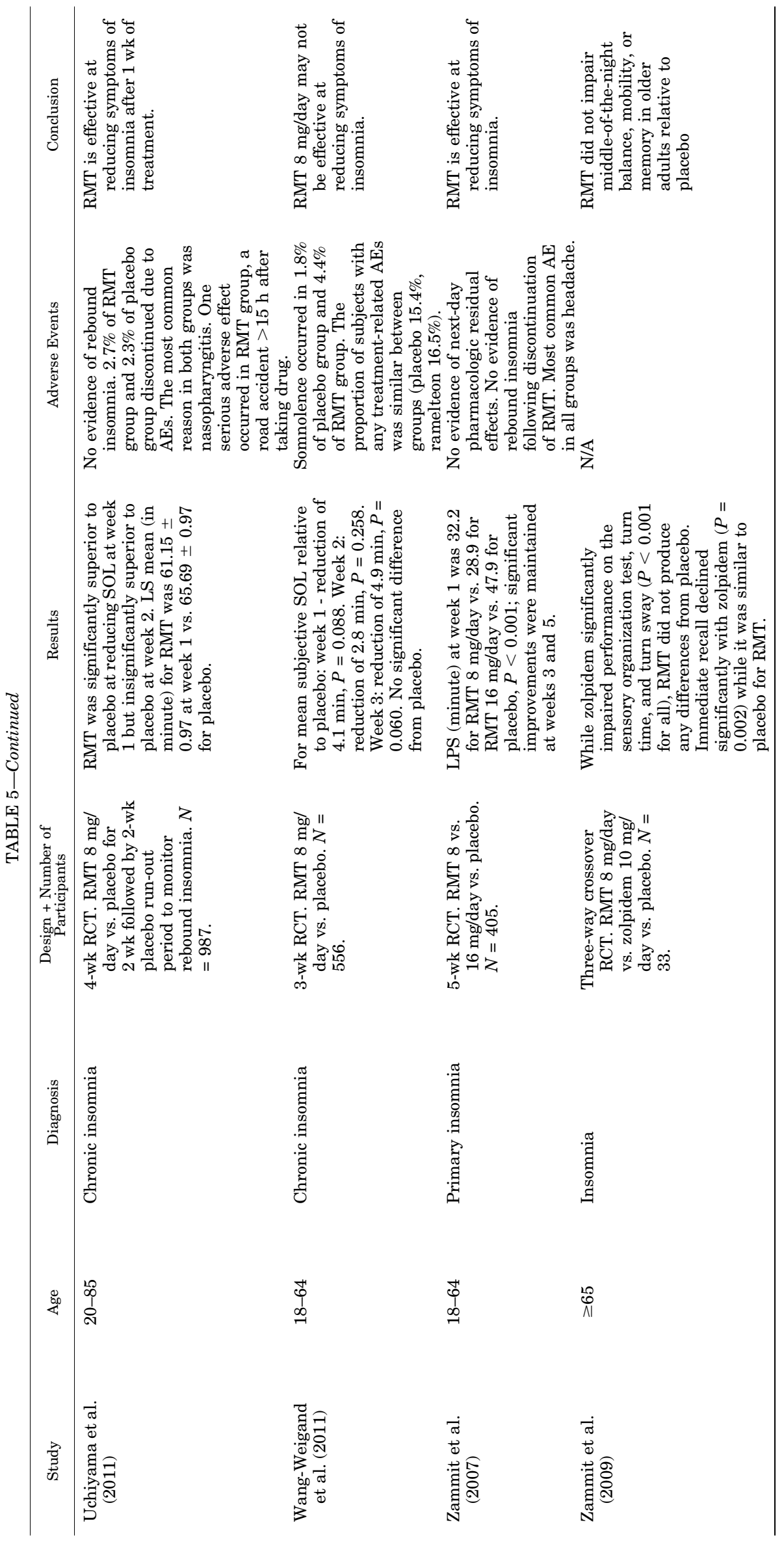


$1.3 \pm 0.4$ hours (US FDA, 2014b). Like for ramelteon, taking tasimelteon with a high-fat meal lowers $C_{\max }$ (by 44\%) and delays $T_{\max }$ (by 1.75 hours) compared with the fasted state. For this reason, the FDA recommends that the drug not be taken with food. CYP1A2 and CYP3A4 are the major isoenzymes associated with its hepatic metabolism, and major metabolites have 13 -fold or less activity at melatonin receptors (US FDA, 2014b). Exposure to tasimelteon increases approximately twofold in the elderly compared with nonelderly adults and in women approximately $20 \%$ $30 \%$ compared with men. Smokers had approximately $40 \%$ lower exposure to tasimelteon than nonsmokers.

4. Results in Healthy Volunteers. Two short RCTs of tasimelteon in healthy volunteers have been published: a phase II RCT and a phase III RCT (again in healthy volunteers) of the drug as a treatment of transient insomnia induced by shifted sleep (Rajaratnam et al., 2009). In the phase II trial, the individuals were monitored for seven nights: three at baseline, three after a 5-hour advance of the sleep-wake schedule, and one night after treatment. In the phase II RCT, tasimelteon reduced sleep latency and increased sleep efficiency relative to placebo and shifted the plasma melatonin rhythm to an earlier hour. The phase III study had similar positive results.

5. Results in Insomnia Disorder. There were no published studies of tasimelteon in patients diagnosed with insomnia disorder. However, one clinical trial in patients with primary insomnia (NCT\#00548340), which was published only as an abstract, found a significant mean change in latency to persistent sleep [standard error]: 45.0 [2.965] for tasimelteon $20 \mathrm{mg} /$ day versus 46.4 [2.954] for tasimelteon $50 \mathrm{mg} /$ day versus 28.3 [3.020] for placebo (Vanda Pharmaceuticals Inc., 2014).

6. Results in Other Conditions. Other trials were conducted in patients diagnosed with non-24 sleepwake disorder (Lockley et al., 2015), for which tasimelteon has gained FDA approval as an orphan drug (Dhillon and Clarke, 2014). The investigators found that tasimelteon significantly improved entrainment.

7. Conclusion. A summary of the effects of tasimelteon on sleep architecture is presented in Table 2 . There is poor-quality evidence for the use of tasimelteon in the treatment of insomnia disorder, based on two studies in healthy volunteers (Rajaratnam et al., 2009).

\section{Orexin Receptor Antagonist Drugs}

\section{A. Suvorexant}

1. Mechanism of Action. Suvorexant's effect as a hypnotic is attributable to its selective antagonism of the orexin receptors OX1R and OX2R (Winrow et al., 2011; Yin et al., 2016) (Table 1). In vitro assay panels demonstrate suvorexant's selectivity for the orexin receptors over 170 known receptors and enzymes (Cox et al., 2010). In mice, suvorexant has been shown to selectively increase REM sleep in the first 4 hours after dosing (Hoyer et al., 2013).
2. Indications. Suvorexant is FDA approved for the treatment of insomnia characterized by difficulty with sleep onset and/or sleep maintenance at the doses of 5 , 10,15 , and $20 \mathrm{mg} /$ day but not the higher doses studied in the clinical trials (US FDA, 2014a). The FDA chose not to approve suvorexant at the 30 or $40 \mathrm{mg} /$ day doses studied in the phase III trials because of safety concerns, particularly next-day driving impairment at doses of 20 $\mathrm{mg} / \mathrm{d}$ and higher (US FDA, 2014a). There were also a few reports of sleep paralysis and hallucinations, unconscious nighttime behaviors, and narcolepsy-like events among drug-treated subjects. Clinical studies examining the hypnotic effects of suvorexant are detailed in Table 7.

3. Pharmacokinetics. Exposure to suvorexant does not increase linearly over the dosage range $10-80 \mathrm{mg}$ because the drug is absorbed less at higher doses (US FDA, 2014a). The mean bioavailability of suvorexant $10 \mathrm{mg}$ is $82 \%$ and ingestion of the drug with food does not meaningfully affect AUC or $C_{\max }$ but does delay $T_{\max }$ by approximately 1.5 hours. Steady-state pharmacokinetics are achieved in 3 days, and the mean half-life of the drug is 12 hours (95\% confidence interval: 12-13). Exposure to suvorexant is higher in women than in men, with AUC increased $17 \%$ and $C_{\text {max }}$ increased $9 \%$, for suvorexant $40 \mathrm{mg}$.

4. Results in Insomnia Disorder. There are two systematic reviews of suvorexant as a treatment of primary insomnia (Citrome, 2014; Kishi et al., 2015). Although both reviews analyze the same four phase II and phase III trials in insomnia patients, one of them differs from the other by following PRISMA reporting guidelines (Kishi et al., 2015). Both systematic reviews analyzed the same four phase II and phase III RCTs and came to similar conclusions: that suvorexant was safe and effective for the treatment of insomnia. Suvorexant improved subjective total sleep time (weighted mean difference $=-20.16,95 \%$ confidence interval $=-25.01$ to $-15.30,1889$ patients, three trials) and subjective time to sleep onset (weighted mean difference $=-7.62$, $95 \%$ confidence interval $=-11.03$ to $-4.21,1889$ patients, three trials) (Kishi et al., 2015).

Subgroup analysis of approved (15 and $20 \mathrm{mg} /$ day) versus unapproved ( 30 or $40 \mathrm{mg} /$ day) found that for efficacy, the number needed to treat values versus placebo of suvorexant 40 and $30 \mathrm{mg} /$ day and that of the 20 and $15 \mathrm{mg} /$ day doses were the same: 8 (Citrome, 2014). However, for adverse effects, there were number needed to harm values versus placebo of 13 for the higher doses and 28 for the lower doses, indicating that the lower doses are better tolerated. Although the other systematic review did not specifically analyze approved versus unapproved doses, the authors performed an analysis in which they excluded the higher doses from the primary outcomes and found that suvorexant remained superior to placebo in subjective total sleep time and subjective time to sleep onset at 1 month (Kishi et al., 2015). Suvorexant was found to have an efficacy similar to the benzodiazepines, ramelteon, and 


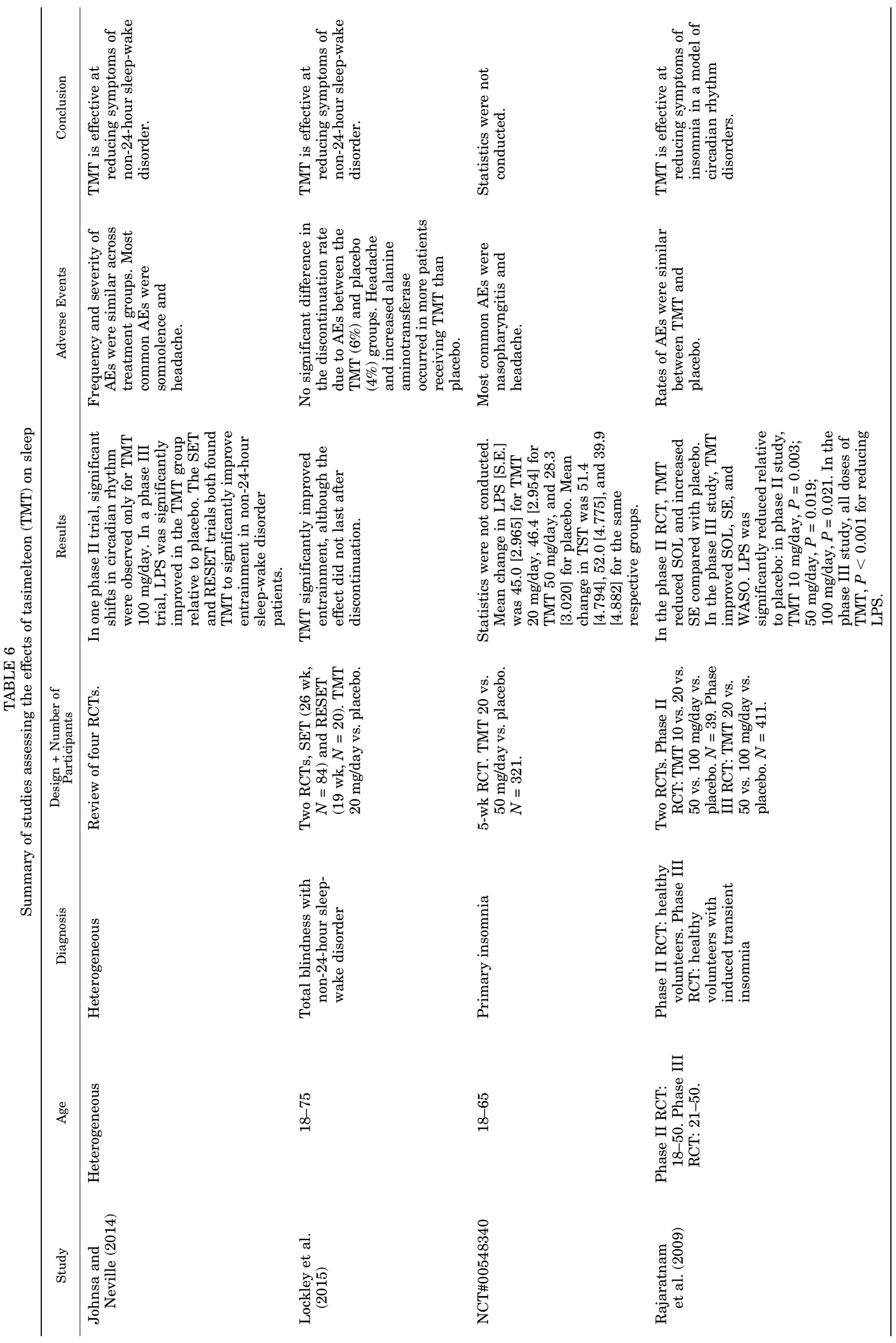




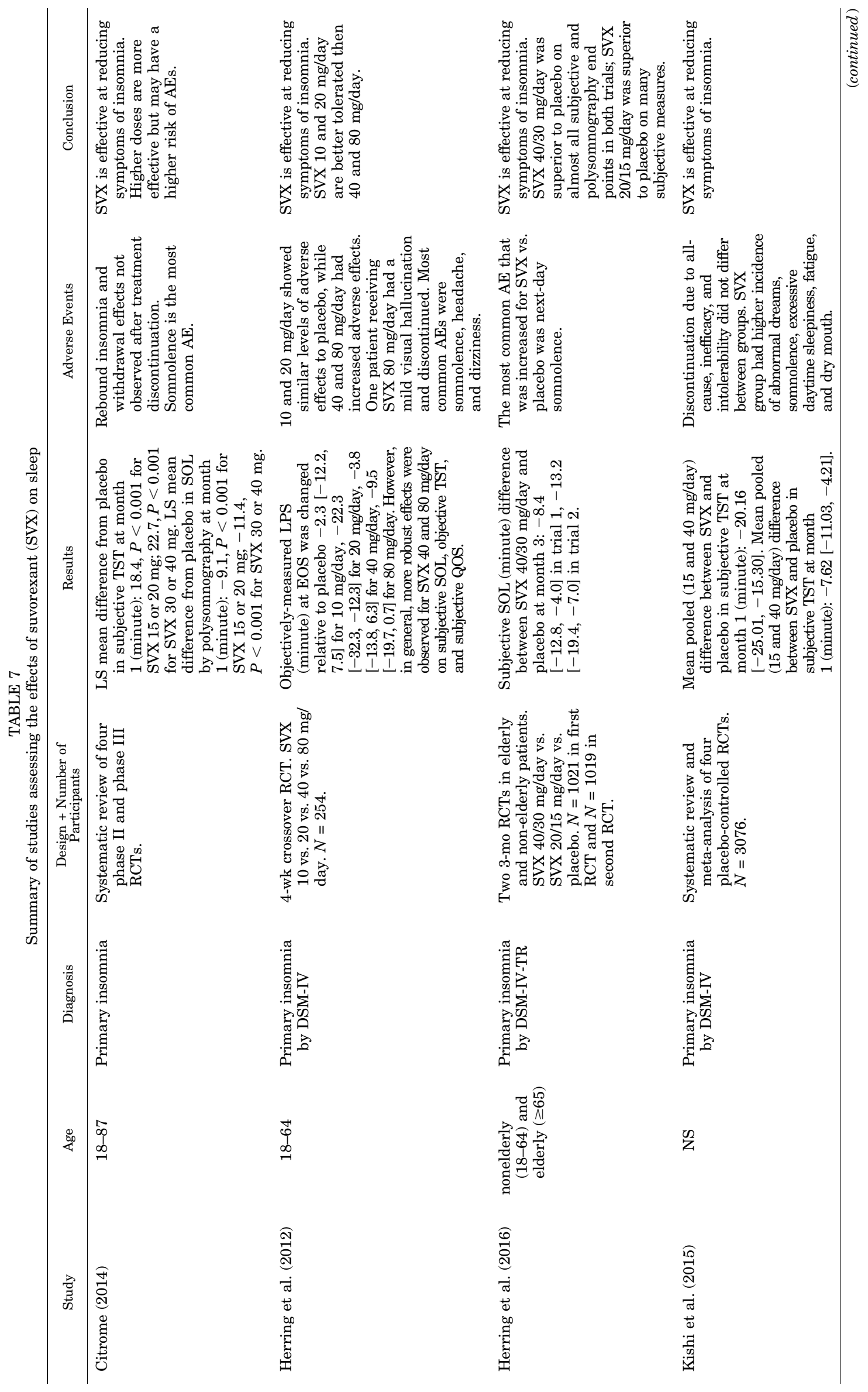



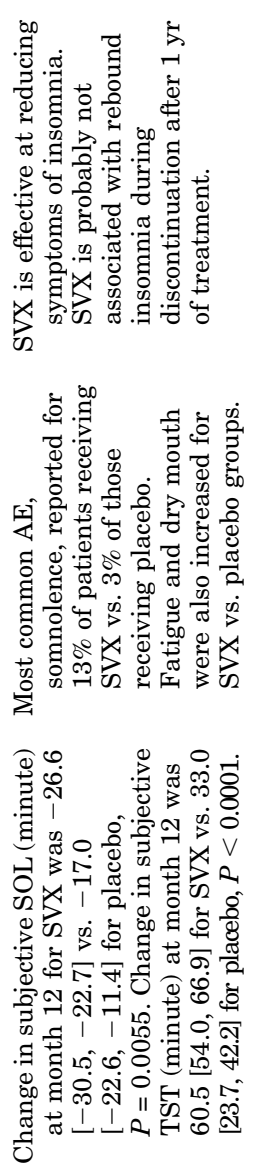

\section{要}
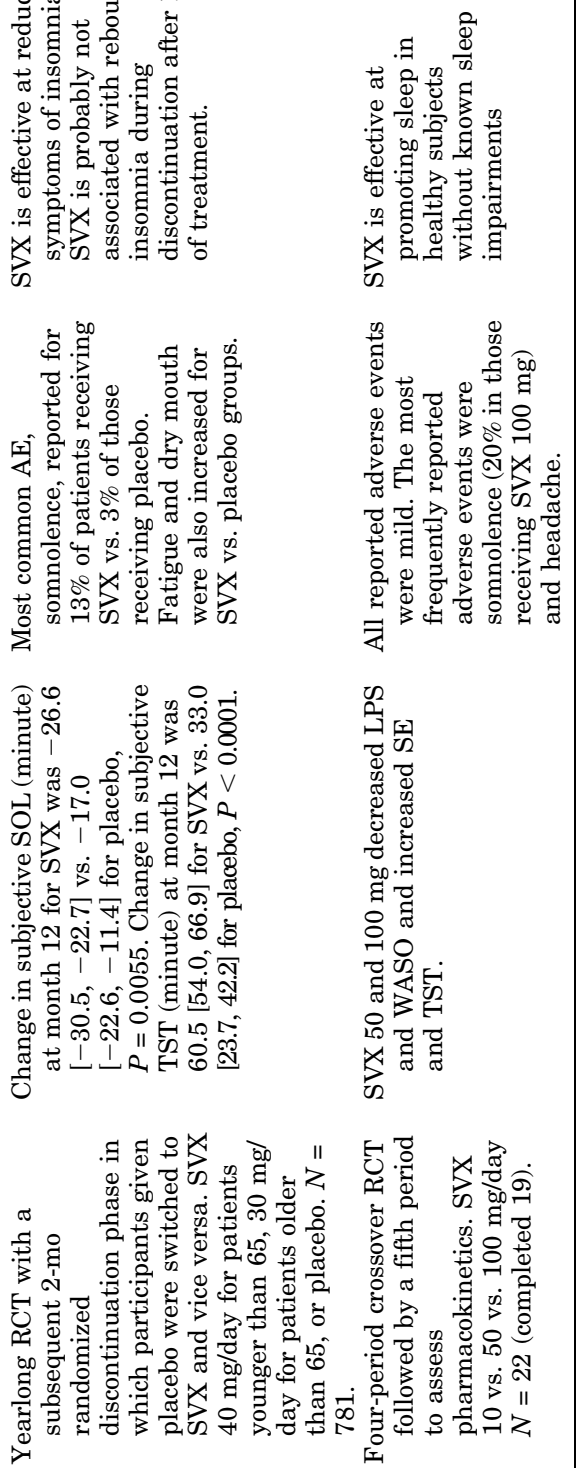

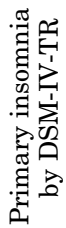

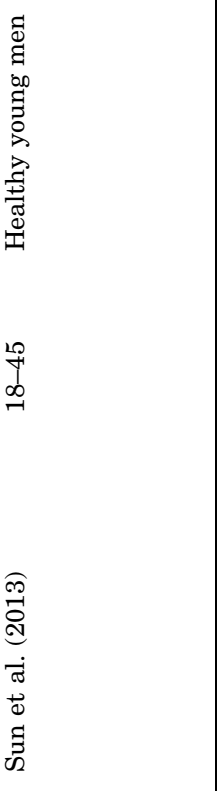

sedating antidepressants at reducing symptoms of insomnia (Kishi et al., 2015).

5. Conclusion. A summary of the effects of suvorexant on sleep architecture is presented in Table 2. There is strong evidence that suvorexant is effective at reducing symptoms of insomnia disorder at doses $15-40 \mathrm{mg} / \mathrm{day}$, based on two systematic reviews (Citrome, 2014; Kishi et al., 2015). Suvorexant exerts strong effects on increasing total sleep time. Lower doses may be preferred, per FDA guidelines, to minimize the risk of adverse effects.

\section{Antidepressant Drugs}

Sedating antidepressants are commonly prescribed for insomnia: one analysis found that they were prescribed more often than the FDA-approved treatments for insomnia in 2002 (Walsh, 2004; McCall, 2016). Trazodone was the most commonly prescribed medication for insomnia in 2002, with $34 \%$ more prescriptions than the most commonly prescribed FDA-approved treatment (Walsh, 2004). In fact, there were 5.28 million prescriptions for antidepressants for insomnia and only 3.4 million prescriptions for FDA-approved hypnotics (Walsh, 2004).

\section{A. Amitriptyline}

1. Mechanism of Action. Amitriptyline is a tricyclic antidepressant with strong effects as a serotonergic reuptake inhibitor [SERT $K_{\mathrm{i}}(\mathrm{nM})=3.13$ ] (Vaishnavi et al., 2004) and moderate effects as a norepinephrine reuptake inhibitor [NET $K_{\mathrm{i}}(\mathrm{nM})=22.4$ ] (Tatsumi et al., 1997). Indeed, serotonergic-norepinephrine reuptake inhibitors lack hypnotic properties, and as thus, amitriptyline's hypnotic effects are attributable to its profile as an $\mathrm{H}_{1}$ and $\mathrm{H}_{2}$ receptor antagonist as well as a $5-\mathrm{HT}_{2 \mathrm{~A}}$ and $5-\mathrm{HT}_{2 \mathrm{C}}$ antagonist. Main molecular targets of amitriptyline are summarized in Table 1.

2. Indications. Amitriptyline is FDA approved for the treatment of major depressive disorder (Alphapharm, 2012). Clinical studies examining the hypnotic effects of amitriptyline are detailed in Table 8.

3. Pharmacokinetics. Amitriptyline is well-absorbed with peak plasma concentrations occurring within 6 hours of oral administration (Alphapharm, 2012). The mean half-life of amitriptyline is 22.4 hours, whereas the mean half-life of its active metabolite nortriptyline is 26 hours. Amitriptyline is $96 \%$ bound to plasma proteins, and undergoes extensive first-pass metabolism in the liver to nortriptyline via $N$-demethylation mediated by CYP2C19 (Rudorfer and Potter, 1999). Other liver enzymes involved in its metabolism are CYP2D6 and CYP3A4 (Rudorfer and Potter, 1999). Genetic heterogeneity between patients affects the concentration of the drug in the body, particularly the ratio between amitriptyline and nortriptyline (Rudorfer and Potter, 1999).

4. Results in Insomnia Disorder. No studies of amitriptyline as a treatment of insomnia disorder were identified. 


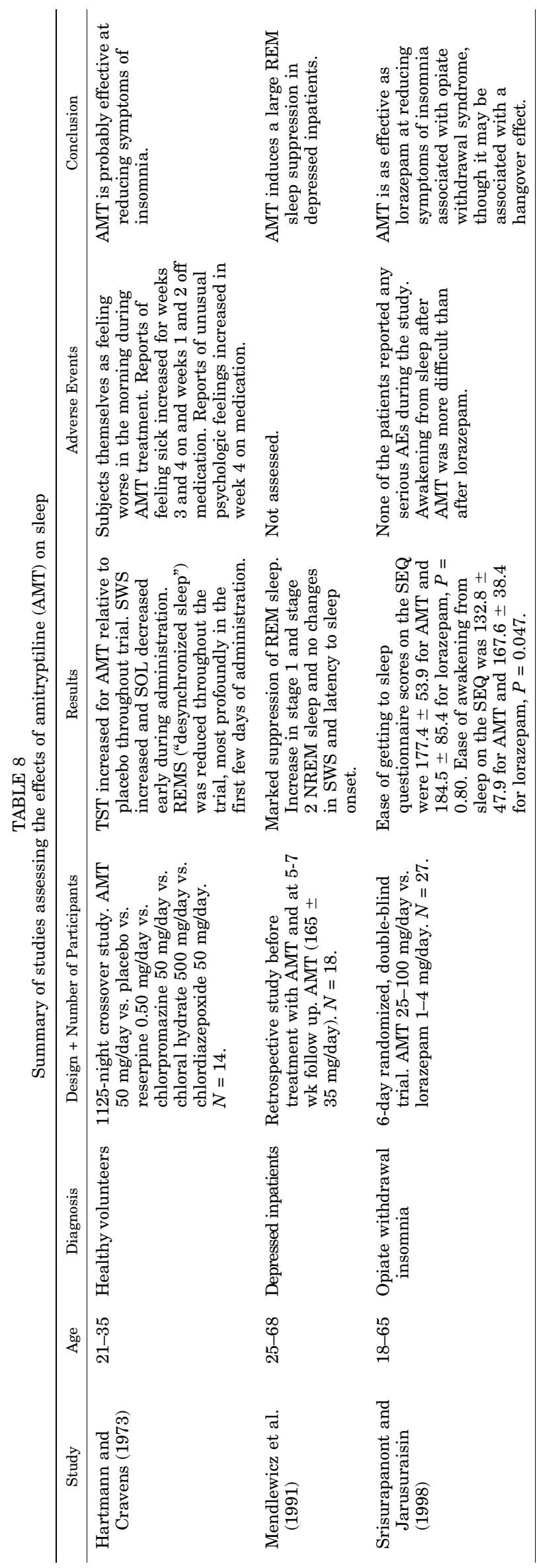

5. Other Results. Two studies of amitriptyline as a treatment of secondary insomnia were identified. One study examined amitriptyline's effect on sleep in healthy volunteers when administered chronically (Hartmann and Cravens, 1973) and one study analyzed patients with opiate withdrawal insomnia (Srisurapanont and Jarusuraisin, 1998). The study in healthy volunteers found altered sleep patterns in the group given amitriptyline compared with placebo, with those given the drug displaying increased total sleep time, increased SWS, and less REM (“desynchronized" sleep) (Hartmann and Cravens, 1973). The other study compared amitriptyline $50 \mathrm{mg} / \mathrm{day}$ to lorazepam 1-4 mg/day in patients with opiate withdrawal insomnia, finding that although amitriptyline was likely as effective as lorazepam at relieving insomnia symptoms, it may have been associated with a hangover effect the next day (Srisurapanont and Jarusuraisin, 1998).

6. Conclusion. A summary of the effects of amitriptyline on sleep architecture is presented in Table 2 . Based on amitriptyline's effect in a study of healthy volunteers (Hartmann and Cravens, 1973) of increasing total sleep time and its efficacy in opiate withdrawal insomnia, there is weak evidence of its efficacy in the treatment of insomnia disorder.

\section{B. Mirtazapine}

1. Mechanism of Action. Mirtazapine is classified as a noradrenergic and specific serotonergic antidepressant, because it enhances adrenergic and serotonergic neurotransmission in a manner distinct from other classes of drugs. Its effects as a sedative and as a hypnotic are attributable to its blockade of the histamine $\mathrm{H}_{1}$ receptor. By antagonizing $\alpha_{2}$-autoreceptors it increases norepinephrine release; by antagonizing $\alpha_{2}$-heteroreceptors it increases serotonin release, although its effect on serotonergic systems is specific to 5 - $\mathrm{HT}_{1 \mathrm{~A}}$-mediated neurotransmission, because it also blocks the $5-\mathrm{HT}_{2}$ and $5-\mathrm{HT}_{3}$ receptors (Anttila and Leinonen, 2001) (See Table 1 for the list of mirtazapine's main molecular targets). In mice, thermal hyperalgesia and sleep disturbance in a model of neuropathic pain were nearly completely normalized by mirtazapine administration (Enomoto et al., 2012).

2. Indications. Mirtazapine is FDA approved for the treatment of major depressive disorder in adults (US FDA, 2007b). Clinical studies examining the hypnotic effects of mirtazapine are detailed in Table 9.

3. Pharmacokinetics. Mirtazapine is rapidly and completely absorbed and has a half-life of between 20 and 40 hours, with women exhibiting significantly longer elimination half-lives than men (mean half of life 37 hours for women vs. 26 hours for men) (US FDA, 2007b). Peak plasma concentration is reached within 2 hours of administration, and the presence or absence of food does not significantly affect its pharmacokinetics. Plasma levels are linear to dose over a dose range of $15-80 \mathrm{mg}$. The drug is $85 \%$ bound to plasma proteins. The drug's absolute bioavailability is about $50 \%$, and 
in vitro data indicate that cytochromes $2 \mathrm{D} 6,1 \mathrm{~A} 2$, and $3 \mathrm{~A}$ are responsible for the formation of its metabolites (US FDA, 2007b).

4. Results in Insomnia Disorder. No studies of mirtazapine as a treatment of primary insomnia were identified, except for a case series (Dolev, 2011) conducted in perimenopausal women who suffered from insomnia $(N=11)$ and who were not depressed by the HAM-D scale (Hamilton, 1960). In this study, the subjects were given mirtazapine $15 \mathrm{mg} /$ day for 24 weeks followed by treatment with prolonged-release melatonin $2 \mathrm{mg} /$ day concurrent with the tapering of mirtazapine over 1-3 months. Combination treatment with mirtazapine and melatonin during the tapering period reduced PSQI global scores from $14.45 \pm 1$ at baseline to $6.00 \pm 0.7$ at endpoint. Sleep latency as measured by PSQI question 2 decreased from $52.73 \pm$ 14.04 minutes at baseline to $18.64 \pm 2.87$ minutes at endpoint.

5. Other Results. Five studies of mirtazapine as a treatment of secondary insomnia were identified. There was one open-label study $(N=36)$ in patients with advanced cancer and pain or other distressing symptoms, including insomnia (Theobald et al., 2002); one open-label trial $(N=6)$ in patients diagnosed with major depressive disorder and poor sleep quality (Winokur et al., 2000); one randomized trial $(N=19)$ comparing mirtazapine to fluoxetine in patients diagnosed with major depressive disorder and insomnia (Winokur et al., 2003); one open-label study $(N=53)$ in patients with cancer and comorbid MDD, anxiety disorders, or adjustment disorder (Cankurtaran et al., 2008); and one open-label study $(N=42)$ in patients with cancer and MDD (Kim et al., 2008). In these studies, mirtazapine was generally effective at reducing symptoms of insomnia; in the randomized trial, it was more effective than fluoxetine (Winokur et al., 2003).

6. Conclusion. A summary of the effects of mirtazapine on sleep architecture is presented in Table 2 . There is weak evidence that mirtazapine is effective at reducing symptoms of insomnia disorder, based on one case series (Dolev, 2011) and the available open-label evidence of mirtazapine's effectiveness in secondary insomnia.

\section{Trazodone}

1. Mechanism of Action. Trazodone's effect as a hypnotic is attributable to its moderate antihistaminergic activity at the $\mathrm{H}_{1}$ receptor, its partial agonism at the $5 \mathrm{HT}_{1 \mathrm{~A}}$ receptor (Odagaki et al., 2005), its antagonism of the $5 \mathrm{HT}_{1 \mathrm{C}}$ and $5 \mathrm{HT}_{2}$ receptors, and its antagonism of the postsynaptic $\alpha_{1}$-adrenergic receptor (Schatzberg and Nemeroff, 2009; McCall, 2016). It also exerts relatively weak, although specific, reuptake inhibition effects at the 5-HT transporter (see Table 1 for a summary of trazodone's main targets). Thus, trazodone has a mixed profile as both an agonist and an antagonist of serotonin receptors. In rats, trazodone has been shown to increase NREMS without affecting REMS (Lelkes et al., 1994).

2. Indications. Trazodone is FDA approved for the treatment of depression. A survey revealed that trazodone was the first-line choice of $78 \%$ or psychiatrists when prescribing medications to treat SSRI-induced insomnia (Dording et al., 2002). As mentioned previously, in 2002, trazodone was the most commonly prescribed medication for insomnia, with $34 \%$ more prescriptions than the most commonly prescribed FDA-approved treatment (Walsh, 2004). Clinical studies examining the hypnotic effects of trazodone are detailed in Table 10.

3. Pharmacokinetics. Trazodone's half-life is $7.0 \pm$ 1.2 after multiple oral administration and shows linear pharmacokinetics within the dosage range of 50$150 \mathrm{mg} /$ day (Nilsen et al., 1993). Its absorption is irregular in fasting subjects, but it is improved if the drug is taken after food. However, no differences are observed in the total amount of trazodone absorbed with and without food: its bioavailability values are $65 \pm 6 \%$ and $63.4 \%$, respectively (Nilsen and Dale, 1992). The drug is primarily metabolized by the liver enzyme CYP3A4, and inhibition of this enzyme by other drugs leads to high blood levels of trazodone (Rotzinger et al., 1998). CYP3A4 mediates the metabolism of trazodone to its main active metabolite, m-chlorophenylpiperazine, which has $5-\mathrm{HT}_{2 \mathrm{C}}$ agonist and $5-\mathrm{HT}_{2 \mathrm{~A}}$ antagonistic properties (Rotzinger et al., 1998).

4. Results in Insomnia Disorder. One 2-week parallel group $\mathrm{RCT}(N=306)$ in patients with primary insomnia was identified (Walsh et al., 1998). The study compared treatment with trazodone $50 \mathrm{mg} /$ day to treatment with zolpidem $10 \mathrm{mg} /$ day and placebo after a 1-week placebo lead-in period. During the first week, both drugs produced significantly shorter self-reported sleep latency and longer self-reported sleep duration than placebo. Sleep latency was significantly shorter with zolpidem than with trazodone. During week 2 , only the zolpidem group maintained a significantly shorter sleep latency than the placebo group, and sleep duration did not vary significantly among groups.

5. Other Results. Two reviews on the use of trazodone as a treatment of insomnia were identified (James and Mendelson, 2004; Mendelson, 2005). Both reviews predominantly analyzed studies of trazodone in patients diagnosed with major depressive disorder. Although trazodone was shown to increase total sleep time in patients with MDD (James and Mendelson, 2004), there was limited evidence of its efficacy (Mendelson, 2005). The high rate of discontinuation due to adverse events, which included sedation, dizziness, and psychomotor impairment, make the riskbenefit ratio of trazodone therapy for insomnia uncertain (Mendelson, 2005). Furthermore, there is a risk of priapism in 1 out of 6000 patients treated with trazodone (James and Mendelson, 2004). 


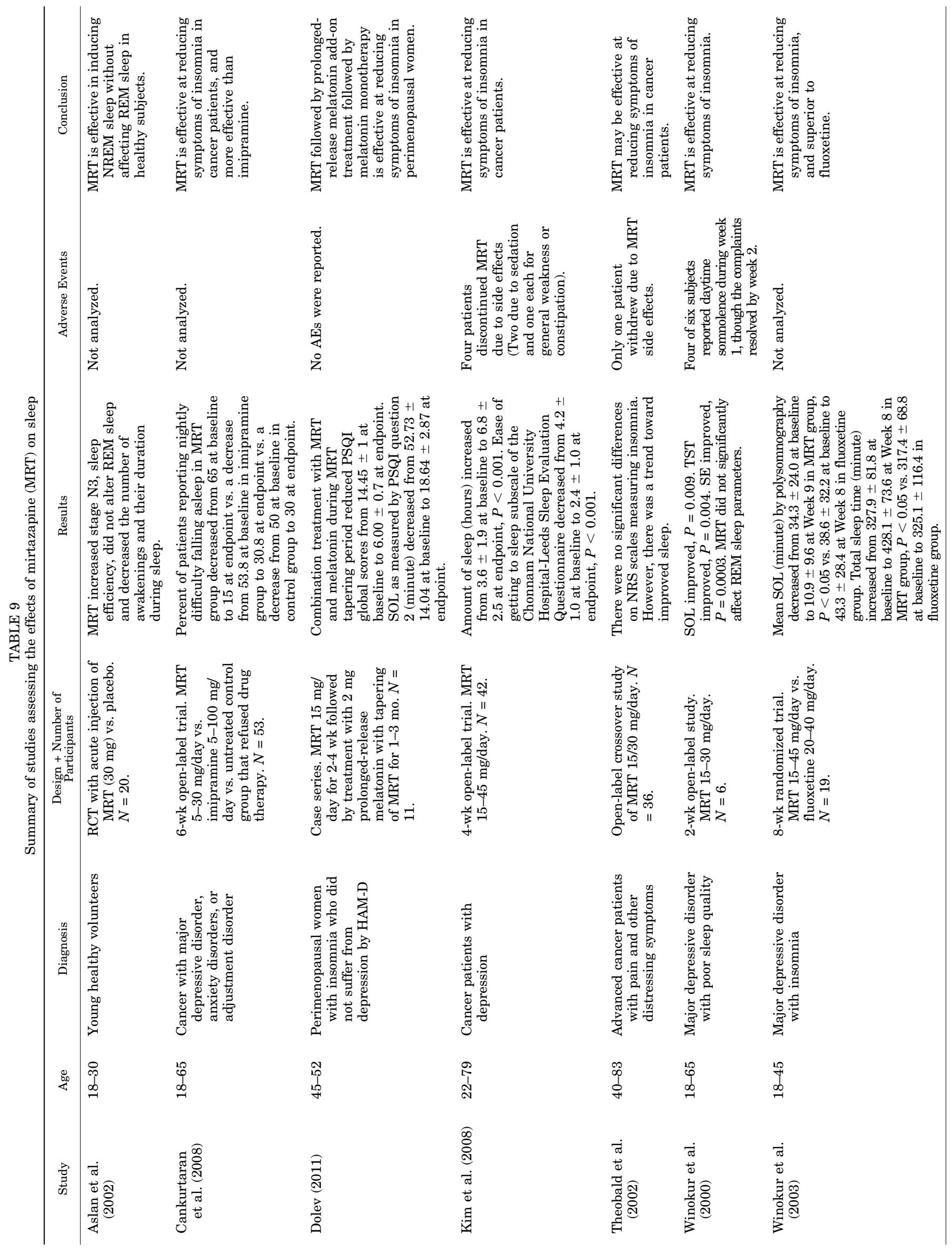




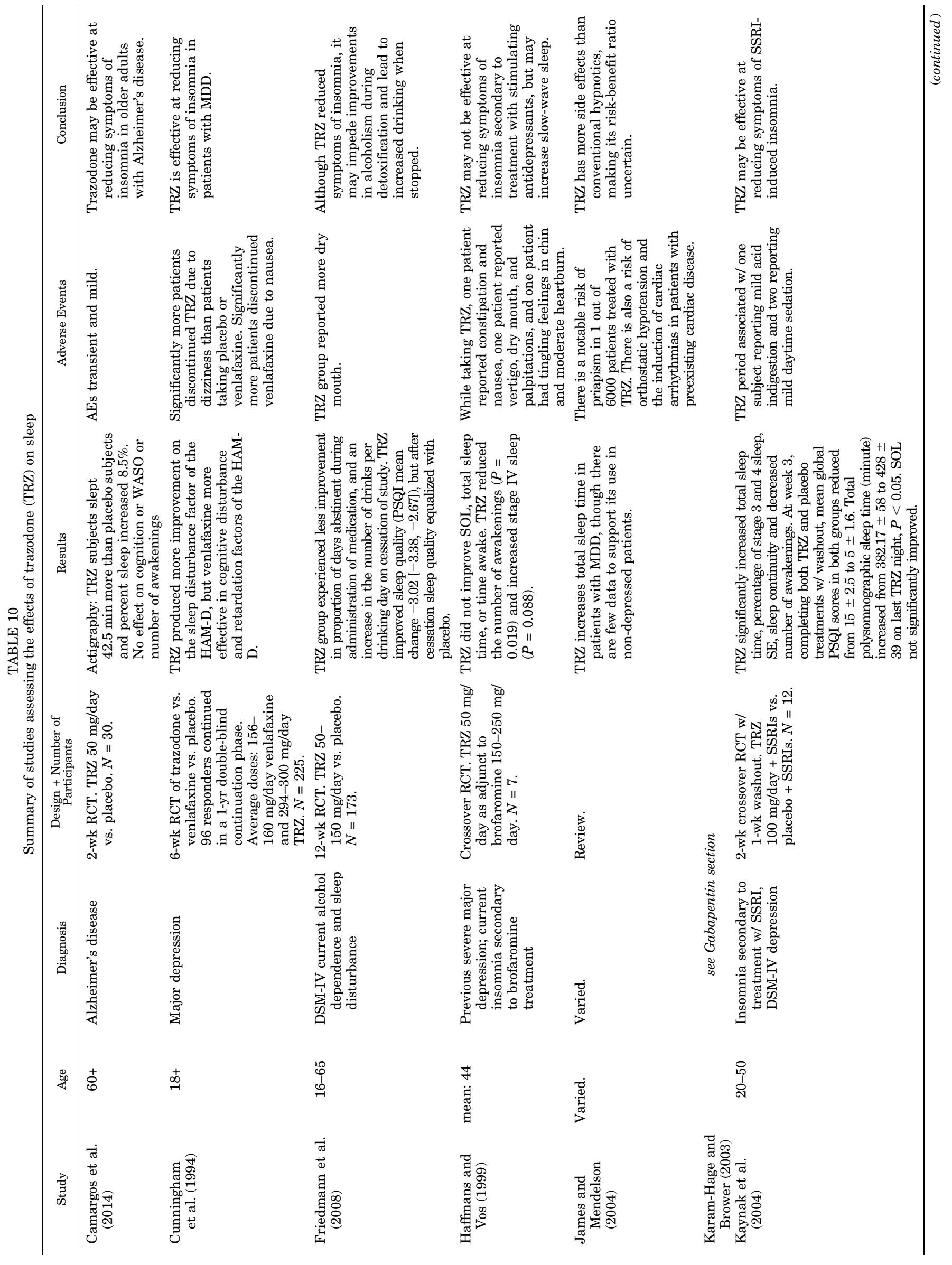




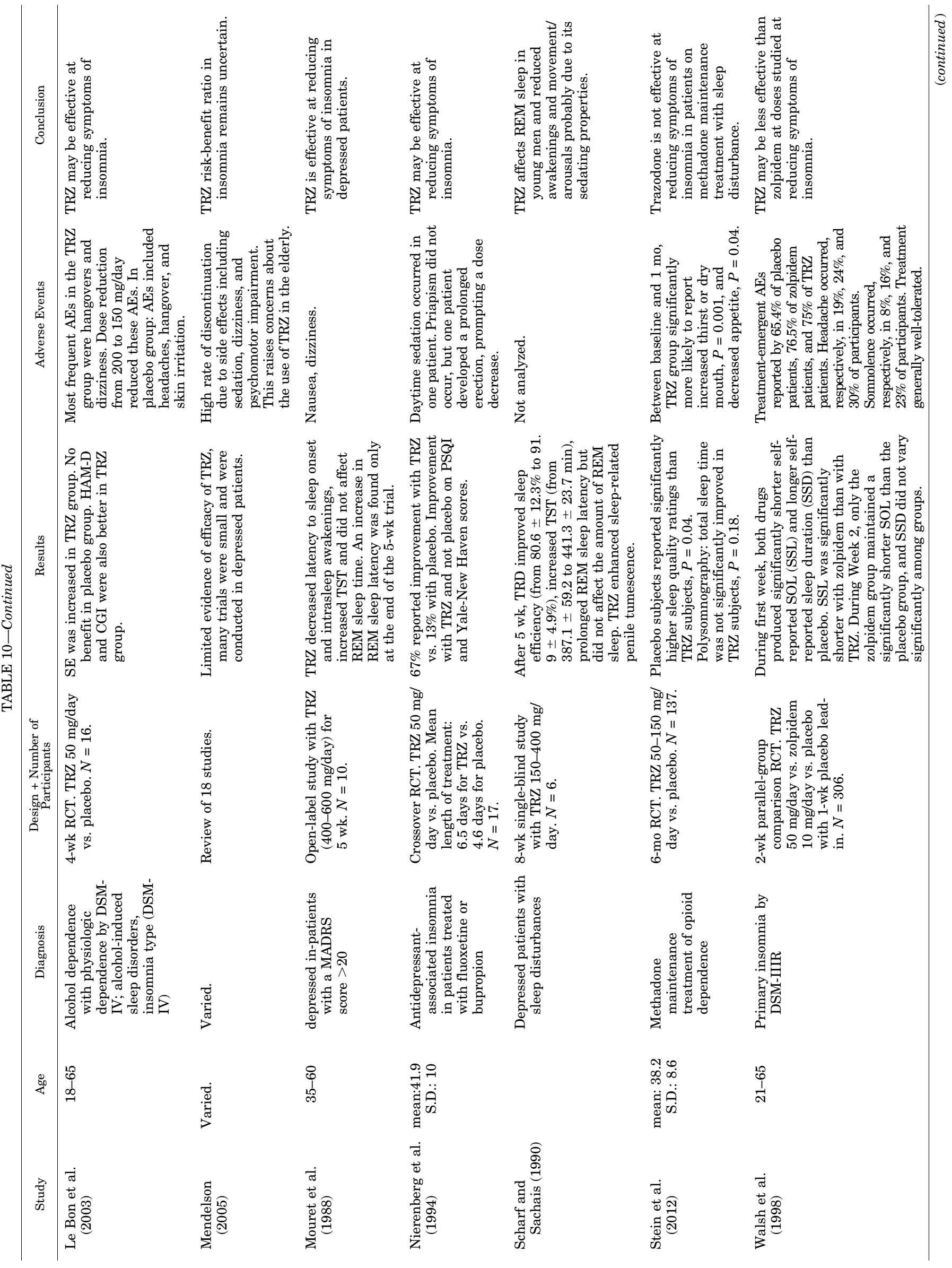




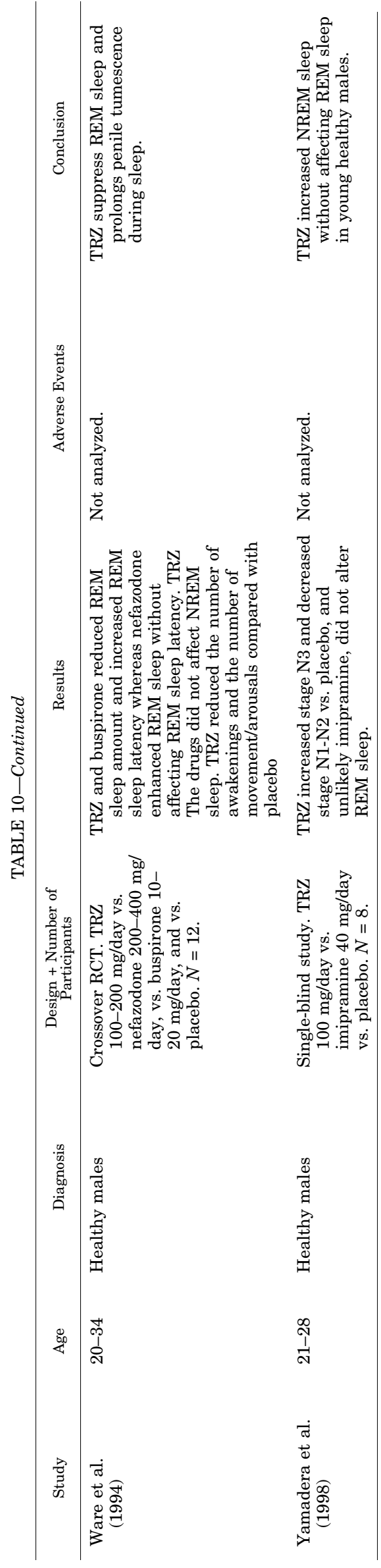

Nine RCTs on the use of trazodone in the treatment of insomnia secondary to other conditions were identified, of which three were conducted in patients with insomnia secondary to treatment with antidepressants (Nierenberg et al., 1994; Haffmans and Vos, 1999; Kaynak et al., 2004). One crossover RCT $(N=17)$ of trazodone $50 \mathrm{mg} /$ day versus placebo in antidepressantassociated insomnia secondary to treatment with fluoxetine or bupropion (Nierenberg et al., 1994) and one 2 -week crossover RCT $(N=12)$ of trazodone $100 \mathrm{mg} /$ day versus placebo in patients with insomnia secondary to treatment with SSRIs (Kaynak et al., 2004) found trazodone effective, with significantly increased total sleep time, sleep efficiency, sleep continuity, and increased stage 3 and stage 4 sleep in the second trial. However, one smaller RCT $(N=7)$ of trazodone $50 \mathrm{mg} /$ day in antidepressant-associated insomnia secondary to treatment with brofaromine (Haffmans and Vos, 1999) found that trazodone did not improve sleep latency, total sleep time, or time awake versus placebo, although it increased SWS. These results suggest that trazodone may be effective in cases of insomnia induced by SSRIs or bupropion, but not brofaromine, an antidepressant that was never brought to market.

A 6-week study of trazodone versus venlafaxine versus placebo in patients diagnosed with major depression was also identified (Cunningham et al., 1994): in this study, trazodone was more effective for improving sleep disturbance on the HAM-D, but venlafaxine was better at relieving cognitive disturbance and retardation. Trazodone caused more dizziness while venlafaxine caused more nausea.

Three studies of trazodone in the context of addiction were identified. One 4-week RCT $(N=16)$ of trazodone $50 \mathrm{mg} /$ day versus placebo in patients with alcoholinduced insomnia and alcohol dependence (Le Bon et al., 2003) found that trazodone increased sleep efficiency. However, caution is warranted because a large 12-week RCT $(N=173)$ of trazodone $50-150 \mathrm{mg} /$ day versus placebo in patients with alcohol dependence and sleep disturbances (Friedmann et al., 2008) found though trazodone reduced symptoms of insomnia, and the trazodone group experienced less improvement in the proportion of days abstinent during detoxification when receiving medication; furthermore, the trazodone group had an increase in the number of drinks per drinking day upon cessation of the study. A 6-month RCT $(N=137)$ of trazodone $50-150 \mathrm{mg} /$ day during methadone maintenance treatment of opioid dependence (Stein et al., 2012) was negative, with placebotreated subjects reporting significantly higher sleep quality ratings than trazodone-treated subjects.

Finally, a 2-week RCT $(N=30)$ of trazodone $50 \mathrm{mg} /$ day in patients with Alzheimer's disease found that trazodone-treated subjects slept significantly longer than placebo-treated subjects, although the drug did not have a detectable effect on cognition (Camargos et al., 2014). 
6. Conclusion. A summary of the effects of trazodone on sleep architecture is presented in Table 2. There is good evidence that trazodone is effective at reducing symptoms of insomnia in patients with SSRI-induced insomnia based on two RCTs (Nierenberg et al., 1994; Kaynak et al., 2004). Trazodone use is discouraged in insomnia associated with opioid dependence or alcoholism based on one negative RCT in patients on methadone maintenance treatment (Stein et al., 2012) and the safety concerns in one RCT conducted in patients with alcoholism (Friedmann et al., 2008).

\section{Low-Dose Doxepin $(<6 \mathrm{mg} /$ day $)$}

1. Mechanism of Action. Doxepin is a tricyclic antidepressant with significant antihistaminic effects. Doxepin is the most potent antihistamine of the tricyclic antidepressants, with four times the potency of amitriptyline and 800 times the potency of diphenhydramine at the $\mathrm{H}_{1}$ receptor (Richelson, 1979; Gillman, 2007). At standard antidepressant doses, $>75 \mathrm{mg} /$ day, doxepin inhibits the reuptake of serotonin and norepinephrine and antagonizes cholinergic, histaminergic, and $\alpha$-adrenergic activity. As a hypnotic, doxepin is used at low doses; at doses $<10 \mathrm{mg} /$ day, it theoretically affects only the histamine receptor, with no meaningful effects on the noradrenergic and serotonergic systems (McCall, 2016) (see Table 1).

2. Indications. Low-dose doxepin, under the brand name Silenor (Pernix Therapeutics, Morristown, NJ), is FDA approved for the treatment of insomnia characterized by difficulties with sleep maintenance to a maximum dose of $6 \mathrm{mg} /$ day (US FDA, 2010b). Doxepin is also approved as an antidepressant in the treatment of "psychoneurotic patients with depression and/or anxiety." Clinical studies examining the hypnotic effects of low-dose doxepin are detailed in Table 11.

3. Pharmacokinetics. Low-dose doxepin has a terminal half-life of 15.3 hours, whereas the half-life of nordoxepin, Median to peak concentration $\left(T_{\max }\right)$ of doxepin $6 \mathrm{mg}$ occurs 3.5 hours after oral administration to healthy fasted subjects; $T_{\max }$ is delayed by approximately 3 hours if the drug is taken with a high-fat meal, whereas AUC is increased by $41 \%$ and $C_{\max }$ by $15 \%$ (US FDA, 2010b). For this reason, it is recommended that doxepin be taken without food, to minimize the risk of next day effects. The major liver enzymes responsible for the metabolism of doxepin are CYP2C19 and CYP2D6, whereas CYP1A2 and CYP2C9 are involved to a lesser extent. The drug is $80 \%$ bound to plasma proteins. Notably, doxepin interacts with cimetidine (causes a twofold increase in doxepin $C_{\max }$ and AUC) and sertraline (causes AUC to be increased $21 \%$ and $C_{\text {max }}$ to be increased $32 \%$ ) (US FDA, 2010b).

4. Results in Insomnia Disorder. One systematic review (Yeung et al., 2015), five published RCTs (Roth et al., 2007; Scharf et al., 2008a; Krystal et al., 2011,
2010; Lankford et al., 2012), and one unpublished RCT (Takeda Global Research \& Development Center Inc., 2008) of low-dose doxepin as a treatment of primary insomnia were identified. The systematic review included two studies of doxepin at antidepressant doses (25-300 mg/day) that are excluded in this review. The authors did not perform meta-analysis of pooled results due to heterogeneity but confirmed that low-dose doxepin had a small to medium effect size versus placebo for sleep maintenance and sleep duration, but was ineffective at improving the time to sleep onset. The findings in the individual RCTs cited above generally came to similar conclusions as the recent systematic review, although some RCTs used subjective measurements and others used polysomnographic measurements.

The unpublished clinical trial is a double-dummy study of ramelteon + low-dose doxepin versus each drug as monotherapy versus placebo (Takeda Global Research \& Development Center Inc., 2008). It found that ramelteon + low-dose doxepin was significantly more effective than ramelteon + placebo by polysomnographymeasured wake time after sleep onset and total sleep time, as well as subjective wake time after sleep onset.

5. Other Results. A single night RCT of low-dose doxepin in healthy volunteers was also identified (Roth et al., 2010). In this trial, the investigators attempted to induce transient insomnia using the first-night effect as well as a 3-hour phase advance. Low-dose doxepin was effective at reducing latency to sleep and increasing total sleep time.

6. Conclusion. A summary of the effects of low-dose doxepin on sleep architecture is presented in Table 2 . There is strong evidence that low-dose doxepin is effective at reducing symptoms of primary insomnia based on one systematic review (Yeung et al., 2015), five published RCTs (Roth et al., 2007; Scharf et al., 2008a; Krystal et al., 2011, 2010; Lankford et al., 2012), and one unpublished RCT (Takeda Global Research \& Development Center Inc., 2008). Low-dose doxepin exerts a strong on improving sleep maintenance.

\section{Anticonvulsant Drugs}

\section{A. Gabapentin}

1. Mechanism of Action. Gabapentin is an anticonvulsant drug that binds to the $\alpha_{2} \delta$ subunit of voltagesensitive calcium channels (Gee et al., 1996) (Table 1). It crosses several lipid membrane barriers; in vitro, it has been shown to modulate the activity of the GABA synthesizing enzyme, glutamic acid decarboxylase, and the glutamate synthesizing enzyme, branchedchain amino acid transaminase (Taylor, 1997). Its modulation of the GABAergic and glutamatergic systems probably underlies its effect as a hypnotic and anxiolytic. Gabapentin is known to increase SWS without affecting other polygraphic variables and without causing increased drowsiness during the day 


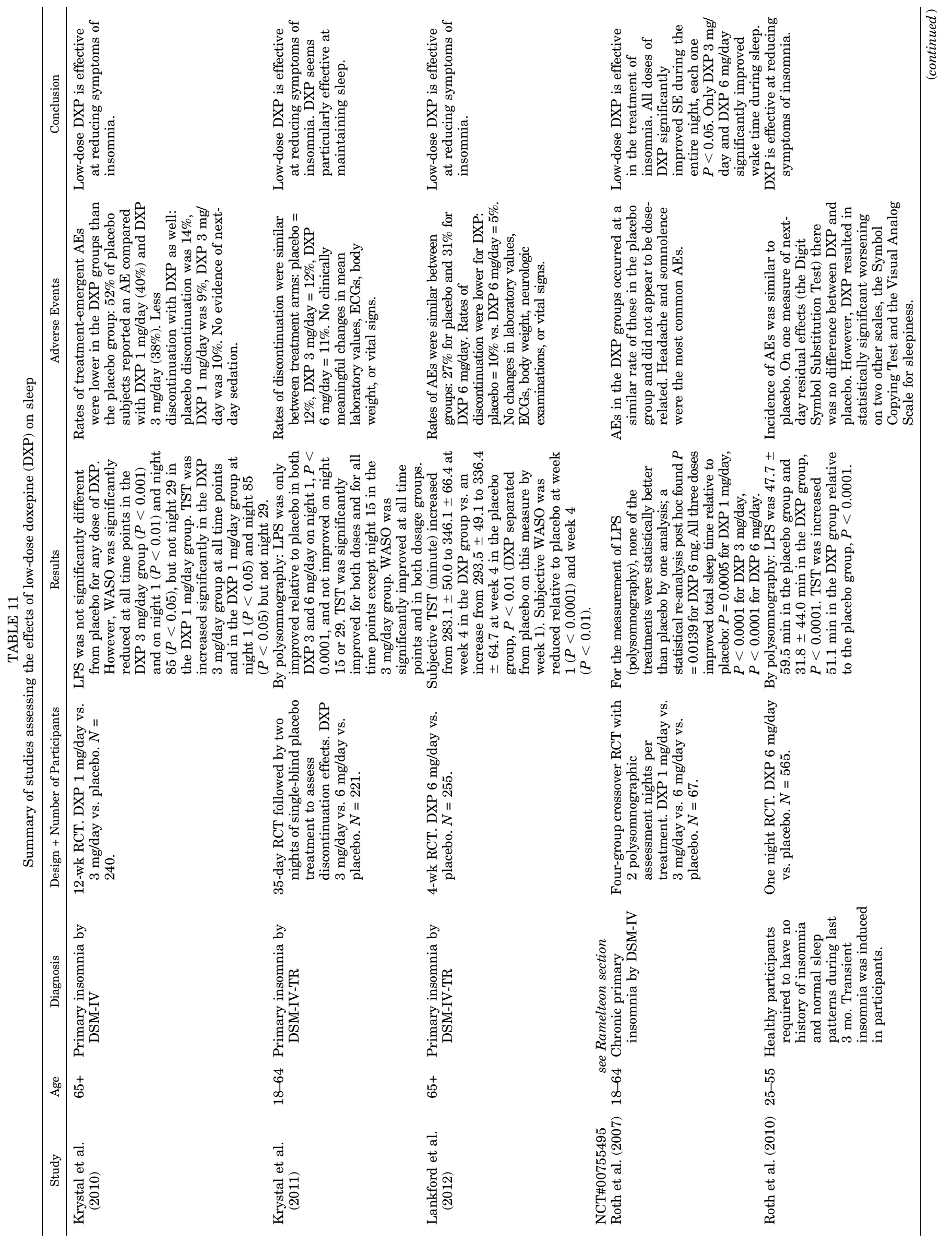




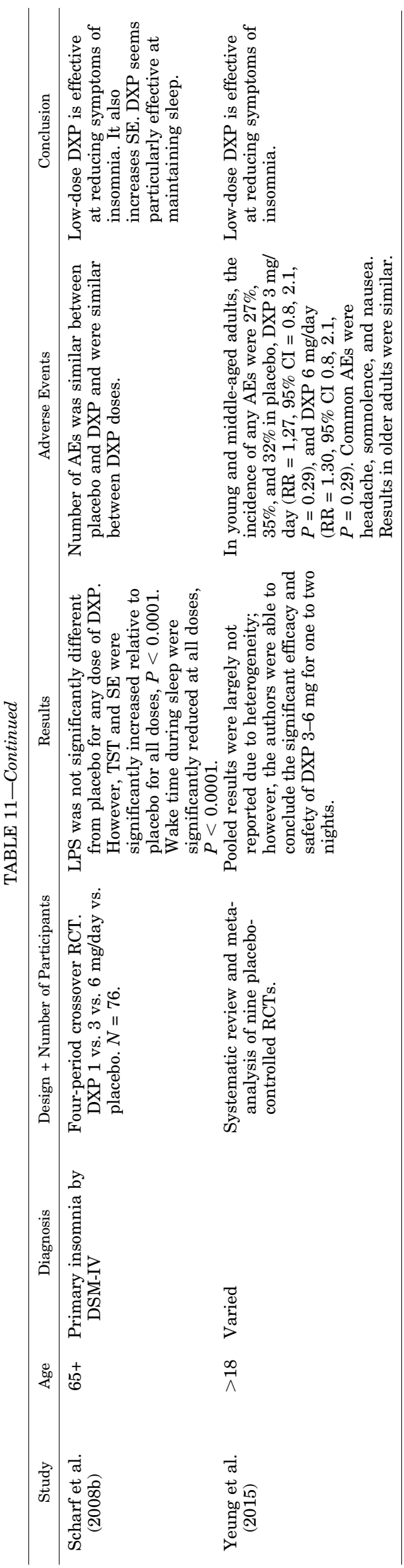

(Foldvary-Schaefer et al., 2002). In mice, gabapentin alleviates sleep disturbances induced by a neuropathic pain-like condition (Takemura et al., 2011).

2. Indications. Gabapentin is FDA-approved for the management of postherpetic neuralgia in adults (US FDA, 2014c). It is FDA approved as adjunctive treatment of partial seizures with and without secondary generalization in patients over 12 years old with epilepsy and as adjunctive treatment of partial seizures in patients aged 3-12. Clinical studies examining the hypnotic effects of gabapentin are detailed in Table 12.

3. Pharmacokinetics. The bioavailability of gabapentin is inversely proportional to its daily dose: as dosage increases, bioavailability decreases. The bioavailability of gabapentin is $60 \%, 47 \%, 34 \%, 33 \%$, and $27 \%$ following oral administration of 900, 1200, 2400, 3600 , and $4800 \mathrm{mg} /$ day of the drug given in three divided doses (US FDA, 2014c). Less than 3\% of gabapentin is bound to plasma protein, and the drug is not appreciably metabolized in humans. Its elimination half-life is 5-7 hours and is unaltered by dose or following multiple dosing. Taking the drug with food has a small effect on its pharmacokinetics, increasing AUC and $C_{\text {max }}$ by $14 \%$ each.

4. Results in Insomnia Disorder. One open-label trial conducted in patients with primary insomnia was identified (Lo et al., 2010). This study ( $N=18$; mean dose of gabapentin $540 \mathrm{mg} /$ day, range $200-900 \mathrm{mg} /$ day) found polysomnographic evidence of increased sleep efficiency $(80.00 \%-87.17 \%, P<0.05)$ and SWS (10.47\%-17.68\%, $P<0.005)$ and decreased wake time after sleep onset $(16.45 \%-7.84 \%, P<0.05)$ (Lo et al., 2010). However, gabapentin did not significantly improve sleep onset latency (17.58-14.58 minutes, not significant).

5. Other Results. Five other studies of gabapentin were identified. Two of the four studies were RCTs: one was conducted in patients diagnosed with alcohol dependence and comorbid insomnia (Brower et al., 2008) and the other was a single-dose study conducted in patients with "occasional disturbed sleep" (Rosenberg et al., 2014). One open-label comparison study of gabapentin versus trazodone conducted in patients with alcohol dependence and "persistent insomnia" (KaramHage and Brower, 2003) and an open-label study conducted in children suffering from refractory insomnia comorbid to neurodevelopmental or neuropsychiatric disorders (Robinson and Malow, 2013) were also identified. Finally, one study in healthy subjects was identified (Foldvary-Schaefer et al., 2002).

In the RCT conducted in patients with alcohol dependence and comorbid insomnia $(N=21$; gabapentin $1500 \mathrm{mg} /$ day), treatment group did not predict changes in the Sleep Problems Questionnaire score (Brower et al., 2008). However, gabapentin treatment significantly reduced the risk of relapse to heavy drinking: at 
Atkin et al.

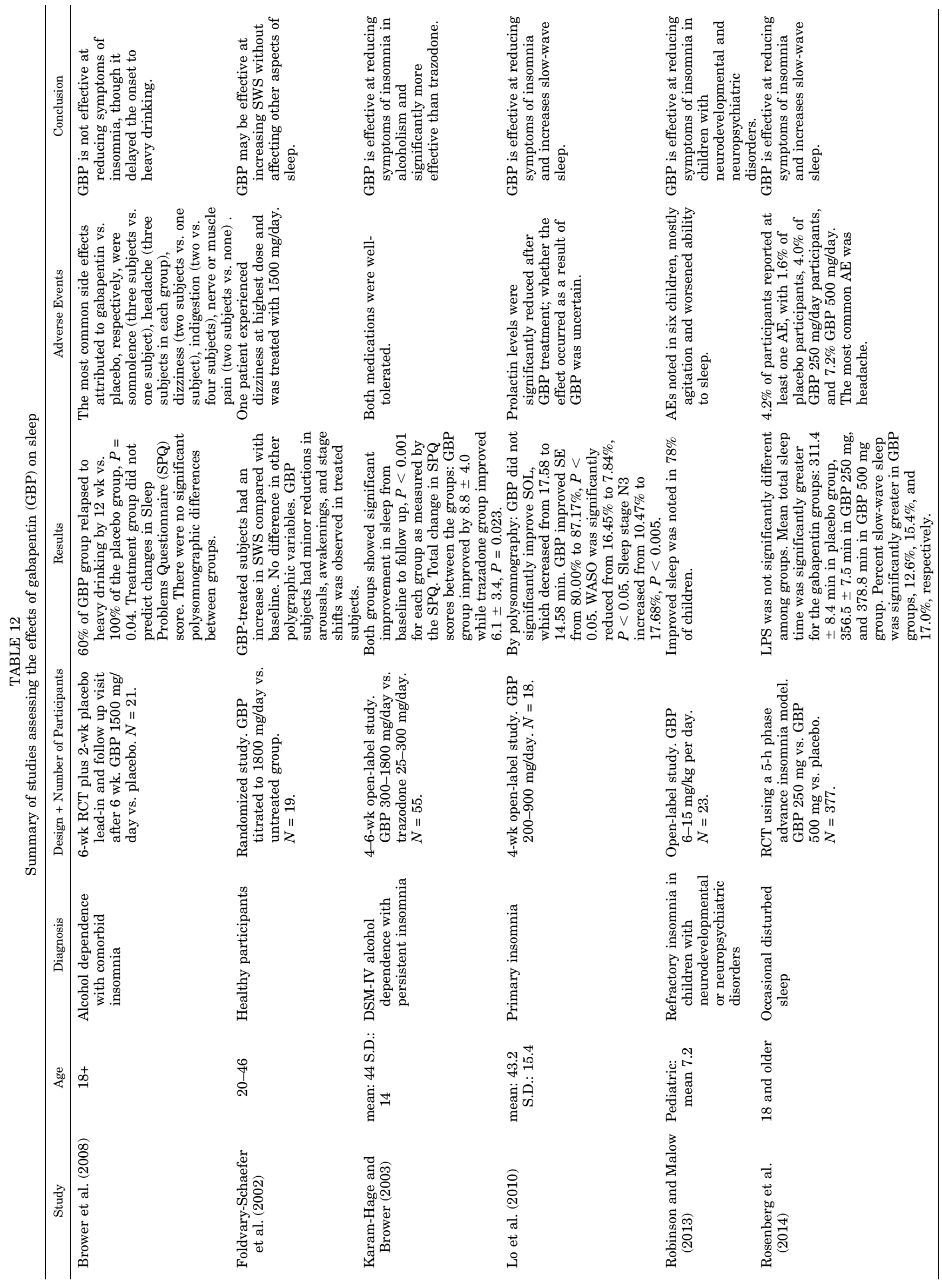


12 weeks, $60 \%$ of the gabapentin group had relapsed compared with $100 \%$ of the placebo group. Similarly, in the single-dose study using a 5-hour phase advance model in patients with "occasional disturbed sleep," gabapentin $250 \mathrm{mg} /$ day and gabapentin $500 \mathrm{mg} /$ day were not significantly superior to placebo at reducing latency to persistent sleep. However, the mean total sleep time was significantly greater for the gabapentin groups: 311.4 [8.4] $\mathrm{min}$ in the placebo group versus 356.5 [7.5] $\mathrm{min}$ in the gabapentin $250 \mathrm{mg} /$ day group $(P \leq$ 0.001 compared with placebo) and 378.7 [7.3] min in the gabapentin $500 \mathrm{mg} /$ day group $(P \leq 0.001$ compared with placebo, $P \leq 0.01$ compared with gabapentin $250 \mathrm{mg} /$ day). Wake after sleep onset was significantly improved in the gabapentin groups, as was the proportion of time spent in SWS (stages 3 and 4) (Rosenberg et al., 2014). Finally, in the open-label comparison study of gabapentin and trazodone in alcoholism, gabapentin was significantly more effective.

6. Conclusion. A summary of the effects of gabapentin on sleep architecture is presented in Table 2 . There is some evidence that gabapentin is effective in the treatment of insomnia disorder according to one openlabel trial, although it did not significantly improve sleep onset latency (Lo et al., 2010).

\section{B. Pregabalin}

1. Mechanism of Action. Similar to gabapentin, pregabalin binds to $\alpha_{2} \delta$ subunit-containing voltagegated calcium channels (Taylor et al., 2007). Pregabalin also modulates the influx of calcium at nerve terminals, which may accounts for its therapeutic benefit in neuropathic pain, seizures, and anxiety. The mechanism of action of pregabalin (Table 1) in improving sleep has not been completely elucidated, but it is known to be different from benzodiazepines as pregabalin is not active at GABA-A or benzodiazepine receptors (Taylor et al., 2007). Furthermore, although benzodiazepines typically reduce SWS, pregabalin has been found to increase it (Hindmarch et al., 2005). In rats, pregabalin has been found to increase NREMS and REMS, while markedly increasing the duration of NREMS episodes and reducing their number (Kubota et al., 2001). In one study, pregabalin increased NREMS in mice with a neuropathic pain-like condition, but not normal mice (Wang et al., 2015).

2. Indications. Pregabalin is FDA approved for the management of neuropathic pain associated with diabetic peripheral neuropathy, the management of postherpetic neuralgia, adjunctive therapy for adult patients with partial onset seizures, the management of fibromyalgia, and the management of neuropathic pain associated with spinal cord injury (US FDA, 2016). Clinical studies examining the hypnotic effects of gabapentin are detailed in Table 13.

3. Pharmacokinetics. Following oral administration, peak plasma concentrations of pregabalin occur within 1.5 hours; its bioavailability is greater than or equal to $90 \%$ and is independent of dose (US FDA, 2016). The half-life of pregabalin is about 6 hours. Taking pregabalin with food increases $T_{\max }$ to approximately 3 hours and reduces $C_{\text {max }}$ by $25 \%-30 \%$, although pregabalin can be taken with or without food. It does not bind to plasma proteins and undergoes negligible metabolism in humans (US FDA, 2016). Oral clearance tends to decrease with increasing age.

4. Results in Insomnia Disorder. No studies of pregabalin as a treatment of insomnia disorder were identified.

5. Other Results. Three reviews were found analyzing the use of pregabalin in patients with insomnia: in two, patients were primarily diagnosed with generalized anxiety disorder (Montgomery et al., 2009; Holsboer-Trachsler and Prieto, 2013), and in one, patients were primarily diagnosed with fibromyalgia (Russell et al., 2009). In the most recent review, pooled data from four RCTs $(N=1354)$ established that among patients with severe difficulty in falling asleep, remission was observed in $54.0 \%$ of the pregabalin group versus $29.8 \%$ of placebo group (Holsboer-Trachsler and Prieto, 2013). In those with severe difficulty in staying asleep, remission was observed in $54.2 \%$ of pregabalin group versus $26.7 \%$ of placebo group. Finally, in those with severe difficulty associated with waking up too early, remission was observed in $59.4 \%$ of pregabalin group versus $34.6 \%$ of placebo group. The fibromyalgia study $(N=1493$, two RCTs $)$ likewise found that pregabalin was significantly superior to placebo in reducing the burden of insomnia symptoms as measured using the Sleep Quality Diary and Medical Outcomes Study Subscales of Sleep Disturbance, Quantity of Sleep, and Sleep Problems Index (Russell et al., 2009). For more information about these psychometric scales, see Smith and Wegener (2003).

6. Conclusion. A summary of the effects of pregabalin on sleep architecture is presented in Table 2. There is good evidence based on two reviews (Montgomery et al., 2009; Holsboer-Trachsler and Prieto, 2013) that pregabalin is effective at reducing symptoms of insomnia in generalized anxiety disorder. There is also good evidence based on one review (Russell et al., 2009) that pregabalin is effective at reducing symptoms of insomnia in fibromyalgia. Based on these same reviews, there is weak evidence that pregabalin is effective in the treatment of insomnia disorder.

\section{Atypical Antipsychotic Drugs}

Sedating atypical antipsychotics, particularly quetiapine, are often used in the clinic for the management of insomnia disorder and insomnia symptoms that occur comorbid to psychiatric illness (Pringsheim and Gardner, 2014). Although they are effective in the management of bipolar and psychotic disorders, systematic 


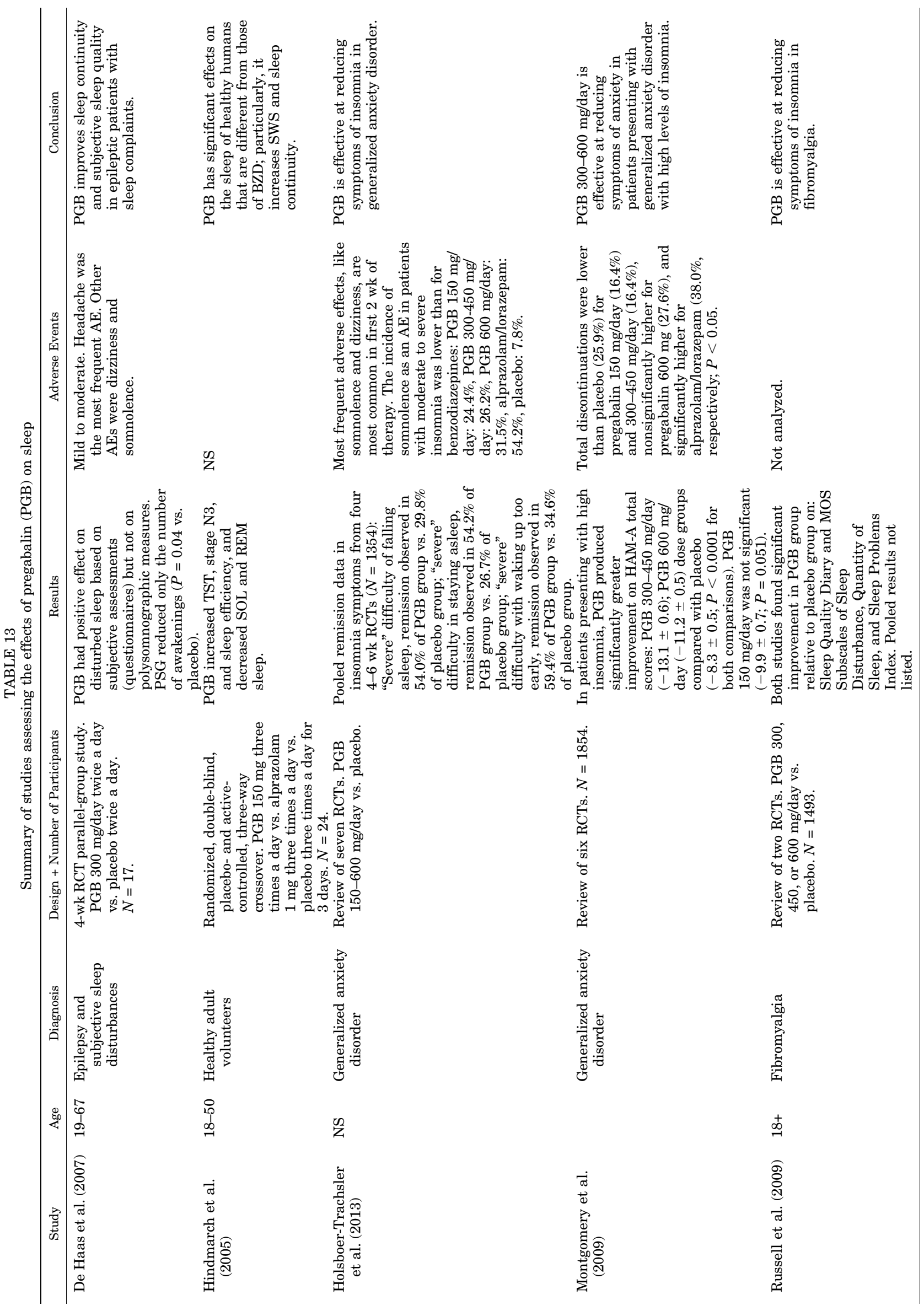


reviews have found a lack of evidence for the use of sedating atypical antipsychotics and explicitly recommend against prescribing them for insomnia disorder (Thompson et al., 2016). The 2016 meta-analysis acknowledges that the use of atypical antipsychotics may be appropriate in patients who have failed other treatment modalities and who have a comorbid condition that could benefit from the primary action of the drug (based on consensus of experts in sleep medicine). Similarly, guidelines for the treatment of chronic insomnia report insufficient evidence for atypical antipsychotics as first-line therapy (Schutte-Rodin et al., 2008), but state that the medications may be suitable for patients with comorbid insomnia who may benefit from the primary action of these drugs as well as from the sedating effect.

\section{A. Olanzapine}

1. Mechanism of Action. Olanzapine is an atypical antipsychotic with affinity for the dopamine $\mathrm{D}_{1}, \mathrm{D}_{2}$, and $\mathrm{D}_{4}$ receptors; the serotonin $5-\mathrm{HT}_{2 \mathrm{~A}}, 5-\mathrm{HT}_{2 \mathrm{C}}$, and $5-\mathrm{HT}_{3}$ receptors; the $\alpha_{1}$-adrenergic receptor; the histamine $\mathrm{H}_{1}$ receptor; and five muscarinic receptor subtypes (Bymaster et al., 1996). Its hypnotic effects are probably attributable to its strong antagonism of the $\mathrm{H}_{1}$ antagonism as well as its antagonism of serotonin receptors. In an assay of compounds tested at the histamine $\mathrm{H}_{1}$ receptor, olanzapine was the most potent compound Richelsen and Souder (2000) had tested of any class of compounds. Olanzapine seems to specifically increase SWS (Salin-Pascual et al., 1999; Giménez et al., 2007; Kluge et al., 2014). Main molecular targets of olanzapine are summarized in Table 1.

2. Indications. Olanzapine is FDA approved for the treatment of schizophrenia in adults and adolescents; for the acute treatment of manic or mixed episodes associated with bipolar I disorder and the maintenance treatment of bipolar I disorder in adults and adolescents; and, as an intramuscular injection, for the treatment of acute agitation associated with schizophrenia and bipolar I mania (US FDA, 2009). Clinical studies examining the hypnotic effects of olanzapine are detailed in Table 14.

3. Pharmacokinetics. Olanzapine reaches peak concentrations about 6 hours following oral administration, and its elimination half-life ranges from 21 to 54 hours, with a mean of 30 hours (US FDA, 2009). It is eliminated extensively by first-pass metabolism: about $40 \%$ of an oral dose is metabolized before it reaches the systemic circulation. Olanzapine is extensively metabolized by CYP1A2, CYP2D6, and the flavin monooxygenase system, although its metabolites do not display pharmacological activity at normal concentrations (US FDA, 2009). Its pharmacokinetics are not affected by food. The drug is $93 \%$ bound to plasma protein. Clearance of olanzapine is approximately $30 \%$ lower in women than in men, and the elimination half-life of olanzapine is about 1.5 times higher in subjects greater than 65 years old.
4. Results in Insomnia Disorder. No studies of olanzapine as a treatment of insomnia disorder were identified.

5. Other Results. Two studies that examined olanzapine's effect on sleep (Salin-Pascual et al., 1999; Sharpley et al., 2000) and three studies on olanzapine as a treatment of secondary insomnia were identified (Jakovljević et al., 2003; Khazaie et al., 2010, 2013). Of the studies analyzing olanzapine's effect on sleep, both were small: one was an open-label study conducted in 20 patients with schizophrenia, during which polysomnographic recordings were taken for 5 days, with patients only receiving olanzapine on two nights (Salin-Pascual et al., 1999) and one was a one-dose crossover RCT conducted in nine healthy male participants, with 7-14 days washout between doses (Sharpley et al., 2000). The crossover RCT examined olanzapine $5,10 \mathrm{mg} /$ day or placebo, whereas the study in patients with schizophrenia examined olanzapine $10 \mathrm{mg} /$ day. Both studies found that olanzapine profoundly increased slow-wave sleep and increased total sleep time as acute treatment.

Of the studies in secondary insomnia, one was conducted in patients suffering from treatment-resistant posttraumatic stress disorder (PTSD) (Jakovljević et al., 2003), whereas the other two were in patients with paradoxical insomnia, also known as sleep state misperception (Khazaie et al., 2010, 2013). The first study was in patients suffering from intractable PTSD in which open-label olanzapine was added to their current medications (Jakovljević et al., 2003). The patients had recurrent nightmares and insomnia resistant to numerous medications. In all five cases, olanzapine resulted in a significant improvement in their symptoms. One randomized, open-label study was conducted in patients diagnosed with paradoxical insomnia, or sleep-state misperception (Khazaie et al., 2013). Patients suffering from this disorder complain of difficulties with initiating and maintaining sleep; however, the hallmark of paradoxical insomnia is that objective polysomnographic measures find that the patients are getting sufficient sleep. In this study, the investigators followed up on a case report study they had published in 2010 (Khazaie et al., 2010), in which they reported successful treatment of recalcitrant, paradoxical insomnia with olanzapine in a single patient. The group's larger study compared treatment with two different atypical antipsychotics: olanzapine and risperidone. They found that, although both treatments were associated with significant improvements in subjective sleep quality, olanzapine was significantly superior to risperidone, as measured using the Pittsburgh Sleep Quality Index (PSQI) (Buysse et al., 1989).

6. Conclusion. A summary of the effects of olanzapine on sleep architecture is presented in Table 2. There is weak evidence that olanzapine acutely increases slow-wave sleep and total sleep time (Salin-Pascual 


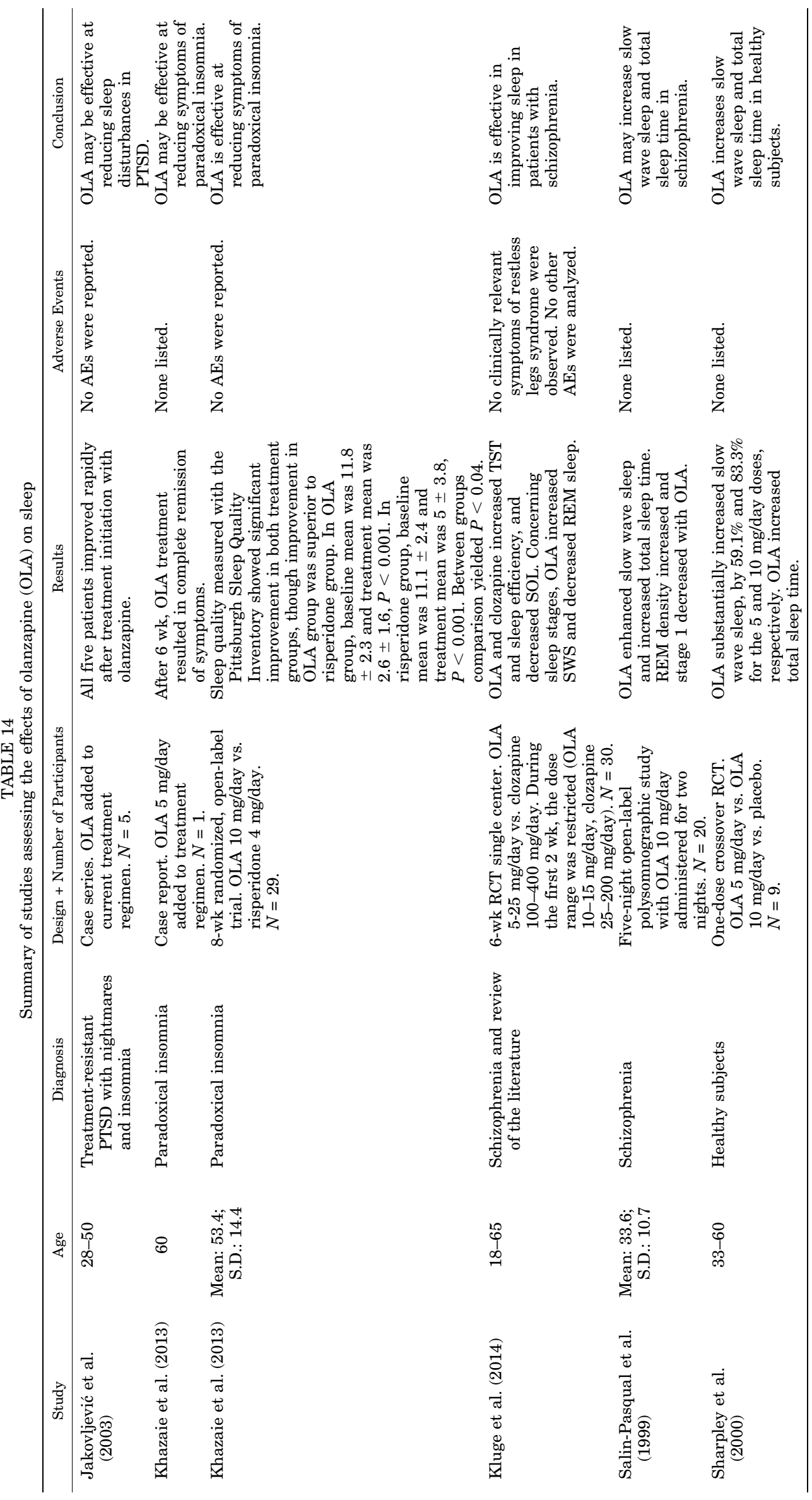


et al., 1999; Sharpley et al., 2000), although this effect has not been confirmed in patients with insomnia. There is also evidence that olanzapine may be useful in 1) the treatment of insomnia associated with PTSD (Jakovljević et al., 2003) based on a case series and 2) paradoxical insomnia, based on a case report (Khazaie et al., 2010) and a randomized, open-label trial (Khazaie et al., 2013).

\section{B. Quetiapine}

1. Mechanism of Action. Quetiapine, a dibenzothiazepine derivative, is the atypical antipsychotic that displays the lowest $\mathrm{D}_{2}$ affinities (Richelson and Souder, 2000; Comai et al., 2012b). It shows antagonism at multiple neurotransmitter receptors, mainly $5-\mathrm{HT}_{2 \mathrm{~A}}$, $5-\mathrm{HT}_{2 \mathrm{c}}, \mathrm{H}_{1}$, and $\mathrm{D}_{2}$ (Table 1). Its sedative and hypnotic properties are attributable to its antagonism of the histamine $\mathrm{H}_{1}$ receptor and various serotonin receptors. In monkeys, neither acute nor chronic administration of quetiapine improved sleep efficiency, whereas the first night after discontinuation, subjects had significantly decreased sleep efficiency and increases in nighttime activity (Brutcher and Nader, 2015).

2. Indications. Quetiapine is FDA approved for the treatment of schizophrenia in adults and adolescents, the treatment of bipolar mania in children and adolescents, and the treatment of bipolar depression in adults. Clinical studies examining the hypnotic effects of quetiapine are detailed in Table 15.

3. Pharmacokinetics. Quetiapine fumarate is rapidly absorbed after oral administration, reaching peak plasma concentrations within 1.5 hours (US FDA, 2017). The drug is $83 \%$ bound to serum proteins (DeVane and Nemeroff, 2001). Administration with food increases $C_{\max }$ and AUC by $25 \%$ and $15 \%$, respectively. The drug is mainly eliminated through hepatic metabolism, specifically CYP3A4, and its mean terminal elimination half-life is 6 hours. Oral clearance is reduced by $40 \%$ in subjects greater than 65 years of age, although sex does not affect its pharmacokinetics.

4. Results in Insomnia Disorder. One RCT was identified in patients diagnosed with primary insomnia (Tassniyom et al., 2010). Surprisingly, although observational evidence suggests that atypical antipsychotics like quetiapine are increasingly prescribed for insomnia, the 2010 study was the only RCT that was found in the literature of an atypical antipsychotic in primary insomnia, and it had a small sample size of only 13 patients who completed the study (Tassniyom et al., 2010). In the RCT, quetiapine $25 \mathrm{mg}$ /day treatment was not significantly superior to placebo at increasing sleep time and reducing latency to sleep, although there was a trend toward the superiority of quetiapine (Tassniyom et al., 2010).

In contrast, an open-label trial of quetiapine 25$75 \mathrm{mg} /$ day found that the drug was effective at reducing symptoms of insomnia, increasing total sleep time and reducing PSQI (Wiegand et al., 2008).

5. Other Results. Eleven other studies of quetiapine that included sleep parameters were identified: five were open label (Juri et al., 2005; Todder et al., 2006; Baune et al., 2007; Pasquini et al., 2009), three were randomized, placebo-controlled trials (Cohrs et al., 2004; Garakani et al., 2008; McElroy et al., 2010), one was a review (Anderson and Vande Griend, 2014) pooling many of the studies cited here, one was a naturalistic study (Šagud et al., 2006), one was a post hoc analysis of two RCTs (Endicott et al., 2008), and one was a retrospective study (Terán et al., 2008).

One RCT in 14 healthy male subjects found that quetiapine 25 and $100 \mathrm{mg} /$ day significantly improved sleep induction and sleep continuity under standard and acoustic stress conditions (Cohrs et al., 2004). Active treatment with quetiapine also increased total sleep time, sleep efficiency, and subjective sleep quality.

In contrast to the results of the RCT in primary insomnia, the open-label studies in other conditions were generally positive, although they were conducted in a wide range of patient populations. The included studies analyzed patients diagnosed with Parkinson's disease, treatment-resistant depression, bipolar disorder, breast cancer with tamoxifen-induced insomnia, and insomnia induced by detoxification from substance abuse. Unfortunately, a retrospective chart review $(N=$ 43) found that quetiapine prescribed for insomnia at a mean dose of $120.3 \pm 58.6 \mathrm{mg} /$ day had adverse metabolic side effects (Cates et al., 2009). However, neither the RCT of quetiapine $25 \mathrm{mg} /$ day study (Tassniyom et al., 2010) nor the open-label trial of quetiapine 25$75 \mathrm{mg} /$ day (Wiegand et al., 2008) reported the rate of metabolic side effects, and the retrospective review did not perform subgroup analysis of the patients taking $25 \mathrm{mg} /$ day $(N=4$ at baseline).

6. Conclusion. A summary of the effects of quetiapine on sleep architecture is presented in Table 2 . There is moderate evidence that quetiapine is not significantly effective for the treatment of primary insomnia, based on one small RCT (Tassniyom et al., 2010). Randomized studies support the usefulness of quetiapine in insomnia that is secondary to conditions for which quetiapine has an FDA-approved indication, like bipolar depression or unipolar depression (as augmentation). There is Level $1 \mathrm{~b}$ evidence based on two RCTs (Calabrese et al., 2005; McElroy et al., 2010) that quetiapine is effective in the treatment of insomnia secondary to bipolar depression. There is Level $1 \mathrm{~b}$ evidence based on one RCT (Garakani et al., 2008) and three open-label trials (Šagud et al., 2006; Todder et al., 2006; Baune et al., 2007) that quetiapine as augmentation of antidepressants is effective in reducing symptoms of insomnia in treatment-resistant depression. 


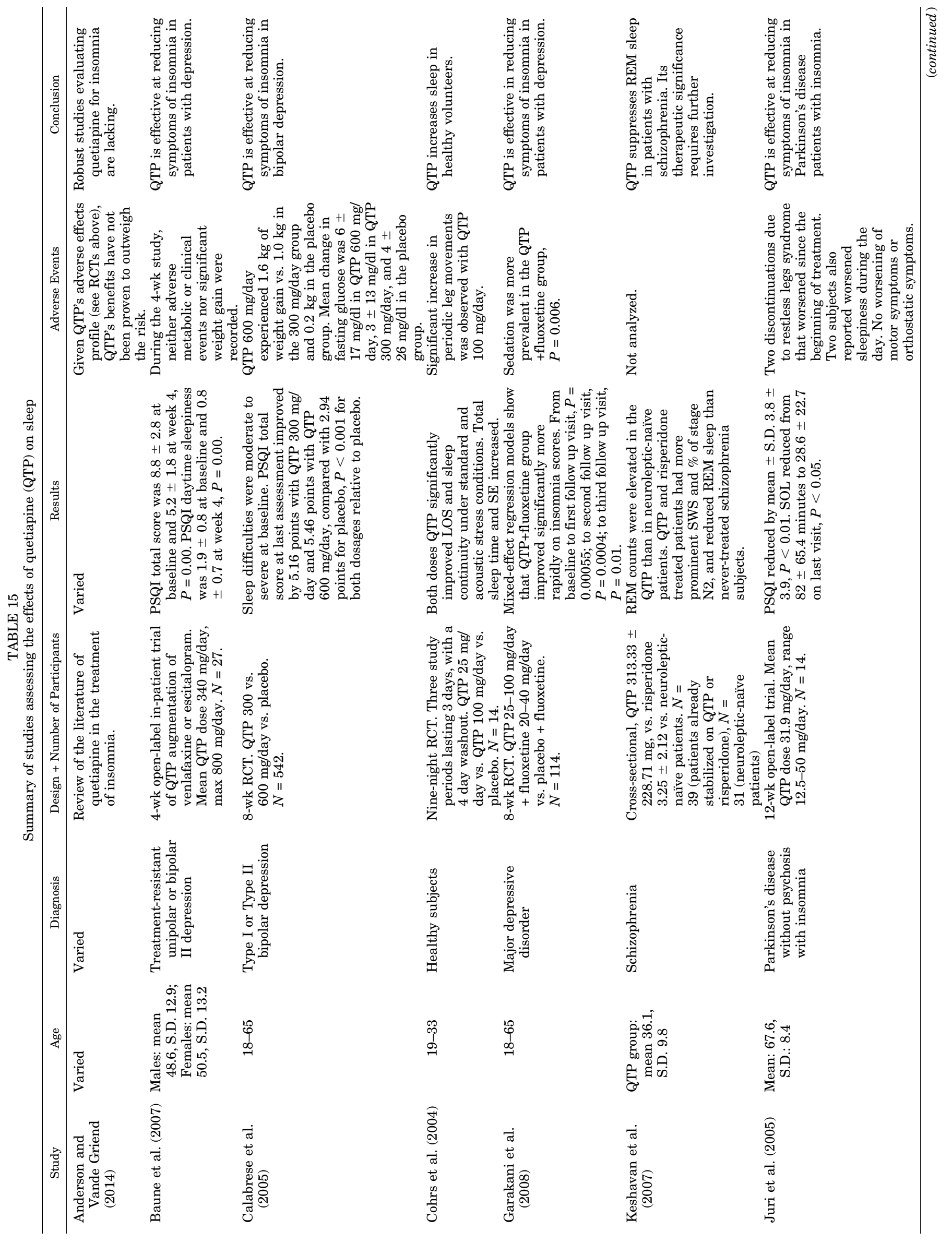




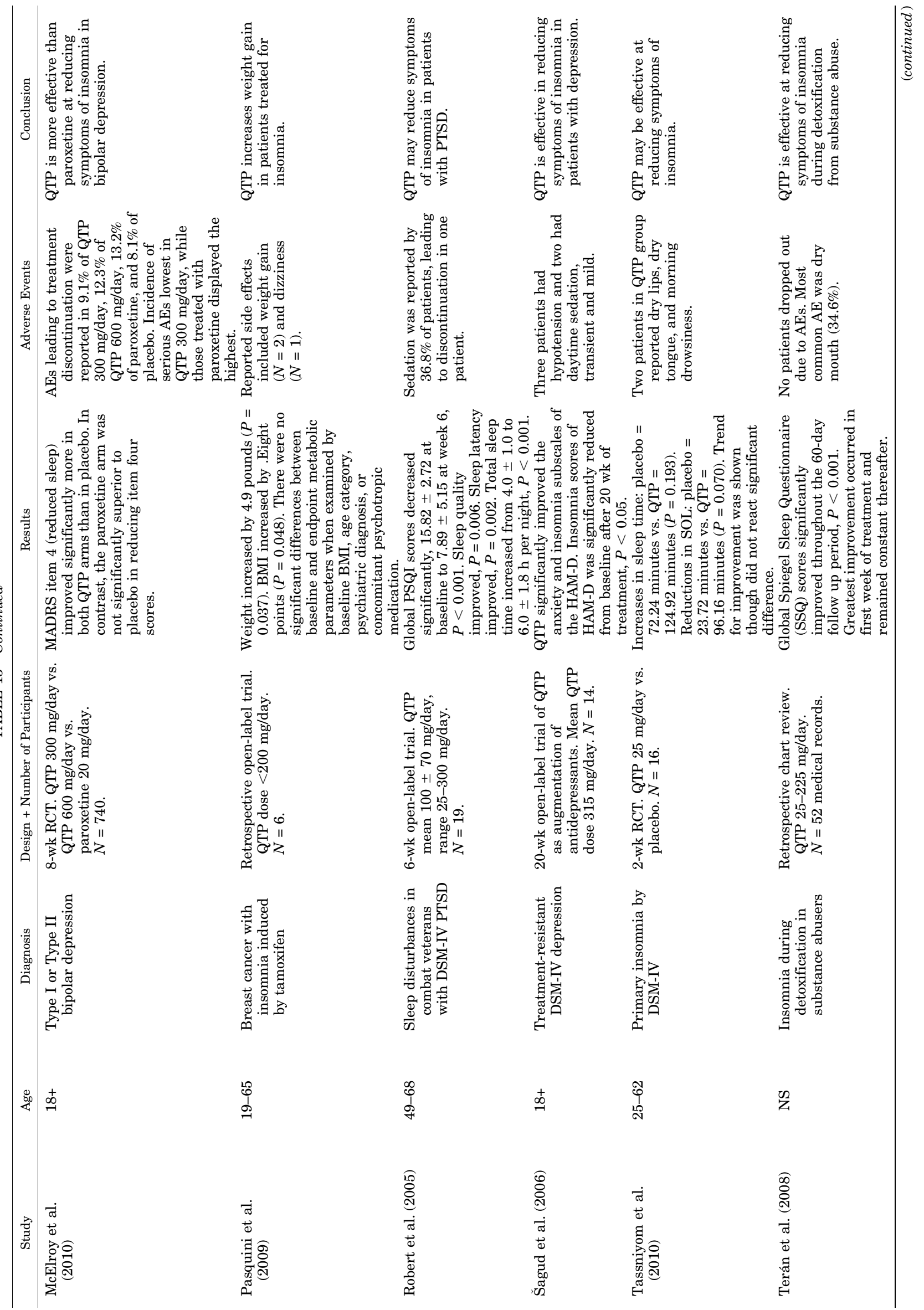




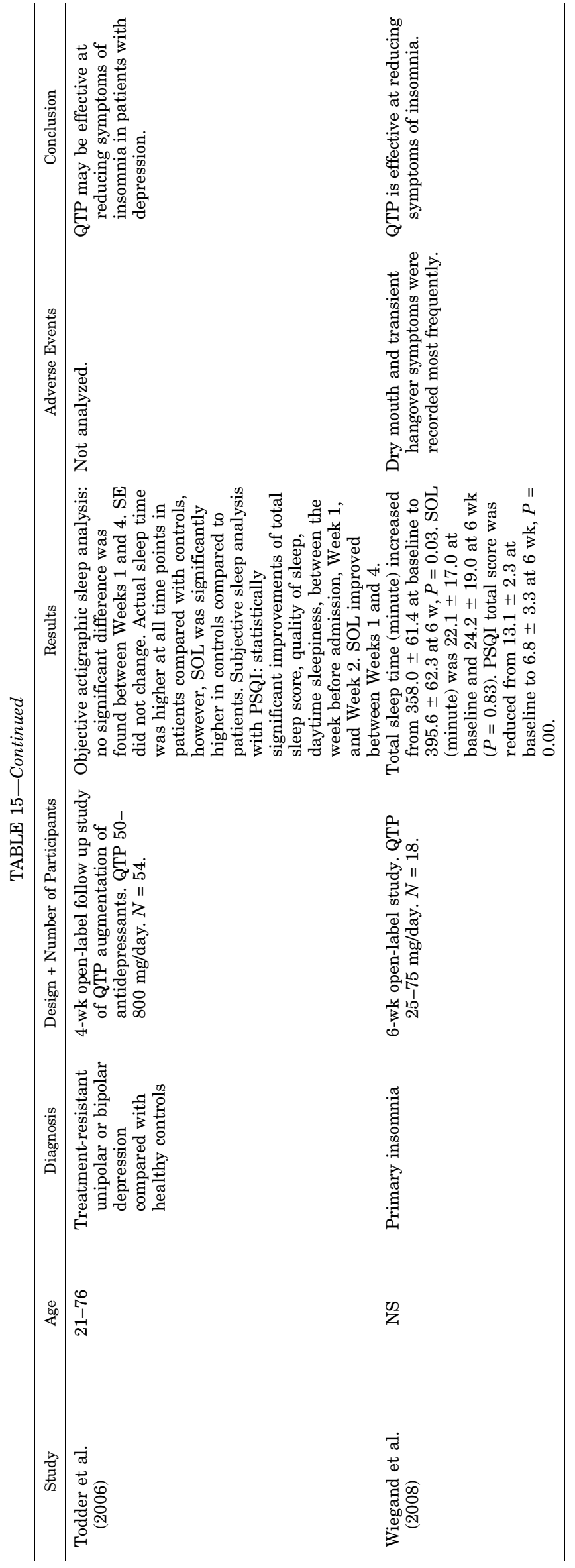

\section{Discoveries, Novel Pathways, and Pipelines}

The discoveries and pipelines in this section, constructed using data from a custom search of the Cortellis database, are an up-to-date (as of February 2017) snapshot of the current state of the research and development of insomnia medications.

\section{A. Discoveries}

1. Adenosine Receptor Agonist. YZG-331 is a promising sedative hypnotic and adenosine analog that exerts its effects by binding to the adenosine receptor. (See the Other Receptors section for a review of the pharmacology of $\mathrm{A}_{1 \mathrm{~A}}$ and $\mathrm{A}_{2 \mathrm{~A}}$.)

2. Casein Kinase-1 $1 \delta / \varepsilon$. The casein kinase- $1 \delta$ and casein kinase- $1 \varepsilon$ proteins are essential elements of the molecular oscillators known as circadian clocks (Lee et al., 2009). Their importance to the functioning of the mammalian circadian rhythm has spurred interest in casein kinase- $1 \delta / \varepsilon$ inhibitors as potential clinical treatments of sleep disorders and other central nervous system disorders including neurodegenerative conditions (Perez et al., 2011).

3. Selective Melatonin $M_{2}$ Receptors. Studies on melatonin $\mathrm{MT}_{1}$ knockout, $\mathrm{MT}_{2}$ knockout, and double $\mathrm{MT}_{1}-\mathrm{MT}_{2}$ knockout mice have demonstrated that these two receptors have opposing or complementary functions. Whereas $\mathrm{MT}_{2}$ receptor activation promotes SWS, $\mathrm{MT}_{1}$ decreases SWS and increases REMS (OchoaSanchez et al., 2011; Ochoa-Sanchez et al., 2014). This evidence prompted the development of novel selective $\mathrm{MT}_{2}$ agonists as hypnotics. The compound UCM765 has greater $\mathrm{MT}_{2}$ receptor affinity $\left(\mathrm{p} K_{\mathrm{i}}=10.18\right)$ than melatonin $\left(\mathrm{p} K_{\mathrm{i}}=9.59\right)$ and has about 100 -fold higher affinity for the $\mathrm{MT}_{2}$ receptor than for the $\mathrm{MT}_{1}$ receptor $\left(\mathrm{p} K_{\mathrm{i}}=\right.$ 8.28). UCM924 also displays $\mathrm{MT}_{2}$ affinity $\left(\mathrm{p} K_{\mathrm{i}}=10.2\right)$ that is 300 -fold higher than for $\mathrm{MT}_{1}\left(\mathrm{p} K_{\mathrm{i}}=6.75\right)$, with an intrinsic activity for MT1: $\mathrm{IA}_{\mathrm{r}}-\mathrm{hMT}_{1}=0.1$; and for MT2: $\mathrm{IA}_{\mathrm{r}}-\mathrm{hMT}_{2}=0.4$ (Rivara et al., 2009).

Both UCM765 (Ochoa-Sanchez et al., 2011) and UCM924 (Ochoa-Sanchez et al., 2014) increase SWS during the inactive phase of the day, without significant change in REMS or sleep architecture. The congener nonselective $\mathrm{MT}_{1}-\mathrm{MT}_{2}$ receptor UCM971 did not alter the 24-hour duration of wakefulness, NREMS, or REMS, but modified the number of episodes. MLT decreased $(-37 \%)$ the latency to the first episode of NREMS and enhanced the power of NREMS delta band $(+33 \%)$, but did not alter the duration of any of the three vigilance states or modify the duration of SWS (OchoaSanchez et al., 2014). These data confirm the importance of targeting the $\mathrm{MT}_{2}$ receptor for hypnotic effects. UCM765 and UCM924 show a good safety profile and are currently under development for clinical studies.

4. Selective Orexin-2 Antagonist. Although dual orexin receptor antagonists like suvorexant are effective at promoting sleep, selective orexin-2 receptor 
blockers may preserve sleep architecture to a greater extent than dual antagonists (Bonaventure et al., 2015). Indeed, only orexin- 2 but not orexin- 1 is involved in the regulation of sleep (Dugovic et al., 2009). JNJ-42847922 is a novel orexin-2 antagonist shown to reduce the latency to NREM sleep and increase NREM sleep in the first 2 hours after administration, without affecting REM sleep in rats (Bonaventure et al., 2015). Importantly, the compound has been shown to reduce time to sleep onset and increase total sleep time after 7 days of chronic dosing $(30 \mathrm{mg} / \mathrm{kg})$. The compound did not produce conditioned-place preference or increase dopamine release in the nucleus accumbens, indicating that it lacks intrinsic motivational properties, in contrast to zolpidem. In a Phase I study in healthy human subjects, JNJ-42847922 (10-80 mg/day) significantly increased somnolence: 22 of 26 subjects (85\%) receiving JNJ42847922 reported somnolence as an adverse event, whereas only 3 of 13 subjects (23\%) receiving placebo did (Bonaventure et al., 2015). The compound's pharmacokinetic profile in humans was favorable, with a half-life of 2 hours. One subject reported experiencing sleep paralysis after receiving the $80 \mathrm{mg} /$ day dose.

\section{B. Pipelines}

1. Lumateperone. Lumateperone is a mechanistically novel investigational antipsychotic drug with a unique pharmacological profile, showing very high $5-\mathrm{HT}_{2 \mathrm{~A}}$ blocking activity $\left(K_{\mathrm{i}}=0.54 \mathrm{nM}\right)$ relative to its $\mathrm{D}_{2}$ modulating activity. The drug has a 60 -fold difference between its affinity for $5 \mathrm{HT}_{2 \mathrm{~A}}$ and $\mathrm{D}_{2}$ receptors compared with a 12 -fold difference for risperidone, a 12.4-fold difference for olanzapine, and a 0.18-fold difference for aripiprazole (Davis et al., 2015; Snyder et al., 2015). Lumateroperone functions as a modulator of the $\mathrm{D}_{2}$ receptor by partially agonizing presynaptic $\mathrm{D}_{2}$ receptors and antagonizing postsynaptic $\mathrm{D}_{2}$ receptors $\left(K_{\mathrm{i}}=32 \mathrm{nM}\right)$ (Snyder et al., 2015). Furthermore, the drug blocks the serotonin transporter with strong affinity $\left(K_{\mathrm{i}}=62 \mathrm{nM}\right)$ while having no affinity for the $\mathrm{H}_{1}$ histaminergic or muscarinic receptors (Snyder et al., 2015). Importantly, the drug's $D_{2}$ and SERT occupancy increase with dose (Davis et al., 2015); at low doses, the drug theoretically functions as a selective $5-\mathrm{HT}_{2 \mathrm{~A}}$ blocker.

The company, Intra-Cellular Therapies (New York, NY), suggests on their website that lower doses of lumateperone could be useful in the treatment of sleep disorders, whereas higher doses are targeted to neuropsychiatric disease. A Phase 2 study $(N=18)$ of lumateperone as a treatment of insomnia characterized by sleep maintenance difficulties was discontinued early when the investigators found robust evidence of efficacy, with increased SWS and decreased wake after sleep time by polysomnography (Intra-Cellular Therapies, 2009). Furthermore, lumateperone did not impair next-day cognition as measured by Leeds Psychomotor
Battery, Digit Symbol Substitution Test, or Word Pair Associates Test.

2. Piromelatine. Piromelatine is a unique drug that combines agonist activity at $\mathrm{MT}_{1}$ and $\mathrm{MT}_{2}$ with agonism at $5-\mathrm{HT}_{1 \mathrm{~A} / 1 \mathrm{D}}$ receptors (Laudon et al., 2012). Piromelatine was shown to have both hypnotic and antinociceptive effects by electroencephalogram (EEG) recordings and an animal model of neuropathic pain, partial sciatic nerve ligation (Liu et al., 2014). The drug was found to increase NREM sleep and decrease wakefulness in partial sciatic nerve ligation mice. Finally, the investigators demonstrated that the effect could be blocked by preadministration of a melatonin receptor antagonist, a $5-\mathrm{HT}_{1 \mathrm{~A}}$ receptor antagonist, or an opiate receptor antagonist (Liu et al., 2014), implicating these receptors in the mechanism of action of the drug.

In 2013, Neurim Pharmaceuticals (Tel-Aviv, Israel) announced positive results from a phase II randomized clinical trial $(N=120)$ of piromelatine in primary insomnia (Neurim Pharmaceuticals, 2013). Active treatment with piromelatine 20 or $50 \mathrm{mg} /$ day over 4 weeks resulted in significantly improved wake after sleep onset, sleep efficiency, and total sleep time. The Clinicaltrials.gov database lists a study currently recruiting patients entitled Safety and Efficacy of Piromelatine in Mild Alzheimer's Disease Patients (ReCOGNITION); it also lists a completed study entitled The Effect of Neu-P11 on Symptoms in Patients with D-IBS. These studies indicate that Neurim Pharmaceuticals is exploring piromelatine's potential efficacy in myriad conditions, including irritable bowel syndrome and Alzheimer's disease.

\section{Conclusions}

In the last 20 years, preclinical and clinical research on sleep has expanded tremendously. The study of knockout mice for specific receptors has generated novel scientific knowledge of the unique role of each receptor in the regulation of sleep, the application of optogenetics to the study of sleep has elucidated new circuits, and the discovery of clock genes has generated insight into the cellular and molecular mechanisms that regulate sleep homeostasis.

In parallel, clinical studies have investigated how sleep architecture is differentially impaired in various neuropsychiatric diseases (including major depressive disorder, posttraumatic stress disorder, and Alzheimer disease) and the manner in which selective receptors' ligands can improve sleep quality and quantity.

Despite these advancements, BZDs continue to be widely prescribed, although their use, particularly in the elderly, is associated with an increased risk of falls, fractures, and emergency hospitalizations. Most or all BZDs and Z-drugs are available as generic drugs; as such, they are available to providers (private insurance companies, universal governmental health care 
systems) for a very low cost compared with innovative hypnotics (Tannenbaum et al., 2015; Goreveski et al., 2012). Innovative drugs cannot compete with the price of BZDs, discouraging academia and pharmaceutical research companies from investing in sleep medicine. Clinicians resort to prescribing drugs off-label, although these compounds often lack a strong evidence base for their use.

Substantial opportunity remains for pipelines that target the unmet needs in the insomnia market. Medicines with comparable efficacy and improved long-term safety would hold a competitive advantage over current first-line therapies, especially hypnotic without cognitive side-effects or not causing motor impairments the next day. Similarly, drugs that improve sleep quality by augmenting SWS would be viewed favorably by physicians. Moreover, drugs that selectively improve sleep in specific diseases would be also a new avenue for a personalized medicine.

Advancing drug discovery for insomnia and sleep disorders requires that the industry, in collaboration with regulatory authorities, clinical experts, and patient communities, engage in promoting and requiring better treatment of this condition. Moreover, there is a need to better define and agree on the nosology of sleeprelated illnesses: the classifications of patient populations and the types of outcomes, other than sleep parameters, to be monitored among clients. Research into novel hypnotics may bolster the growing conception that sleep disorders are an integral part of, rather than secondary to, diseases such as depression and Alzheimer's (Wafford and Ebert, 2008). Since the burden of insomnia and sleep disorders will likely increase in coming decades due to the aging of the population and the growing use of computer technologies (Fossum et al., 2014), research on novel hypnotics should be considered a priority.

\section{Acknowledgments}

We acknowledge Martina Dick for technical help in Fig. 1.

\section{Authorship Contributions}

Wrote or contributed to the writing of the manuscript: Atkin, Comai, Gobbi.

\section{References}

Adamantidis A, Carter MC, and de Lecea L (2010) Optogenetic deconstruction of sleep-wake circuitry in the brain. Front Mol Neurosci 2:31.

Adams KH, Pinborg LH, Svarer C, Hasselbalch SG, Holm S, Haugbøl S, Madsen K, Frøkjaer V, Martiny L, Paulson OB, et al. (2004) A database of [(18)F]-altanserin binding to $5-\mathrm{HT}(2 \mathrm{~A})$ receptors in normal volunteers: normative data and reAghajanian GK and Sanders-Bush E (2002) Serotonin, in NeuropsychopharmacologyThe Fifth Generation of Progress (Davis KL, Charney D, Coyle JT, and Nemeroff C, eds) pp 15-25, Lippincott Williams \& Wilkins, New York.

Al-Barazanji KA, Wilson S, Baker J, Jessop DS, and Harbuz MS (2001) Central orexin-A activates hypothalamic-pituitary-adrenal axis and stimulates hypothalamic corticotropin releasing factor and arginine vasopressin neurones in conscious rats. J Neuroendocrinol 13:421-424.

Alphapharm (2012) Prescribing information for Endep Amitriptyline Hydrochloride. Alphapharm Pty Limited. Millers Point, Australia.

American Psychiatric Association (2013) Diagnostic and Statistical Manual of Mental Disorders, 5th ed, American Psychiatric Pub., Arlington, VA.

Amzica F and Steriade M (2002) The functional significance of K-complexes. Sleep Med Rev 6:139-149.
Anderson SL and Vande Griend JP (2014) Quetiapine for insomnia: a review of the literature. Am J Health Syst Pharm 71:394-402.

Anttila SA and Leinonen EV (2001) A review of the pharmacological and clinical profile of mirtazapine. CNS Drug Rev 7:249-264.

Arbon EL, Knurowska M, and Dijk DJ (2015) Randomised clinical trial of the effects of prolonged-release melatonin, temazepam and zolpidem on slow-wave activity during sleep in healthy people. $J$ Psychopharmacol 29:764-776.

Ashton H (2005) The diagnosis and management of benzodiazepine dependence. Curr Opin Psychiatry 18:249-255.

Aslan S, Isik E, and Cosar B (2002) The effects of mirtazapine on sleep: a placebo controlled, double-blind study in young healthy volunteers. Sleep 25:677-679.

Banasr M, Soumier A, Hery M, Mocaër E, and Daszuta A (2006) Agomelatine, a new antidepressant, induces regional changes in hippocampal neurogenesis. Biol Psychiatry 59:1087-1096.

Barnes NM and Sharp T (1999) A review of central 5-HT receptors and their function. Neuropharmacology 38:1083-1152.

Bastien CH, LeBlanc M, Carrier J, and Morin CM (2003) Sleep EEG power spectra, insomnia, and chronic use of benzodiazepines. Sleep 26:313-317.

Baune BT, Caliskan S, and Todder D (2007) Effects of adjunctive antidepressant therapy with quetiapine on clinical outcome, quality of sleep and daytime motor activity in patients with treatment-resistant depression. Hum Psychopharmacol 22:1-9.

Bazil CW, Dave J, Cole J, Stalvey J, and Drake E (2012) Pregabalin increases slowwave sleep and may improve attention in patients with partial epilepsy and insomnia. Epilepsy Behav 23:422-425.

Berridge CW and España RA (2000) Synergistic sedative effects of noradrenergic $\alpha(1)$ - and $\beta$-receptor blockade on forebrain electroencephalographic and behavioral indices. Neuroscience 99:495-505.

Berridge CW, Schmeichel BE, and España RA (2012) Noradrenergic modulation of wakefulness/arousal. Sleep Med Rev 16:187-197.

Bertisch SM, Herzig SJ, Winkelman JW, and Buettner C (2014) National use of prescription medications for insomnia: NHANES 1999-2010. Sleep 37:343-349.

Bonaventure P, Shelton J, Yun S, Nepomuceno D, Sutton S, Aluisio L, Fraser I, Lord B, Shoblock J, Welty N, et al. (2015) Characterization of JNJ-42847922, a selective orexin-2 receptor antagonist, as a clinical candidate for the treatment of insomnia. $J$ Pharmacol Exp Ther 354:471-482.

Boutrel B, Franc B, Hen R, Hamon M, and Adrien J (1999) Key role of 5-HT1B receptors in the regulation of paradoxical sleep as evidenced in 5-HT1B knock-out mice. J Neurosci 19:3204-3212.

Boutrel B, Monaca C, Hen R, Hamon M, and Adrien J (2002) Involvement of 5-HT1A receptors in homeostatic and stress-induced adaptive regulations of paradoxical sleep: studies in 5-HT1A knock-out mice. J Neurosci 22:4686-4692.

Brower KJ, Myra Kim H, Strobbe S, Karam-Hage MA, Consens F, and Zucker RA (2008) A randomized double-blind pilot trial of gabapentin versus placebo to treat alcohol dependence and comorbid insomnia. Alcohol Clin Exp Res 32:1429-1438.

Brutcher RE and Nader MA (2015) Effects of quetiapine treatment on cocaine selfadministration and behavioral indices of sleep in adult rhesus monkeys. Psychopharmacology (Berl) 232:411-420.

Buysse DJ, Reynolds CF III, Monk TH, Berman SR, and Kupfer DJ (1989) The Pittsburgh sleep quality index: a new instrument for psychiatric practice and research. Psychiatry Res 28:193-213.

Buysse DJ, Thompson W, Scott J, Franzen PL, Germain A, Hall M, Moul DE, Nofzinger EA, and Kupfer DJ (2007) Daytime symptoms in primary insomnia: a prospective analysis using ecological momentary assessment. Sleep Med 8:198-208.

Bymaster FP, Calligaro DO, Falcone JF, Marsh RD, Moore NA, Tye NC, Seeman P, and Wong DT (1996) Radioreceptor binding profile of the atypical antipsychotic olanzapine. Neuropsychopharmacology 14:87-96.

Calabrese JR, Keck PE Jr, Macfadden W, Minkwitz M, Ketter TA, Weisler RH, Cutler AJ, McCoy R, Wilson E, and Mullen J (2005) A randomized, double-blind, placebo-controlled trial of quetiapine in the treatment of bipolar I or II depression. Am J Psychiatry 162:1351-1360.

Camargos EF, Louzada LL, Quintas JL, Naves JO, Louzada FM, and Nóbrega OT (2014) Trazodone improves sleep parameters in Alzheimer disease patients: a randomized, double-blind, and placebo-controlled study. Am J Geriatr Psychiatry 22:1565-1574.

Cankurtaran ES, Ozalp E, Soygur H, Akbiyik DI, Turhan L, and Alkis N (2008) Mirtazapine improves sleep and lowers anxiety and depression in cancer patients: superiority over imipramine. Support Care Cancer 16:1291-1298.

Cates ME, Jackson CW, Feldman JM, Stimmel AE, and Woolley TW (2009) Metabolic consequences of using low-dose quetiapine for insomnia in psychiatric patients. Community Ment Health J 45:251-254.

Chemelli RM, Willie JT, Sinton CM, Elmquist JK, Scammell T, Lee C, Richardson JA, Williams SC, Xiong Y, Kisanuki Y, et al. (1999) Narcolepsy in orexin knockout mice: molecular genetics of sleep regulation. Cell 98:437-451.

Chou TC, Bjorkum AA, Gaus SE, Lu J, Scammell TE, and Saper CB (2002) Afferents to the ventrolateral preoptic nucleus. J Neurosci 22:977-990.

Citrome L (2014) Suvorexant for insomnia: a systematic review of the efficacy and safety profile for this newly approved hypnotic - what is the number needed to treat, number needed to harm and likelihood to be helped or harmed? Int J Clin Pract 68:1429-1441.

Cohrs S, Rodenbeck A, Guan Z, Pohlmann K, Jordan W, Meier A, and Rüther E (2004) Sleep-promoting properties of quetiapine in healthy subjects. Psychophar macology (Berl) 174:421-429.

Comai S, Ochoa-Sanchez R, Dominguez-Lopez S, Bambico FR, and Gobbi G (2015) Melancholic-like behaviors and circadian neurobiological abnormalities in melatonin MT1 receptor knockout mice. Int $J$ Neuropsychopharmacol 18:pyu075

Comai S, Ochoa-Sanchez R, and Gobbi G (2013) Sleep-wake characterization of double $\mathrm{MT}_{1} / \mathrm{MT}_{2}$ receptor knockout mice and comparison with $\mathrm{MT}_{1}$ and $\mathrm{MT}_{2}$ receptor knockout mice. Behav Brain Res 243:231-238.

Comai S, Tau M, Pavlovic Z, and Gobbi G (2012a) The psychopharmacology of aggressive behavior: a translational approach: part 1: neurobiology. J Clin Psychopharmacol 32:83-94. 
Comai S, Tau M, Pavlovic Z, and Gobbi G (2012b) The psychopharmacology of aggressive behavior: a translational approach: part 2: clinical studies using atypical antipsychotics, anticonvulsants, and lithium. J Clin Psychopharmacol 32:237-260.

Cox CD, Breslin MJ, Whitman DB, Schreier JD, McGaughey GB, Bogusky MJ, Roecker AJ, Mercer SP, Bednar RA, Lemaire W, et al. (2010) Discovery of the dua orexin receptor antagonist [(7R)-4-(5-chloro-1,3-benzoxazol-2-yl)-7-methyl-1,4-diazepan-1-yl][5-methyl-2-(2H-1,2,3-triazol-2-yl)phenyl]methanone (MK-4305) for the treatment of insomnia. J Med Chem 53:5320-5332.

Cunningham LA, Borison RL, Carman JS, Chouinard G, Crowder JE, Diamond BI, Fischer DE, and Hearst E (1994) A comparison of venlafaxine, trazodone, and placebo in major depression. J Clin Psychopharmacol 14:99-106.

Davis RE, Vanover KE, Zhou Y, Brašić JR, Guevara M, Bisuna B, Ye W, Raymont V, Willis W, Kumar A, et al. (2015) ITI-007 demonstrates brain occupancy at serotonin $5-\mathrm{HT}_{2} \mathrm{~A}$ and dopamine $\mathrm{D}_{2}$ receptors and serotonin transporters using positron emission tomography in healthy volunteers. Psychopharmacology (Berl) 232 2863-2872.

De Gennaro L and Ferrara M (2003) Sleep spindles: an overview. Sleep Med Rev 7: $423-440$

de Haas S, Otte A, de Weerd A, van Erp G, Cohen A, and van Gerven J (2007) Exploratory polysomnographic evaluation of pregabalin on sleep disturbance in patients with epilepsy. J Clin Sleep Med 3:473-478.

de Lecea L, Kilduff TS, Peyron C, Gao X, Foye PE, Danielson PE, Fukuhara C, Battenberg EL, Gautvik VT, Bartlett FS II, et al. (1998) The hypocretins hypothalamus-specific peptides with neuroexcitatory activity. Proc Natl Acad Sci USA 95:322-327.

De Sarro GB, Ascioti C, Froio F, Libri V, and Nisticò G (1987) Evidence that locus coeruleus is the site where clonidine and drugs acting at $\alpha 1$ - and $\alpha 2$-adrenoceptors affect sleep and arousal mechanisms. Br J Pharmacol 90:675-685.

Descamps A, Rousset C, Millan MJ, Spedding M, Delagrange P, and Cespuglio R (2009) Influence of the novel antidepressant and melatonin agonist/serotonin2C receptor antagonist, agomelatine, on the rat sleep-wake cycle architecture. Psychopharmacology (Berl) 205:93-106.

DeVane CL and Nemeroff CB (2001) Clinical pharmacokinetics of quetiapine: an atypical antipsychotic. Clin Pharmacokinet 40:509-522.

Dhillon S and Clarke M (2014) Tasimelteon: first global approval. Drugs 74:505-511.

Dolev Z (2011) Case series of perimenopausal women with insomnia treated with mirtazapine followed by prolonged-release melatonin add-on and monotherapy. Arch Women Ment Health 14:269-273.

Dording CM, Mischoulon D, Petersen TJ, Kornbluh R, Gordon J, Nierenberg AA Rosenbaum JE, and Fava M (2002) The pharmacologic management of SSRIinduced side effects: a survey of psychiatrists. Ann Clin Psychiatry 14:143-147.

Dugovic C, Shelton JE, Aluisio LE, Fraser IC, Jiang X, Sutton SW, Bonaventure P, Yun S, Li X, Lord B, et al. (2009) Blockade of orexin-1 receptors attenuates orexin-2 receptor antagonism-induced sleep promotion in the rat. J Pharmacol Exp Ther 330:142-151.

Ekmekcioglu C (2006) Melatonin receptors in humans: biological role and clinical relevance. Biomed Pharmacother 60:97-108.

Endicott J, Paulsson B, Gustafsson U, Schiöler H, and Hassan M (2008) Quetiapine monotherapy in the treatment of depressive episodes of bipolar I and II disorder: improvements in quality of life and quality of sleep. J Affect Disord 111:306-319.

Enomoto T, Yamashita A, Torigoe K, Horiuchi H, Hirayama S, Nakahara K, Yanase M, Sakai H, Ikegami D, Nagase H, et al. (2012) Effects of mirtazapine on sleep disturbance under neuropathic pain-like state. Synapse 66:483-488.

Erman M, Seiden D, Zammit G, Sainati S, and Zhang J (2006) An efficacy, safety, and doseresponse study of Ramelteon in patients with chronic primary insomnia. Sleep Med 7:17-24

España RA and Scammell TE (2011) Sleep neurobiology from a clinical perspective. Sleep 34:845-858.

European Medicines Agency (2008a) CHMP assessment for valdoxan, European Medicines Agency, London.

European Medicines Agency (2008b) Questions and answers on the withdrawal of the marketing application for ramelteon, European Medicines Agency, London.

European Medicines Agency (2016) Annex I: summary of product characteristics for valdoxan, European Medicines Agency, London.

European Medicines Agency (2017) Annex I: summary of product characteristics for circadin, European Medicines Agency, London.

Feeney J, Birznieks G, Scott C, Torres R, Welsch C, Baroldi P, Polymeropoulos M and Walsh J (2009) Melatonin agonist tasimelteon improves sleep in primary insomnia characterized by difficulty falling asleep. Sleep 32:A43.

Ferracioli-Oda E, Qawasmi A, and Bloch MH (2013) Meta-analysis: melatonin for the treatment of primary sleep disorders. PLoS One 8:e63773.

Fisher SP, Davidson K, Kulla A, and Sugden D (2008) Acute sleep-promoting action of the melatonin agonist, ramelteon, in the rat. J Pineal Res 45:125-132.

Foldvary-Schaefer N, De Leon Sanchez I, Karafa M, Mascha E, Dinner D, and Morris HH (2002) Gabapentin increases slow-wave sleep in normal adults. Epilepsia 43:1493-1497.

Ford ES, Wheaton AG, Cunningham TJ, Giles WH, Chapman DP, and Croft JB (2014) Trends in outpatient visits for insomnia, sleep apnea, and prescriptions for sleep medications among US adults: findings from the National Ambulatory Medical Care survey 1999-2010. Sleep 37:1283-1293.

Fortier-Brochu E, Beaulieu-Bonneau S, Ivers H, and Morin CM (2012) Insomnia and daytime cognitive performance: a meta-analysis. Sleep Med Rev 16:83-94.

Fossum IN, Nordnes LT, Storemark SS, Bjorvatn B, and Pallesen S (2014) The association between use of electronic media in bed before going to sleep and in somnia symptoms, daytime sleepiness, morningness, and chronotype. Behav Sleep Med 12:343-357.

Foy A, O'Connell D, Henry D, Kelly J, Cocking S, and Halliday J (1995) Benzodiazepine use as a cause of cognitive impairment in elderly hospital inpatients. $J$ Gerontol A Biol Sci Med Sci 50:M99-M106.

Friedmann PD, Rose JS, Swift R, Stout RL, Millman RP, and Stein MD (2008) Trazodone for sleep disturbance after alcohol detoxification: a double-blind, placebo-controlled trial. Alcohol Clin Exp Res 32:1652-1660.
Garakani A, Martinez JM, Marcus S, Weaver J, Rickels K, Fava M, and Hirschowitz $\mathrm{J}$ (2008) A randomized, double-blind, and placebo-controlled trial of quetiapine augmentation of fluoxetine in major depressive disorder. Int Clin Psychopharmacol 23:269-275.

Gee NS, Brown JP, Dissanayake VU, Offord J, Thurlow R, and Woodruff GN (1996 The novel anticonvulsant drug, gabapentin (Neurontin), binds to the alpha2delta subunit of a calcium channel. J Biol Chem 271:5768-5776.

Gillman PK (2007) Tricyclic antidepressant pharmacology and therapeutic drug interactions updated. $\mathrm{Br}$ J Pharmacol 151:737-748.

Giménez S, Clos S, Romero S, Grasa E, Morte A, and Barbanoj MJ (2007) Effects of olanzapine, risperidone and haloperidol on sleep after a single oral morning dose in healthy volunteers. Psychopharmacology (Berl) 190:507-516.

Gobbi G and Blier P (2005) Effect of neurokinin-1 receptor antagonists on serotoninergic, noradrenergic and hippocampal neurons: comparison with antidepressant drugs. Peptides 26:1383-1393.

Gobbi G, Murphy DL, Lesch K, and Blier P (2001) Modifications of the serotonergic system in mice lacking serotonin transporters: an in vivo electrophysiological study. J Pharmacol Exp Ther 296:987-995.

Gondard E, Anaclet C, Akaoka H, Guo R-X, Zhang M, Buda C, Franco P, Kotani H, and Lin J-S (2013) Enhanced histaminergic neurotransmission and sleep-wake alterations, a study in histamine H3-receptor knock-out mice. Neuropsychopharmacology 38:1015-1031.

Gooneratne NS, Gehrman P, Gurubhagavatula I, Al-Shehabi E, Marie E, and Schwab R (2010) Effectiveness of ramelteon for insomnia symptoms in older adults with obstructive sleep apnea: a randomized placebo-controlled pilot study. J Clin Sleep Med 6:572-580.

Gorevski E, Bian B, Kelton CM, Martin Boone JE, and Guo JJ (2012) Utilization, spending, and price trends for benzodiazepines in the US Medicaid program: 19912009. Ann Pharmacother 46:503-12.

Greenblatt DJ, Harmatz JS, and Karim A (2007) Age and gender effects on the pharmacokinetics and pharmacodynamics of ramelteon, a hypnotic agent acting via melatonin receptors MT1 and MT2. J Clin Pharmacol 47:485-496.

Greene RW, Bjorness TE, and Suzuki A (2017) The adenosine-mediated, neuronalglial, homeostatic sleep response. Curr Opin Neurobiol 44:236-242.

Gunja N (2013a) The clinical and forensic toxicology of Z-drugs. J Med Toxicol 9: $155-162$.

Gunja N (2013b) In the Zzz zone: the effects of Z-drugs on human performance and driving. J Med Toxicol 9:163-171.

Haas $\mathrm{H}$ and Panula P (2003) The role of histamine and the tuberomamillary nucleus in the nervous system. Nat Rev Neurosci 4:121-130.

Haffmans PM and Vos MS (1999) The effects of trazodone on sleep disturbances induced by brofaromine. Eur Psychiatry 14:167-171.

Hagan JJ, Leslie RA, Patel S, Evans ML, Wattam TA, Holmes S, Benham CD, Taylor SG, Routledge C, Hemmati P, et al. (1999) Orexin A activates locus coeruleus cell firing and increases arousal in the rat. Proc Natl Acad Sci USA 96:10911-10916. Hamilton M (1960) A rating scale for depression. J Neurol Neurosurg Psychiatry 23:56-62

Hara J, Beuckmann CT, Nambu T, Willie JT, Chemelli RM, Sinton CM, Sugiyama F, Yagami K, Goto K, Yanagisawa M, et al. (2001) Genetic ablation of orexin neurons in mice results in narcolepsy, hypophagia, and obesity. Neuron 30:345-354.

Hartmann E and Cravens J (1973) The effects of long term administration of psychotropic drugs on human sleep. 3. The effects of amitriptyline. Psychopharmacology (Berl) 33:185-202.

Hassani OK, Lee MG, and Jones BE (2009) Melanin-concentrating hormone neurons discharge in a reciprocal manner to orexin neurons across the sleep-wake cycle. Proc Natl Acad Sci USA 106:2418-2422.

Hemmelgarn B, Suissa S, Huang A, Boivin JF, and Pinard G (1997) Benzodiazepine use and the risk of motor vehicle crash in the elderly. JAMA 278:27-31.

Herring WJ, Connor KM, Ivgy-May N, Snyder E, Liu K, Snavely DB, Krystal AD, Walsh JK, Benca RM, Rosenberg R, et al. (2016) Suvorexant in patients with insomnia: results from two 3-month randomized controlled clinical trials. Biol Psychiatry 79:136-148.

Herring WJ, Snyder E, Budd K, Hutzelmann J, Snavely D, Liu K, Lines C, Roth T, and Michelson D (2012) Orexin receptor antagonism for treatment of insomnia: a randomized clinical trial of suvorexant. Neurology 79:2265-2274.

Hindmarch I, Dawson J, and Stanley N (2005) A double-blind study in healthy volunteers to assess the effects on sleep of pregabalin compared with alprazolam and placebo. Sleep 28:187-193.

Hinz R, Bhagwagar Z, Cowen PJ, Cunningham VJ, and Grasby PM (2007) Validation of a tracer kinetic model for the quantification of 5-HT(2A) receptors in human brain with [(11)C]MDL 100,907. J Cereb Blood Flow Metab 27:161-172.

Holsboer-Trachsler E and Prieto R (2013) Effects of pregabalin on sleep in generalized anxiety disorder. Int $J$ Neuropsychopharmacol 16:925-936.

Hoyer D, Dürst T, Fendt M, Jacobson LH, Betschart C, Hintermann S, Behnke D, Cotesta S, Laue G, Ofner S, et al. (2013) Distinct effects of IPSU and suvorexant on mouse sleep architecture. Front Neurosci 7:235.

Huang Z-L, Mochizuki T, Qu W-M, Hong Z-Y, Watanabe T, Urade Y, and Hayaishi O (2006) Altered sleep-wake characteristics and lack of arousal response to H3 receptor antagonist in histamine $\mathrm{H} 1$ receptor knockout mice. Proc Natl Acad Sci USA 103:4687-4692

Huang Z-L, Qu W-M, Eguchi N, Chen J-F, Schwarzschild MA, Fredholm BB, Urade $\mathrm{Y}$, and Hayaishi $\mathrm{O}$ (2005) Adenosine A2A, but not A1, receptors mediate the arousal effect of caffeine. Nat Neurosci 8:858-859.

Iber C, Ancoli-Israel S, Chesson A, and Quan SF (2007) The AASM Manual for the Scoring of Sleep and Associated Events: Rules, Terminology and Technical Specifications. American Academy of Sleep Medicine, Westchester, IL.

Intra-Cellular Therapies (Press release, Jan 13, 2009) Intra-Cellular Therapies An nounces Successful Outcome of a Phase II Clinical Trial with ITI-007 in Patients With Sleep Maintenance Insomnia, Intra-Cellular Therapies, New York.

Jacobson KA and Gao Z-G (2006) Adenosine receptors as therapeutic targets. Nat Rev Drug Discov 5:247-264 
Jakab RL and Goldman-Rakic PS (1998) 5-Hydroxytryptamine2A serotonin receptors in the primate cerebral cortex: possible site of action of hallucinogenic and antipsychotic drugs in pyramidal cell apical dendrites. Proc Natl Acad Sci USA 95: $735-740$

Jakovljević M, Šagud M, and Mihaljević-Peles A (2003) Olanzapine in the treatmentresistant, combat-related PTSD-a series of case reports. Acta Psychiatr Scand 107: 394-396, discussion 396.

James SP and Mendelson WB (2004) The use of trazodone as a hypnotic: a critical review. J Clin Psychiatry 65:752-755.

Johnsa JD and Neville MW (2014) Tasimelteon: a melatonin receptor agonist for non24-hour sleep-wake disorder. Ann Pharmacother 48:1636-1641.

Jones BE (2005) From waking to sleeping: neuronal and chemical substrates. Trends Pharmacol Sci 26:578-586.

Juri C, Chaná P, Tapia J, Kunstmann C, and Parrao T (2005) Quetiapine for insomnia in Parkinson disease: results from an open-label trial. Clin Neuropharmacol 28:185-187.

Karam-Hage M and Brower KJ (2003) Open pilot study of gabapentin versus trazodone to treat insomnia in alcoholic outpatients. Psychiatry Clin Neurosci 57:542-544.

Kasper S, Hajak G, Wulff K, Hoogendijk WJ, Montejo AL, Smeraldi E, Rybakowski JK, Quera-Salva M-A, Wirz-Justice AM, Picarel-Blanchot F, et al. (2010) Efficacy of the novel antidepressant agomelatine on the circadian rest-activity cycle and depressive and anxiety symptoms in patients with major depressive disorder: a randomized, double-blind comparison with sertraline. J Clin Psychiatry 71 $109-120$.

Kato K, Hirai K, Nishiyama K, Uchikawa O, Fukatsu K, Ohkawa S, Kawamata Y, Hinuma S, and Miyamoto M (2005) Neurochemical properties of ramelteon (TAK375), a selective MT1/MT2 receptor agonist. Neuropharmacology 48:301-310.

Kaynak H, Kaynak D, Gözükirmizi E, and Guilleminault C (2004) The effects of trazodone on sleep in patients treated with stimulant antidepressants. Sleep Med 5:15-20.

Keshavan MS, Prasad KM, Montrose DM, Miewald JM, and Kupfer DJ (2007) Sleep quality and architecture in quetiapine, risperidone, or never-treated schizophrenia patients. J Clin Psychopharmacol 27:703-705.

Khazaie H, Rezaie L, Darvishi F, Najafi F, and Avis K (2013) Treatment of paradoxical insomnia with atypical antipsychotic drugs. A comparison of olanzapine and risperidone. Neurosciences 18:64-69.

Khazaie H, Rezaie L, Tahmasian M, and Schwebel DC (2010) Insomnia treatment by olanzapine. Is sleep state misperception a psychotic disorder? Neurosciences 15 110-112.

Kim SW, Shin IS, Kim JM, Kim YC, Kim KS, Kim KM, Yang SJ, and Yoon JS (2008) Effectiveness of mirtazapine for nausea and insomnia in cancer patients with depression. Psychiatry Clin Neurosci 62:75-83.

Kishi T, Matsunaga S, and Iwata N (2015) Suvorexant for primary insomnia: a systematic review and meta-analysis of randomized placebo-controlled trials. PLoS One 10:e0136910.

Kluge M, Schacht A, Himmerich H, Rummel-Kluge C, Wehmeier PM, Dalal M, HinzeSelch D, Kraus T, Dittmann RW, Pollmächer T, et al. (2014) Olanzapine and clozapine differently affect sleep in patients with schizophrenia: results from a double-blind, polysomnographic study and review of the literature. Schizophr Res 152:255-260.

Kohsaka M, Kanemura T, Taniguchi M, Kuwahara H, Mikami A, Kamikawa K, Uno H, Ogawa A, Murasaki M, and Sugita Y (2011) Efficacy and tolerability of ramelteon in a double-blind, placebo-controlled, crossover study in Japanese patients with chronic primary insomnia. Expert Rev Neurother 11:1389-1397.

Krystal AD, Durrence HH, Scharf M, Jochelson P, Rogowski R, Ludington E, and Roth T (2010) Efficacy and safety of doxepin $1 \mathrm{mg}$ and $3 \mathrm{mg}$ in a 12-week sleep laboratory and outpatient trial of elderly subjects with chronic primary insomnia. Sleep 33:1553-1561.

Krystal AD, Lankford A, Durrence HH, Ludington E, Jochelson P, Rogowski R, and Roth T (2011) Efficacy and safety of doxepin 3 and $6 \mathrm{mg}$ in a 35-day sleep laboratory trial in adults with chronic primary insomnia. Sleep 34:1433-1442. Kubota T, Fang J, Meltzer LT, and Krueger JM (2001) Pregabalin enhances nonrapid eye movement sleep. J Pharmacol Exp Ther 299:1095-1105.

Kuriyama A, Honda M, and Hayashino Y (2014) Ramelteon for the treatment of insomnia in adults: a systematic review and meta-analysis. Sleep Med 15:385-392

Lacoste B, Angeloni D, Dominguez-Lopez S, Calderoni S, Mauro A, Fraschini F, Descarries L, and Gobbi G (2015) Anatomical and cellular localization of melatonin MT1 and MT2 receptors in the adult rat brain. J Pineal Res 58:397-417.

Landolt HP and Wehrle R (2009) Antagonism of serotonergic 5-HT2A/2C receptors: mutual improvement of sleep, cognition and mood? Eur J Neurosci 29:1795-1809.

Lankford A, Rogowski R, Essink B, Ludington E, Heith Durrence H, and Roth T (2012) Efficacy and safety of doxepin $6 \mathrm{mg}$ in a four-week outpatient trial of elderly adults with chronic primary insomnia. Sleep Med 13:133-138.

Laudon M, Katz A, Metzger D, Staner L, Pross N, Cornette F, Guichard N, Nir T, and Zisapel N (2012) Tolerability, pharmacokinetic and pharmacodynamic evaluation of multiple ascending doses of Neu-P11 in insomnia patients. Sleep 35:A221.

Lavedan C, Forsberg M, and Gentile AJ (2015) Tasimelteon: a selective and unique receptor binding profile. Neuropharmacology 91:142-147.

Le Bon O, Murphy JR, Staner L, Hoffmann G, Kormoss N, Kentos M, Dupont P, Lion K, Pelc I, and Verbanck P (2003) Double-blind, placebo-controlled study of the efficacy of trazodone in alcohol post-withdrawal syndrome: polysomnographic and clinical evaluations. J Clin Psychopharmacol 23:377-383.

Lee H, Chen R, Lee Y, Yoo S, and Lee C (2009) Essential roles of CKIdelta and CKIepsilon in the mammalian circadian clock. Proc Natl Acad Sci USA 106: 21359-21364.

Lelkes Z, Obál F Jr, Alföldi P, Erdös A, Rubicsek G, and Benedek G (1994) Effects of acute and chronic treatment with trazodone, an antidepressant, on the sleep-wake activity in rats. Pharmacol Res 30:105-115.

Lemoine P, Garfinkel D, Laudon M, Nir T, and Zisapel N (2011) Prolonged-release melatonin for insomnia - an open-label long-term study of efficacy, safety, and withdrawal. Ther Clin Risk Manag 7:301-311.
Lemoine P, Nir T, Laudon M, and Zisapel N (2007) Prolonged-release melatonin improves sleep quality and morning alertness in insomnia patients aged 55 years and older and has no withdrawal effects. J Sleep Res 16:372-380.

Lemoine P and Zisapel N (2012) Prolonged-release formulation of melatonin (Circadin) for the treatment of insomnia. Expert Opin Pharmacother 13:895-905.

Lin L, Faraco J, Li R, Kadotani H, Rogers W, Lin X, Qiu X, de Jong PJ, Nishino S, and Mignot $\mathrm{E}$ (1999) The sleep disorder canine narcolepsy is caused by a mutation in the hypocretin (orexin) receptor 2 gene. Cell 98:365-376.

Liu $J$ and Wang LN (2012) Ramelteon in the treatment of chronic insomnia: systematic review and meta-analysis. Int $J$ Clin Pract 66:867-873.

Liu Y-Y, Yin D, Chen L, Qu W-M, Chen C-R, Laudon M, Cheng N-N, Urade Y, and Huang Z-L (2014) Piromelatine exerts antinociceptive effect via melatonin opioid, and 5HT1A receptors and hypnotic effect via melatonin receptors in a mouse model of neuropathic pain. Psychopharmacology (Berl) 231:3973-3985.

Lo H-S, Yang C-M, Lo HG, Lee C-Y, Ting H, and Tzang B-S (2010) Treatment effects of gabapentin for primary insomnia. Clin Neuropharmacol 33:84-90.

Lockley SW, Dressman MA, Licamele L, Xiao C, Fisher DM, Flynn-Evans EE, Hull JT, Torres R, Lavedan C, and Polymeropoulos MH (2015) Tasimelteon for non-24hour sleep-wake disorder in totally blind people (SET and RESET): two multicentre, randomised, double-masked, placebo-controlled phase 3 trials. Lancet 386 : $1754-1764$

López-Giménez JF, Mengod G, Palacios JM, and Vilaró MT (2001) Regional distribution and cellular localization of 5-HT2C receptor mRNA in monkey brain comparison with $[3 \mathrm{H}]$ mesulergine binding sites and choline acetyltransferase mRNA. Synapse 42:12-26.

Lovenberg TW, Roland BL, Wilson SJ, Jiang X, Pyati J, Huvar A, Jackson MR, and Erlander MG (1999) Cloning and functional expression of the human histamine H3 receptor. Mol Pharmacol 55:1101-1107.

Lugoboni F, Mirijello A, Faccini M, Casari R, Cossari A, Musi G, Bissoli G, Quaglio G, and Addolorato G (2014) Quality of life in a cohort of high-dose benzodiazepine dependent patients. Drug Alcohol Depend 142:105-109.

Luppi P-H, Peyron C, and Fort P (2017) Not a single but multiple populations of GABAergic neurons control sleep. Sleep Med Rev 32:85-94.

Luthringer R, Muzet M, Zisapel N, and Staner L (2009) The effect of prolongedrelease melatonin on sleep measures and psychomotor performance in elderly patients with insomnia. Int Clin Psychopharmacol 24:239-249.

Mäkelä JP and Hilakivi IT (1986) Effect of alpha-adrenoceptor blockade on sleep and wakefulness in the rat. Pharmacol Biochem Behav 24:613-616.

Mander BA, Winer JR, and Walker MP (2017) Sleep and human aging. Neuron 94:19-36

Manns ID, Lee MG, Modirrousta M, Hou YP, and Jones BE (2003) Alpha 2 adrenergic receptors on GABAergic, putative sleep-promoting basal forebrain neurons. Eur $J$ Neurosci 18:723-727.

Marek GJ (2010) Electrophysiology of serotonin receptors, in Handbook of Behavioral Neurobiology of Serotonin (C. Müller and B. Jacobs eds) vol. 21, pp 163-182, Elsevier, London.

Mayer G, Wang-Weigand S, Roth-Schechter B, Lehmann R, Staner C, and Partinen M (2009) Efficacy and safety of 6-month nightly ramelteon administration in adults with chronic primary insomnia. Sleep 32:351-360.

McAllister-Williams RH, Baldwin DS, Haddad PM, and Bazire S (2010) The use of antidepressants in clinical practice: focus on agomelatine. Hum Psychopharmacol 25:95-102.

McCall WV (2010) Off-label use of prescription medications for insomnia: sedating antidepressants, antipsychotics, anxiolytics, and anticonvulsants, in Insomnia: Diagnosis and Treatment (Sateia MJ and Buysse DJ, eds) p 397, Informa UK Ltd. McElroy SL, Weisler RH, Chang W, Olausson B, Paulsson B, Brecher M, Agambaram V, Merideth C, Nordenhem A, and Young AH; EMBOLDEN II (Trial D1447C00134) Investigators (2010) A double-blind, placebo-controlled study of quetiapine and paroxetine as monotherapy in adults with bipolar depression (EMBOLDEN II). J Clin Psychiatry 71:163-174

McElroy SL, Winstanley EL, Martens B, Patel NC, Mori N, Moeller D, McCoy J, and Keck PE Jr (2011) A randomized, placebo-controlled study of adjunctive ramelteon in ambulatory bipolar I disorder with manic symptoms and sleep disturbance. Int Clin Psychopharmacol 26:48-53.

Mendelson WB (2005) A review of the evidence for the efficacy and safety of trazodone in insomnia. J Clin Psychiatry 66:469-476.

Mendlewicz J, Kempenaers C, and de Maertelaer V (1991) Sleep EEG and amitryptiline treatment in depressed inpatients. Biol Psychiatry 30:691-702.

Mets MA, de Vries JM, de Senerpont Domis LM, Volkerts ER, Olivier B, and Verster JC (2011) Next-day effects of ramelteon $(8 \mathrm{mg})$, zopiclone $(7.5 \mathrm{mg})$, and placebo on highway driving performance, memory functioning, psychomotor performance, and mood in healthy adult subjects. Sleep 34:1327-1334.

Michelson D, Snyder E, Paradis E, Chengan-Liu M, Snavely DB, Hutzelmann J, Walsh JK, Krystal AD, Benca RM, Cohn M, et al. (2014) Safety and efficacy of suvorexant during 1-year treatment of insomnia with subsequent abrupt treatment discontinuation: a phase 3 randomised, double-blind, placebo-controlled trial. Lancet Neurol 13:461-471.

Mieda M, Hasegawa E, Kisanuki YY, Sinton CM, Yanagisawa M, and Sakurai T (2011) Differential roles of orexin receptor-1 and -2 in the regulation of non-REM and REM sleep. J Neurosci 31:6518-6526.

Millan MJ, Gobert A, Lejeune F, Dekeyne A, Newman-Tancredi A, Pasteau V, Rivet $\mathrm{J}-\mathrm{M}$, and Cussac D (2003) The novel melatonin agonist agomelatine (S20098) is an antagonist at 5-hydroxytryptamine $2 \mathrm{C}$ receptors, blockade of which enhances the activity of frontocortical dopaminergic and adrenergic pathways. J Pharmacol Exp Ther 306:954-964.

Miyamoto M, Nishikawa H, Doken Y, Hirai K, Uchikawa O, and Ohkawa S (2004) The sleep-promoting action of ramelteon (TAK-375) in freely moving cats. Sleep $\mathbf{2 7}$ $1319-1325$

Montgomery SA, Herman BK, Schweizer E, and Mandel FS (2009) The efficacy of pregabalin and benzodiazepines in generalized anxiety disorder presenting with high levels of insomnia. Int Clin Psychopharmacol 24:214-222. 
Monti JM and Jantos H (1992) Dose-dependent effects of the 5-HT1A receptor agonist 8-OH-DPAT on sleep and wakefulness in the rat. J Sleep Res 1:169-175.

Monti JM and Monti D (2007) The involvement of dopamine in the modulation of sleep and waking. Sleep Med Rev 11:113-133.

Morin CM and Jarrin DC (2013) Epidemiology of insomnia : prevalence, course, risk factors, and public health burden. Sleep Med Clin 8:281-297.

Mouret J, Lemoine P, Minuit MP, Benkelfat C, and Renardet M (1988) Effects of trazodone on the sleep of depressed subjects-a polygraphic study. Psychopharmacology (Berl) 95 (Suppl):S37-S43.

Nakamura T, Uramura K, Nambu T, Yada T, Goto K, Yanagisawa M, and Sakurai T (2000) Orexin-induced hyperlocomotion and stereotypy are mediated by the dopaminergic system. Brain Res 873:181-187.

Neurim Pharmaceuticals (Tel-Aviv, Israel) (Press release Feb 18 2013) Neurim Pharmaceuticals announces positive Phase 2 clinical trial results of Piromelatine for the treatment of insomnia, Neurim Pharmaceuticals, Tel-Aviv, Israel.

Nierenberg AA, Adler LA, Peselow E, Zornberg G, and Rosenthal M (1994) Trazodone for antidepressant-associated insomnia. Am J Psychiatry 151:1069-1072.

Nierenberg AA, Husain MM, Trivedi MH, Fava M, Warden D, Wisniewski SR, Miyahara S, and Rush AJ (2010) Residual symptoms after remission of major depressive disorder with citalopram and risk of relapse: a STAR*D report. Psychol Med 40:41-50.

Nilsen OG and Dale O (1992) Single dose pharmacokinetics of trazodone in healthy subjects. Pharmacol Toxicol 71:150-153.

Nilsen OG, Dale O, and Husebø B (1993) Pharmacokinetics of trazodone during multiple dosing to psychiatric patients. Pharmacol Toxicol 72:286-289.

Nishiyama K, Nishikawa H, Kato K, Miyamoto M, Tsukamoto T, and Hirai K (2014) Pharmacological characterization of M-II, the major human metabolite of ramelteon. Pharmacology 93:197-201.

Nollet M, Gaillard P, Minier F, Tanti A, Belzung C, and Leman S (2011) Activation of orexin neurons in dorsomedial/perifornical hypothalamus and antidepressant reversal in a rodent model of depression. Neuropharmacology 61:336-346.

Nutt DJ and Stahl SM (2010) Searching for perfect sleep: the continuing evolution of GABAA receptor modulators as hypnotics. J Psychopharmacol 24:1601-1612.

Ochoa-Sanchez R, Comai S, Lacoste B, Bambico FR, Dominguez-Lopez S, Spadoni G, Rivara S, Bedini A, Angeloni D, Fraschini F, et al. (2011) Promotion of non-rapid eye movement sleep and activation of reticular thalamic neurons by a novel MT2 melatonin receptor ligand. J Neurosci 31:18439-18452

Ochoa-Sanchez R, Comai S, Spadoni G, Bedini A, Tarzia G, and Gobbi G (2014) Melatonin, selective and non-selective MT1/MT2 receptors agonists: differential effects on the 24-h vigilance states. Neurosci Lett 561:156-161.

Oda T, Morikawa N, Saito Y, Masuho Y, and Matsumoto S (2000) Molecular cloning and characterization of a novel type of histamine receptor preferentially expressed in leukocytes. $J$ Biol Chem 275:36781-36786.

Odagaki Y, Toyoshima R, and Yamauchi T (2005) Trazodone and its active metabolite $\mathrm{m}$-chlorophenylpiperazine as partial agonists at 5-HT1A receptors assessed by [35S]GTPgammaS binding. J Psychopharmacol 19:235-241.

Ohayon MM (2002) Epidemiology of insomnia: what we know and what we still need to learn. Sleep Med Rev 6:97-111.

Olsen RW and Sieghart W (2009) GABA A receptors: subtypes provide diversity of function and pharmacology. Neuropharmacology 56:141-148.

Otmani S, Demazières A, Staner C, Jacob N, Nir T, Zisapel N, and Staner L (2008) Effects of prolonged-release melatonin, zolpidem, and their combination on psychomotor functions, memory recall, and driving skills in healthy middle aged and elderly volunteers. Hum Psychopharmacol 23:693-705.

Pasquini M, Speca A, and Biondi M (2009) Quetiapine for tamoxifen-induced insomnia in women with breast cancer. Psychosomatics 50:159-161.

Passani MB and Blandina P (2011) Histamine receptors in the CNS as targets for therapeutic intervention. Trends Pharmacol Sci 32:242-249.

Paus S, Brecht HM, Köster J, Seeger G, Klockgether T, and Wüllner U (2003) Sleep attacks, daytime sleepiness, and dopamine agonists in Parkinson's disease. Mov Disord 18:659-667.

Perez DI, Gil C, and Martinez A (2011) Protein kinases CK1 and CK2 as new targets for neurodegenerative diseases. Med Res Rev 31:924-954

Pompeiano M, Palacios JM, and Mengod G (1994) Distribution of the serotonin 5-HT2 receptor family mRNAs: comparison between 5 -HT2A and 5-HT2C receptors. Brain Res Mol Brain Res 23:163-178.

Popa D, Léna C, Fabre V, Prenat C, Gingrich J, Escourrou P, Hamon M, and Adrien J (2005) Contribution of 5-HT2 receptor subtypes to sleep-wakefulness and respiratory control, and functional adaptations in knock-out mice lacking 5-HT2A receptors. J Neurosci 25:11231-11238.

Portaluppi F, Cortelli P, Avoni P, Vergnani L, Maltoni P, Pavani A, Sforza E, Degli Uberti EC, Gambetti P, and Lugaresi E (1994) Progressive disruption of the circadian rhythm of melatonin in fatal familial insomnia. J Clin Endocrinol Metab $\mathbf{7 8}$ 1075-1078.

Portas CM, Thakkar M, Rainnie D, and McCarley RW (1996) Microdialysis perfusion of 8-hydroxy-2-(di-n-propylamino)tetralin (8-OH-DPAT) in the dorsal raphe nucleus decreases serotonin release and increases rapid eye movement sleep in the freely moving cat. J Neurosci 16:2820-2828.

Pringsheim T and Gardner DM (2014) Dispensed prescriptions for quetiapine and other second-generation antipsychotics in Canada from 2005 to 2012: a descriptive study. CMAJ Open 2:E225-E232.

Purves D, Augustine GJ, Fitzpatrick D, Hall WC, Lamantia A-S, McNamara JO, and Williams SM (2004) Neuroscience, Sinauer Associates Inc, Sunderland, MA

Qu W-M, Xu X-H, Yan M-M, Wang Y-Q, Urade Y, and Huang Z-L (2010) Essential role of dopamine D2 receptor in the maintenance of wakefulness, but not in homeostatic regulation of sleep, in mice. J Neurosci 30:4382-4389.

Quera-Salva M-A, Hajak G, Philip P, Montplaisir J, Keufer-Le Gall S, Laredo J, and Guilleminault C (2011) Comparison of agomelatine and escitalopram on nighttime sleep and daytime condition and efficacy in major depressive disorder patients. Int Clin Psychopharmacol 26:252-262.
Quera-Salva MA, Lemoine P, and Guilleminault C (2010) Impact of the novel antidepressant agomelatine on disturbed sleep-wake cycles in depressed patients. Hum Psychopharmacol 25:222-229.

Rajaratnam SM, Polymeropoulos MH, Fisher DM, Roth T, Scott C, Birznieks G, and Klerman EB (2009) Melatonin agonist tasimelteon (VEC-162) for transient insomnia after sleep-time shift: two randomised controlled multicentre trials. Lancet 373:482-491.

Rechtschaffen A and Kales A (1968) A Manual of Standardized Terminology, Techniques, and Scoring Systems for Sleep Stages of Human Subjects, UCLA Brain Information Service/Brain Research Institute, Los Angeles.

Richelson E (1979) Tricyclic antidepressants and histamine H1 receptors. Mayo Clin Proc 54:669-674.

Richelson E and Souder T (2000) Binding of antipsychotic drugs to human brain receptors focus on newer generation compounds. Life Sci 68:29-39.

Richer M, Hen R, and Blier P (2002) Modification of serotonin neuron properties in mice lacking 5-HT1A receptors. Eur J Pharmacol 435:195-203.

Rivara S, Vacondio F, Fioni A, Silva C, Carmi C, Mor M, Lucini V, Pannacci M, Caronno A, Scaglione F, et al. (2009) N-(Anilinoethyl)amides: design and synthesis of metabolically stable, selective melatonin receptor ligands. ChemMedChem 4: 1746-1755.

Robert S, Hamner MB, Kose S, Ulmer HG, Deitsch SE, and Lorberbaum JP (2005) Quetiapine improves sleep disturbances in combat veterans with PTSD: sleep data from a prospective, open-label study. J Clin Psychopharmacol 25:387-388.

Robinson AA and Malow BA (2013) Gabapentin shows promise in treating refractory insomnia in children. $J$ Child Neurol 28:1618-1621.

Rodríguez JJ, Noristani HN, Hoover WB, Linley SB, and Vertes RP (2011) Serotonergic projections and serotonin receptor expression in the reticular nucleus of the thalamus in the rat. Synapse 65:919-928.

Rosenberg RP, Hull SG, Lankford DA, Mayleben DW, Seiden DJ, Furey SA, Jayawardena S, and Roth T (2014) A randomized, double-blind, single-dose, placebocontrolled, multicenter, polysomnographic study of gabapentin in transient insomnia induced by sleep phase advance. J Clin Sleep Med 10:1093-1100.

Roth T, Heith Durrence H, Jochelson P, Peterson G, Ludington E, Rogowski R, Scharf $\mathrm{M}$, and Lankford A (2010) Efficacy and safety of doxepin $6 \mathrm{mg}$ in a model of transient insomnia. Sleep Med 11:843-847.

Roth T, Rogowski R, Hull S, Schwartz H, Koshorek G, Corser B, Seiden D, and Lankford A (2007) Efficacy and safety of doxepin $1 \mathrm{mg}, 3 \mathrm{mg}$, and $6 \mathrm{mg}$ in adults with primary insomnia. Sleep 30:1555-1561.

Roth T, Seiden D, Sainati S, Wang-Weigand S, Zhang J, and Zee P (2006) Effects of ramelteon on patient-reported sleep latency in older adults with chronic insomnia. Sleep Med 7:312-318.

Rotzinger S, Fang J, and Baker GB (1998) Trazodone is metabolized to m-chlorophenylpiperazine by CYP3A4 from human sources. Drug Metab Dispos 26 $572-575$.

Rudorfer MV and Potter WZ (1999) Metabolism of tricyclic antidepressants. Cell Mol Neurobiol 19:373-409.

Russell IJ, Crofford LJ, Leon T, Cappelleri JC, Bushmakin AG, Whalen E, Barrett JA, and Sadosky A (2009) The effects of pregabalin on sleep disturbance symptoms among individuals with fibromyalgia syndrome. Sleep Med 10:604-610.

Šagud M, Mihaljević-Peles A, Mück-Seler D, Jakovljević M, and Pivac N (2006) Quetiapine augmentation in treatment-resistant depression: a naturalistic study. Psychopharmacology (Berl) 187:511-514.

Sakai K (2011) Sleep-waking discharge profiles of median preoptic and surrounding neurons in mice. Neuroscience 182:144-161.

Sakurai T, Amemiya A, Ishii M, Matsuzaki I, Chemelli RM, Tanaka H, Williams SC, Richardson JA, Kozlowski GP, Wilson S, et al. (1998) Orexins and orexin receptors: a family of hypothalamic neuropeptides and $\mathrm{G}$ protein-coupled receptors that regulate feeding behavior. Cell 92:573-585.

Salin-Pascual RJ, Herrera-Estrella M, Galicia-Polo L, and Laurrabaquio MR (1999) Olanzapine acute administration in schizophrenic patients increases delta sleep and sleep efficiency. Biol Psychiatry 46:141-143.

Sanger DJ (2004) The pharmacology and mechanisms of action of new generation, non-benzodiazepine hypnotic agents. CNS Drugs 18 (Suppl 1):9-15; discussion 41, $43-15$.

Sansone RA and Sansone LA (2011) Agomelatine: a novel antidepressant. Innov Clin Neurosci 8:10-14.

Saper CB, Chou TC, and Scammell TE (2001) The sleep switch: hypothalamic control of sleep and wakefulness. Trends Neurosci 24:726-731.

Sateia MJ, Buysse DJ, Krystal AD, Neubauer DN, and Heald JL (2017a) Clinical practice guideline for the pharmacologic treatment of chronic insomnia in adults: an American Academy of Sleep Medicine clinical practice guideline. J Clin Sleep Med 13:307-349.

Sateia MJ, Sherrill WC Jr, Winter-Rosenberg C, and Heald JL (2017b) Payer perspective of the American Academy of Sleep Medicine clinical practice guideline for the pharmacologic treatment of chronic insomnia. J Clin Sleep Med 13:155-157.

Scammell TE, Arrigoni E, and Lipton JO (2017) Neural circuitry of wakefulness and sleep. Neuron 93:747-765.

Scharf M, Rogowski R, Hull S, Cohn M, Mayleben D, Feldman N, Ereshefsky L, Lankford A, and Roth T (2008a) Efficacy and safety of doxepin $1 \mathrm{mg}, 3 \mathrm{mg}$, and $6 \mathrm{mg}$ in elderly patients with primary insomnia: a randomized, double-blind, placebo-controlled crossover study. J Clin Psychiatry 69:1557-1564.

Scharf MB and Sachais BA (1990) Sleep laboratory evaluation of the effects and efficacy of trazodone in depressed insomniac patients. J Clin Psychiatry 51 (Suppl):13-17.

Schatzberg AF and Nemeroff CB (2009) The American Psychiatric Publishing Textbook of Psychopharmacology, American Psychiatric Pub, Washington, DC.

Schlicker E, Malinowska B, Kathmann M, and Göthert M (1994) Modulation of neurotransmitter release via histamine H3 heteroreceptors. Fundam Clin Phar macol 8:128-137.

Schmitt KC and Reith ME (2010) Regulation of the dopamine transporter: aspects relevant to psychostimulant drugs of abuse. Ann N Y Acad Sci 1187:316-340. 
Schutte-Rodin S, Broch L, Buysse D, Dorsey C, and Sateia M (2008) Clinical guideline for the evaluation and management of chronic insomnia in adults. J Clin Sleep Med 4:487-504.

Sharpley AL, Elliott JM, Attenburrow M-J, and Cowen PJ (1994) Slow wave sleep in humans: role of 5-HT2A and 5-HT2C receptors. Neuropharmacology 33:467-471.

Sharpley AL, Vassallo CM, and Cowen PJ (2000) Olanzapine increases slow-wave sleep: evidence for blockade of central 5-HT(2C) receptors in vivo. Biol Psychiatry 47:468-470.

Sills GJ (2006) The mechanisms of action of gabapentin and pregabalin. Curr Opin Pharmacol 6:108-113.

Smith MT and Wegener ST (2003) Measures of sleep: the insomnia severity index, medical outcomes study (MOS) sleep scale, Pittsburgh sleep diary (PSD), and Pittsburgh sleep quality index (PSQI). Arthritis Care Res 49:S184-S196.

Snyder GL, Vanover KE, Zhu H, Miller DB, O'Callaghan JP, Tomesch J, Li P, Zhang Q, Krishnan V, Hendrick JP, et al. (2015) Functional profile of a novel modulator of serotonin, dopamine, and glutamate neurotransmission. Psychopharmacology (Berl) 232:605-621.

Soldatos CR, Dikeos DG, and Whitehead A (1999) Tolerance and rebound insomnia with rapidly eliminated hypnotics: a meta-analysis of sleep laboratory studies. Int Clin Psychopharmacol 14:287-303.

Song L, Du Q, Jiang X, and Wang L (2014) Effect of CYP1A2 polymorphism on the pharmacokinetics of agomelatine in Chinese healthy male volunteers. J Clin Pharm Ther 39:204-209.

Springer Adis Insight (2017) Atagabalin, Adis Insight Drug Profiles Database.

Srisurapanont M and Jarusuraisin N (1998) Amitriptyline vs. lorazepam in the treatment of opiate-withdrawal insomnia: a randomized double-blind study. Acta Psychiatr Scand 97:233-235.

Stahl S (2008) Stahl's Essential Psychopharmacology, Neuroscientific Basis and Practical Applications, Applications, 3rd ed. Cambridge University Press, NY.

Stahl SM (2009) Mechanism of action of trazodone: a multifunctional drug. CNS Spectr 14:536-546.

Stein MD, Kurth ME, Sharkey KM, Anderson BJ, Corso RP, and Millman RP (2012) Trazodone for sleep disturbance during methadone maintenance: a double-blind, placebo-controlled trial. Drug Alcohol Depend 120:65-73.

Stenberg D, Litonius E, Halldner L, Johansson B, Fredholm BB, and Porkka-Heiskanen T (2003) Sleep and its homeostatic regulation in mice lacking the adenosine A1 receptor. J Sleep Res 12:283-290.

Steriade M, Contreras D, Curró Dossi R, and Nuñez A (1993) The slow $(<1 \mathrm{~Hz})$ oscillation in reticular thalamic and thalamocortical neurons: scenario of sleep rhythm generation in interacting thalamic and neocortical networks. $J$ Neurosci 13:3284-3299.

Steriade M and Timofeev I (2003) Neuronal plasticity in thalamocortical networks during sleep and waking oscillations. Neuron 37:563-576.

Sun H, Kennedy WP, Wilbraham D, Lewis N, Calder N, Li X, Ma J, Yee KL, Ermlich S, Mangin E, et al. (2013) Effects of suvorexant, an orexin receptor antagonist, on sleep parameters as measured by polysomnography in healthy men. Sleep 36:259-267.

Szabo ST and Blier P (2001) Functional and pharmacological characterization of the modulatory role of serotonin on the firing activity of locus coeruleus norepinephrine neurons. Brain Res 922:9-20.

Takahashi K, Suwa H, Ishikawa T, and Kotani H (2002) Targeted disruption of H3 receptors results in changes in brain histamine tone leading to an obese phenotype. $J$ Clin Invest 110:1791-1799.

Takeda Global Research \& Development Center Inc. (2008) Clinical Trial Synopsis 01-05-TL-375-067, NCT\#00755495.

Takemura Y, Yamashita A, Horiuchi H, Furuya M, Yanase M, Niikura K, Imai S, Hatakeyama N, Kinoshita H, Tsukiyama Y, et al. (2011) Effects of gabapentin on brain hyperactivity related to pain and sleep disturbance under a neuropathic pain-like state using fMRI and brain wave analysis. Synapse 65:668-676.

Tannenbaum C, Diaby V, Singh D, Perreault S, Luc M, and Vasiliadis HM (2015) Sedative-hypnotic medicines and falls in community-dwelling older adults: a costeffectiveness (decision-tree) analysis from a US Medicare perspective. Drugs Aging 32:305-314.

Tassniyom K, Paholpak S, Tassniyom S, and Kiewyoo J (2010) Quetiapine for primary insomnia: a double blind, randomized controlled trial. J Med Assoc Thai 93: $729-734$

Tatsumi M, Groshan K, Blakely RD, and Richelson E (1997) Pharmacological profile of antidepressants and related compounds at human monoamine transporters. Eur $J$ Pharmacol 340:249-258.

Taylor CP (1997) Mechanisms of action of gabapentin. Rev Neurol (Paris) 153 (Suppl 1):S39-S45.

Taylor CP, Angelotti T, and Fauman E (2007) Pharmacology and mechanism of action of pregabalin: the calcium channel alpha2-delta (alpha2-delta) subunit as a target for antiepileptic drug discovery. Epilepsy Res 73:137-150.

Terán A, Majadas S, and Galan J (2008) Quetiapine in the treatment of sleep disturbances associated with addictive conditions: a retrospective study. Subst Use Misuse 43:2169-2171.

Theobald DE, Kirsh KL, Holtsclaw E, Donaghy K, and Passik SD (2002) An openlabel, crossover trial of mirtazapine $(15$ and $30 \mathrm{mg})$ in cancer patients with pain and other distressing symptoms. J Pain Symptom Manage 23:442-447.

Thomas RE (1998) Benzodiazepine use and motor vehicle accidents. Systematic review of reported association. Can Fam Physician 44:799-808.

Thompson W, Quay TAW, Rojas-Fernandez C, Farrell B, and Bjerre LM (2016) Atypical antipsychotics for insomnia: a systematic review. Sleep Med 22:13-17.

Todder D, Caliskan S, and Baune BT (2006) Night locomotor activity and quality of sleep in quetiapine-treated patients with depression. J Clin Psychopharmacol 26: 638-642.

Tsunematsu T, Ueno T, Tabuchi S, Inutsuka A, Tanaka KF, Hasuwa H, Kilduff TS, Terao A, and Yamanaka A (2014) Optogenetic manipulation of activity and temporally controlled cell-specific ablation reveal a role for $\mathrm{MCH}$ neurons in sleep/ wake regulation. $J$ Neurosci 34:6896-6909.
Uchimura N, Ogawa A, Hamamura M, Hashimoto T, Nagata H, and Uchiyama M (2011) Efficacy and safety of ramelteon in Japanese adults with chronic insomnia: a randomized, double-blind, placebo-controlled study. Expert Rev Neurother 11: $215-224$

Uchiyama M, Hamamura M, Kuwano T, Nishiyama H, Nagata H, and Uchimura N (2011) Evaluation of subjective efficacy and safety of ramelteon in Japanese subjects with chronic insomnia. Sleep Med 12:119-126.

Urade Y, Eguchi N, Qu W-M, Sakata M, Huang Z-L, Chen J-F, Schwarzschild MA, Fink JS, and Hayaishi O (2003) Sleep regulation in adenosine A2A receptordeficient mice. Neurology 61 (11, Suppl 6)S94-S96.

US FDA (2007a) Doxepin Prescribing Information. United States Food and Drug Administration, Washington, DC.

US FDA (2007b) Remeron Prescribing Information. United States Food and Drug Administration, Washington, DC

US FDA (2009) Zyprexa Prescribing Information. United States Food and Drug Administration, Washington, DC

US FDA (2010a) Rozerem Prescribing Information. United States Food and Drug Administration, Washington, DC.

US FDA (2010b) Silenor Prescribing Information. United States Food and Drug Administration, Washington, DC

US FDA (2014a) Belsomra Prescribing Information. United States Food and Drug Administration, Washington, DC

US FDA (2014b) Hetlioz Prescribing Information. United States Food and Drug Administration, Washington, DC

US FDA (2014c) Neurontin Prescribing Information. United States Food and Drug Administration, Washington, DC

US FDA (2016) Lyrica Prescribing Information. United States Food and Drug Administration, Washington, DC.

US FDA (2017) Seroquel Prescribing Information. United States Food and Drug Administration, Washington, DC

Vaishnavi SN, Nemeroff CB, Plott SJ, Rao SG, Kranzler J, and Owens MJ (2004) Milnacipran: a comparative analysis of human monoamine uptake and transporter binding affinity. Biol Psychiatry 55:320-322.

van Dyck CH, Tan PZ, Baldwin RM, Amici LA, Garg PK, Ng CK, Soufer R, Charney DS, and Innis RB (2000) PET quantification of 5-HT2A receptors in the human brain: a constant infusion paradigm with [18F] altanserin. J Nucl Med 41:234-241.

Vanda Pharmaceuticals Inc. (Press release, June 26, 2008) Phase III data show Vanda Pharmaceuticals' tasimelteon (VEC-162) significantly improves sleep in patients with chronic insomnia, Vanda Pharmaceuticals, Rockville, MD

Vanda Pharmaceuticals Inc. (2014) VEC-162 Study in Adult Patients With Primary Insomnia National Library of Medicine, ClinicalTrials.gov.

Viola AU, Brandenberger G, Toussaint M, Bouhours P, Paul Macher J, and Luthringer R (2002) Ritanserin, a serotonin-2 receptor antagonist, improves ultradian sleep rhythmicity in young poor sleepers. Clin Neurophysiol 113: 429-434.

Wade AG, Farmer M, Harari G, Fund N, Laudon M, Nir T, Frydman-Marom A, and Zisapel N (2014) Add-on prolonged-release melatonin for cognitive function and sleep in mild to moderate Alzheimer's disease: a 6-month, randomized, placebo-controlled, multicenter trial. Clin Interv Aging 9:947-961.

Wade AG, Ford I, Crawford G, McConnachie A, Nir T, Laudon M, and Zisapel N (2010) Nightly treatment of primary insomnia with prolonged release melatonin for 6 months: a randomized placebo controlled trial on age and endogenous melatonin as predictors of efficacy and safety. BMC Med 8:51

Wade AG, Ford I, Crawford G, McMahon AD, Nir T, Laudon M, and Zisapel N (2007) Efficacy of prolonged release melatonin in insomnia patients aged 55-80 years: quality of sleep and next-day alertness outcomes. Curr Med Res Opin 23: $2597-2605$.

Wafford KA and Ebert B (2008) Emerging anti-insomnia drugs: tackling sleeplessness and the quality of wake time. Nat Rev Drug Discov 7:530-540.

Walsh JK (2004) Drugs used to treat insomnia in 2002: regulatory-based rather than evidence-based medicine. Sleep 27:1441-1442.

Walsh JK, Erman M, Erwin C, Jamieson A, Mahowald M, Regestein Q, Scharf M, Tigel P, Vogel G, and Ware JC (1998) Subjective hypnotic efficacy of trazodone and zolpidem in DSMIII-R primary insomnia. Hum Psychopharmacol 13:191-198.

Wang-Weigand S, Watissée M, and Roth T (2011) Use of a post-sleep questionnaireinteractive voice response system (PSQ-IVRS) to evaluate the subjective sleep ef fects of ramelteon in adults with chronic insomnia. Sleep Med 12:920-923.

Wang T-X, Yin D, Guo W, Liu Y-Y, Li Y-D, Qu W-M, Han W-J, Hong Z-Y, and Huang Z-L (2015) Antinociceptive and hypnotic activities of pregabalin in a neuropathic pain-like model in mice. Pharmacol Biochem Behav 135:31-39.

Ware JC, Rose FV, and McBrayer RH (1994) The acute effects of nefazodone, trazodone and buspirone on sleep and sleep-related penile tumescence in normal subjects. Sleep 17:544-550.

What's wrong with prescribing hypnotics? (2004) Drug Ther Bull 42:89-93.

Wickwire EM, Shaya FT, and Scharf SM (2016) Health economics of insomnia treatments: the return on investment for a good night's sleep. Sleep Med Rev 30: $72-82$.

Wiegand MH, Landry F, Brückner T, Pohl C, Veselý Z, and Jahn T (2008) Quetiapine in primary insomnia: a pilot study. Psychopharmacology (Berl) 196:337-338.

Willie JT, Chemelli RM, Sinton CM, Tokita S, Williams SC, Kisanuki YY, Marcus JN, Lee C, Elmquist JK, Kohlmeier KA, et al. (2003) Distinct narcolepsy syndromes in orexin receptor-2 and orexin null mice: molecular genetic dissection of Non-REM and REM sleep regulatory processes. Neuron 38:715-730.

Wilson S and Argyropoulos S (2005) Antidepressants and sleep: a qualitative review of the literature. Drugs 65:927-947.

Wilson S and Nutt D (2007) Management of insomnia: treatments and mechanismsi. Br J Psychiatry 191:195-197.

Winokur A, DeMartinis NA III, McNally DP, Gary EM, Cormier JL, and Gary KA (2003) Comparative effects of mirtazapine and fluoxetine on sleep physiology measures in patients with major depression and insomnia. J Clin Psychiatry 64:1224-1229. 
Winokur A, Sateia MJ, Hayes JB, Bayles-Dazet W, MacDonald MM, and Gary KA (2000) Acute effects of mirtazapine on sleep continuity and sleep architecture in depressed patients: a pilot study. Biol Psychiatry 48:75-78.

Winrow CJ, Gotter AL, Cox CD, Doran SM, Tannenbaum PL, Breslin MJ, Garson SL, Fox SV, Harrell CM, Stevens J, et al. (2011) Promotion of sleep by suvorexant-a novel dual orexin receptor antagonist. $J$ Neurogenet 25:52-61.

Winrow CJ and Renger JJ (2014) Discovery and development of orexin receptor antagonists as therapeutics for insomnia. Br J Pharmacol 171:283-293.

Yamadera H, Nakamura S, Suzuki H, and Endo S (1998) Effects of trazodone hydrochloride and imipramine on polysomnography in healthy subjects. Psychiatry Clin Neurosci 52:439-443.

Yamashita T and Yamanaka A (2017) Lateral hypothalamic circuits for sleep-wake control. Curr Opin Neurobiol 44:94-100.

Yeung W-F, Chung K-F, Yung K-P, and Ng TH-Y (2015) Doxepin for insomnia: a systematic review of randomized placebo-controlled trials. Sleep Med Rev 19:75-83.

Yin J, Babaoglu K, Brautigam CA, Clark L, Shao Z, Scheuermann TH, Harrell CM, Gotter AL, Roecker AJ, Winrow CJ, et al. (2016) Structure and ligand-binding mechanism of the human OX1 and OX2 orexin receptors. Nat Struct Mol Biol 23: 293-299.

Yukuhiro N, Kimura H, Nishikawa H, Ohkawa S, Yoshikubo S, and Miyamoto M (2004) Effects of ramelteon (TAK-375) on nocturnal sleep in freely moving monkeys. Brain Res 1027:59-66.

Zammit G, Erman M, Wang-Weigand S, Sainati S, Zhang J, and Roth T (2007) Evaluation of the efficacy and safety of ramelteon in subjects with chronic insomnia. J Clin Sleep Med 3:495-504

Zammit G, Wang-Weigand S, Rosenthal M, and Peng X (2009) Effect of ramelteon on middle-of-the-night balance in older adults with chronic insomnia. J Clin Sleep Med 5:34-40.

Zammit GK, Weiner J, Damato N, Sillup GP, and McMillan CA (1999) Quality of life in people with insomnia. Sleep 22 (Suppl 2):S379-S385.

Zhang Z, Ferretti V, Güntan I, Moro A, Steinberg EA, Ye Z, Zecharia AY, Yu X, Vyssotski AL, Brickley SG, et al. (2015) Neuronal ensembles sufficient for recovery sleep and the sedative actions of $\alpha 2$ adrenergic agonists. Nat Neurosci 18 $553-561$. 